Aus dem pathologisch-anatomischen Instjtut der Universität Helsingfors, Finland. (Direktor: Prof. Dr. E. A. Hom én.)

\title{
Eine neue Methode zur Darstellung des Gliagewebes, nebst Beiträgen zur Kenntnis des Baues und der Anordnung der Neuroglia des Hundehirns.
}

\author{
Von
}

Halvar von Fieandt, II. Assistent am pathologischen Institut.

Hierza Tafel VI-IX.

Es ist eine allgemein bekannte und anerkannte Tatsache, dass die Frage von dem normalhistologischen Bau des Gliagewebes und von den morphologischen Verănderungen desselben bei verschiedenen pathologischen Prozessen des Zentralnervensystems eines der dunkelsten und am wenigsten klargestellten Kapitel der normalen bezw. pathologischen Histologie bildet. Die Ursache der wenigen sichergestellten positiven Resultate, welche die moderne Gliaforschung nach der epochemachenden Arbeit von Weigert (62) aufuweisen hat, ist zweifelsohne in der Unzulänglichkeit unserer teclnischen Hilfsmittel oder vielleicht besser gesagt in der eigenartigen biochemischen Beschaffenheit der Formenelemente, welche das Neurogliagewebe zusammensetzen, zu suchen. Diese der Glia eigene Beschaffenbeit bewirkt, dass das Gewebe in seiner Gesamtheit oder wenigstens teilweise sich von unseren chemischen Reagentien, die eine differenzierende Färbung bezwecken, nicht beeinflussen lässt. Die in der Histologie gewöhnlichen Methoden zur Darstellung des Neurogliagewebes sind nämlich nicht allein mangelhaft in der gewöhnlichen Bedeutung des Wortes, i. e. mit Rücksicht auf konstante Farbungsresultate, gleichmässige, nicht fleckenweise Färbung usw., sondern zeigen auch mit wenigen Ausnahmen selbst unter optimalen Verhältnissen weniger befriedigende Resultate. Ich meine hiermit die Eigentümlichkeit der klassischen Gliafärbungsmethoden - die Golgi sche einerseits, die Weigertsche und die Mallorysche ebenso wie die nach diesen ausgearbeiteten andererseits - nur gewisse 
morphologische Elemente oder Strukturteile zu färben, während andere Gewebsteile regelmässig ausserhalb des Wirkungskreises der Methode bleiben. So färbt z. B. die Methode von Weigert und zwar nur unter den günstigsten Verhältnissen in konstanter Weise - ausschliesslich die Neurogliafasern und die Kerne, während sie keine Aufklärung über die Beschaffenheit und Ausdehnung des Protoplasmas der Gliazellen gibt. Die Golgische Silberimprägnation dagegen gibt Bilder, welche nur als Konturbilder von einzelnen Zellindividuen gedeutet werden können, wobei die fasernartigen Zellausliuufer in den Golgipräparaten nicht ohne weiteres mit den Gliafasern nach We i gert identifiziert werden können. Die verschiedenen Resultate der erwabnten Methoden und die Schwierigkeit oder Unmöglichkeit, mit ihrer Hilfe isomorphe Gewebselemente darzustellen und zu erkennen, macht, dass die betreffenden Methoden bezüglich der Fürbungsresultate keineswegs einander ergänzen, sondern vielmehr auszuschliessen scheinen. Die verschiedenen Auffassungen, welche seit Ranvier (55) und Weigert sich bezüglich der normalen Gliastrukturen, besonders in betreff' des Verhaltens der Gliafasern zu den Gliazellen resp. dem Zellprotoplasma, Anordnung der Gliazellen und Ausläufer rings um die Blutgefässe ebenso wie Beschaffenheit und Bau des subpialen Gliagewebes sich geltend gemacht haben, sind alle zweifelsohne durch die fehlende Gleichmässigkeit der angewandten Methoden verursacht. Bei der Deutung der mit diesen erhaltenen Resultate hat sich ausserdem auch auf diesem Gebiete der histologischen Forschung die Neigung geltend gemacht, die Färbungsresultate als Beweismaterial nach der negativen Seite hin zu verwenden. So sind oft Strukturen und morphologische Elemente, welche sich nicht mit der im gegebenen Falle angewendeten, dagegen sehr leicht mit einer anderen Methode darstellen liessen, ohne weiteres als Kunstprodukte oder einfach als nicht existierend erklärt worden. Ich will an dieser Stelle nur an die Weigertsche (62) Auffassung von den mit der Golgischen Methode nachweisbaren Gliazellausläufern und an die gliösen Grenzmembranen erinnern.

Indessen kann es nicht verneint werden, dass die Forschung der letzten Zeit bis zu einem gewissen Grade die scharfen Gegensätze zwischen den verschiedenen Anschauungen ausgeglichen hat. Auch hierbei tritt in ausgesprochener Weise die dominierende 
Rolle, welche die Technik in der histologischen Wissenschaft spielt, hervor.

Ein Teil der zahlreichen neuen Methoden und sämtliche Modifikationen der Weigertschen Färbung suchen aber nur die Weigertschen Gliastrukturen darzustellen und beabsichtigen hauptsächlich eine Vereinfachung der Technik oder konstantere Färbungsresultate. In diese Kategorie gehören die Methoden von Mallory $(41,42)$, Yam a giva (65), Müller (48), Benda (9-11), Mallory (43), Anglade und Morel (3), Fischer (23), Huber (35), Rubaschkin (57), Bartel (8), Sabrazès und Letessier (58), Wimmer (64), Hoppe (34), da Fano (21). Alle diese Verfahren, von welchen die Methoden von $\mathrm{Huber}$, Bartel, Wimmer und Hoppe nur als unwesentliche Modifikationen derjenigen von Weigert und Benda anzusehen sind, liefern in allem wesentlichen dieselben Bilder wie diese; Yamagivas, Bendas, Rubaschkins und möglicherweise auch da Fanos Methoden scheinen das Gliazellprotoplasma etwas besser zu fürben als das klassische Weigertsche Verfabren.

Alle genannten Methoden haben aber doch nicht in nennenswertem Grade zur Erweiterung unserer Kenntnisse von dem normalhistologischen Bau des Gliagewebes und vor allem nicht zur Lösung der Kontroversen zwischen den entgegengesetzten Resultaten der Silberimprägnationsverfabren einerseits und der Neurogliafaserfärbung andererseits beigetragen.

In viel höherem Grade ist dies der Fall gewesen bei einer Anzahl anderer Methoden, welche im Gegensatz zu den soeben erwähnten die Darstellung nicht allein der chemisch wohl differenzierten Gliafasersubstanz, sondern auch der protoplasmatischen Bestandteile des Gliagewebes beabsichtigen. In diese Kategorie gehören die Methoden von Reinke (56), Held (32), Eisath (20), Lhermitte und Guccione (40) und möglicherweise auch diejenige von Merzbacher (44). Diese Methoden lassen aber hinsichtlich der Resultate viel zu wünschen übrig. Was das Verfahren von Reinke für die Darstellung der Neurogliaelemente betrifft, so besteht dasselbe in einer Silberimprägnation mit nachfolgender Eisenhämatoxylinfärbung nach Heidenhain, wobei es sich ereignet, dass die Silberniederschläge, welche in der Regel durch die nachfolgenden Manipulationen gelöst werden und verschwinden, zuweilen bestehen 
bleiben und zusammen mit den nachgefärbten Gliafasern im Präparat wenigstens stellenweise ein vollständiges oder ziemlich vollständiges Bild von sämtlichen Elementen del Glia geben können. Die Methode ist gewiss nicht ohne Interesse als der erste zielbewusste Versuch einer totalen Gliafürbung, scheint jedoch infolge ihrer unsicheren Resultate kaum zu einer allgemeineren Verwendung kommen zu können. Held (32), der durch seine ausgezeichnete Arbeit über die Neuroglia nach verschiedenen Richtungen hin unsere Kenntnisse erweitert hat, bat leider die von ihm angewandte Methode nicht veröffentlicht. Es geht aber aus den Zeichnungen von Held hervor, diss er eine nicht spezifisch gliafärbende Methode benutzt hat, angeblich eine modifizierte Eisenhämatoxylin-Methode. Ich werde spatter in einem anderen Zusammenhange auf die interessanten Resultate Helds bezüglich der protoplasmatischen l'eile des Glianetzwerkes, des Verhaltens zwischen Gliaprotoplasma und Gliafasern, ehenso wie der Beziehungen der Gliazellen untereinander, zurückkommen. Obgleich die Arbeit von Held als ein schönes und treffendes Beispiel betrachtet werden kann, wieviel ein geübter Hikroskopilier und guter Beobachter auch mit einer nicht spezifischen Methode erreichen kann, scheint sie doch besonders unter den Pathologen nicht die gebührende Beachtung gefunden zu haben. Dass die Ursache hierfür wenigstens teilweise in der Unkenntnis der von $\mathrm{Held}$ angewandten Methode und in der Unmöglichleit einer Kontrolle der damit gewonnenen Resultate liegt, ist offenbar. Soviel scheint mir sicher, dass die Heidenhainsche Eisenbämatoxylinfärbung bei einer Menge verschiedener Fixierungsmethoden nicht Bilder liefert, welche man auch nur annübernd mit den $\mathrm{Heldschen} \mathrm{vergleichen} \mathrm{kann,} \mathrm{obgleich} \mathrm{es} \mathrm{natürlich} \mathrm{ab}$ und zu vorkommt, dass die von ihm beschriebenen Strukturen mebr oder weniger deutlich hervortreten.

Mit der von Eisath (20) angegebenen Methode habe ich ziemlich viel experimentiert, ohne dabei besonders gute Resultate erzielt zu haben. Man kann mit ihr zweifelsobne einen Teil der protoplasmatischen Bestandteile des Gliagewebes darstellen und speziell tritt, obgleich blass und undeutlich, das an den Kern angrenzende Gliaprotoplasma ebenso wie e in T eil der Gliafasern hervor. Indessen lässt sich durch Kontrollfärbungen leicht konstatieren, dass keineswegs sämtliche Gliaelemente gefärbt werden 
und die Methode also wenigstens in quantitativer Beziehung als wenig befriedigend angesehen werden muss. Das geht auch deutlich aus einem Vergleich zwischen den Figuren von Held (32) und Eis a th (20) hervor. Was die Methode von M erzbacher (44) betrifft, scheint sie auch dieselben Febler wie die meisten Neurogliafärbungsmethoden darzubieten: das Gliaprotoplasma nur in geringem Grade oder fast gar nicht zu Gesicht zu bringen. „An Zellen der normalen Rinde wird es (Protoplasma) kaum sichtbar", sagt der Verfasser, und an einer anderen Stelle: "Schliesslich muss ich noch mit einigen Worten des plasmatischen gliösen Maschenwerkes gedenken. Dasselbe konnte ich in einem Falle in sehr anschaulicher Weise zur Darstellung bringen. Die Verhältnisse waren in dem Falle zur Darstellung dieser Gebilde auch sehr günstig"; sodann folgt die Beschreibung des pathologisch veränderten Gewebes. Es dürfte aus diesen Zitaten obne weiteres hervorgehen, dass die betreffende Methode sich nicht für die Darstellung der protoplasmatischen Bestandteile des Gliagewebes, wenigstens nicht in dem normalen Gewebe, eignet, wohl aber für das Studium der Gliafasern. Sie schliesst sich also in dieser Hinsicht den Methoden von Weigert, Yamagiva, Benda, Rubaschkin u. a. an.

Es bleiben noch von hierhergebörigen Methoden diejenigen von $L$ hermitte und Guccione $(39,40)$ übrig. Da dieselben erst publiziert wurden, nachdem die vorliegende Arbeit zum grössten Teile fertiggestellt war, habe ich ihnen nicht die gebührende Aufmerksamkeit widmen können. Von den zwei Methoden, welche die Verfasser angeben, ist die erste eine für Gefrierschnitte bearbeitete modifizierte Weigert-Methode, die andere stellt eine Färbung (von mit Osmium-Chrom-Essigsäure bearbeitetem Materiale) mit Mallorys Phosphorwolframsäurehämatoxylinlösung dar. Mit der letzteren erzielt man angeblich an pathologischem Materiale eine Färbung sämtlicher gliösen Elemente, auch des Gliaprotoplasmas, obgleich aus dem summarischen, allzu kurz gefassten Berichte der Färbungsresultate nicht deutlich hervorgeht, in welchem Grade oder in welcher Ausdehnung dies der Fall ist.

Wie aus den bisherigen Ausführungen hervorgehen dürfte, und wie auch jeder, der sich etwas eingehender mit diesem Problem beschäftigt hat, ohne weiteres zugeben wird, ist es eine ziemlich schwierige und undankbare Aufgabe, mit Hilfe der schon 
bekannten Methoden sich eine nur annahernd befriedigende Kenntnis von der Struktur und Beschaffenheit des normalen Neurogliagewebes zu verschaffen.

Wenn also schon das Studium des normalen Gliagewebes mit bedeutenden Schwierigkeiten verknüpft ist, bietet die Arbeit mit pathologisch verändertem Gliagewebe, besonders bei experimentellem Materiale, noch viel grössere Schwierigkeiten. Seit einigen Jahren mit Studien über die hämatogene Gehirntuberkulose an Hunden und Kaninchen beschäftigt, habe auch ich in vollem Maße die Schwierigkeiten, die man hier zu bekämpfen hat, erfahren müssen. Wie bekannt, hat ja auch die experimentelle Forschung hinsichtlich der pathologischen Anatomie des Gliagewebes nichts Nennenswertes an den Tag gebracht. Dass dieser Umstand seinen Grund in den erwähnten technischen Schwierigkeiten hat, ist offenbar. Die Golgi sche Methode ist auf Grund der inkonstanten Resultate und der isolierten Färbung von einzelnen Zellenindividuen auf diesem Gebiete nicht anwendbar oder würde wenigstens, um zu sicheren Schlüssen zu berechtigen, ein so grosses Material erfordern, dass es kaum von einem einzelnen bearbeitet und beherrscht werden könnte. Von den Gliafaserfürbemethoden können die Weigertsche und ibre zahlreichen Moditikationen ausgeschlossen werden, da sie fast alle an Tiermaterial keine oder doch nur ausserst ungenügende Resultate geben. Auch die Methode von Rubaschkin ( $\overline{0} \overline{7})$, welche wie bekannt, eine vorhergehende intraarterielle Injektion der FixierungsHüssigkeit erfordert, habe ich auf Grund des mir zu Gebote stehenden begrenzten Tiermaterials nicht anwenden können. Von den sümtlichen übrigen Methoden, welche ich geprüft habe, gebe ich unbedingt der von Benda $(9-11)$ angegebenen den Vorzug. Die besten Resultate habe ich mit der Bendaschen modifizierten Eisenhämatoxylinfärbung, ebenso wie mit der Toluidinblaualizarinfärbung an Material, das in Alkohol fixiert und nacb Benda gebeizt wurde, erhalten. Indessen haben auch hierbei die Resultate in mehrfacher Hinsicht viel zu wünschen übrig gelassen; besonders babe ich mit nur wenigen Ausnahmen, trotz vieler Mühe, nicht eine gleichmässige, fleckenfreie Färbung erzielen können. Dass eine fleckenweise auftretende Färbung, obgleich unter gewissen Umständen für das Studium der normalhistologischen Einzelheiten hinreichend, bei pathologischen Untersuchungen aber ganz und 
gar unbrauchbar ist, leuchtet ein. Ist doch die Aussicht, dass ein solcher Fleck, wo die Gliafaserfürbung gelungen ist, im Schnitte z. B. mit einem kleinen Gehirntuberkel oder seiner Umgebung zusammenfallen soll, ziemlich gering. Indessen kann selbstverständlich durch eine hinreichende Zahl von Schnitten dieser Übelstand doch wenigstens zum grossen Teil kompensiert werden. Dagegen ist mir die Darstellung der rein protoplasmatischen Strukturen des Gliagewebes mit den zu Gebote stehenden Methoden, besonders mit der Eis athschen, garnicht oder wenigstens nicht befriedigend gelungen. Dasselbe ist in noch höherem Grade mit den reinen Gliafaserfärbemethoden (Benda, Mallory) der Fall gewesen.

Und doch tritt gerade bei pathologischem Nateriale ein Umstand uns entgegen, der unsere Bestrebungen, eine Furbung des Gliaprotoplasmas zu erhalten, wesentlich zu erleicbtern scheint, namlich die verănderte chemische Beschaffenheit des Protoplasmas der gereizten, proliferierenden Gliazellen. Es ist dies jene eigentümliche Veranderung des Protoplasmas, welche uns als eine gestcigerte chemische event. physilialische Affinität für basische Farbstoffe, eine Basophilie, entgegentritt, und welche, wie bekannt, leineswegs für das Gliagewebe spezifisch ist. Die Anwendung von Vethoden, bei denen diese basischen Farbstoffe die Hauptrolle spielen, ist für das Studium der pathologisch veränderten Glia sicher von grosser Bedeutung gewesen. Ich erinnere nur an die Resultate mit der Nisslschen Seifenmethylenblaulösung, $\mathrm{zu}$ denen besonders $\mathrm{Nissl}(49,50,51), \mathrm{Alzheimer}(2)$ und Spielmeyer (59) gelangt sind. Diese Untersuchungen baben nicht nur die Wissenschaft um eine Reihe wichtiger Tatsachen bereichert, sondern auch zur Genüge die wichtige Rolle dargelegt, welche die protoplasmatischen Gliasubstanzen bei pathologischen Prozessen des Zentralnervensystems spielen. Obgleich die aktive Beteiligung der Gliazellen an pathologischen Prozessen überhaupt auch in früheren Perioden der Pathologie nicht unbeliannt war, scheint doch ihre Rolle, speziell die Bedeutung der progressiven Verănderungen des Gliaprotoplasmas, im allgemeinen stark unterschätzt gewesen zu sein. Nur so kann ich die Worte Weigerts (62) deuten, wenn er bei Besprechung der Anwendbarkeit seiner Methode sagt: ${ }^{1}$ ) „Die Methode stellt ferner, abgesehen

1) 1oc. cit. S. 29. 
von den Kernen der Neurogliazellen, nur die, wie wir sehen werden, in besonderer Weise differenzierten $\mathrm{F}$ a ser $\mathrm{n}$ dar. We $\mathrm{n}$ daher, was a priori durchaus nicht bestritten werden kann, Zwischensubstanzen im Zentralnervensystem existieren, welche solcher differenzierter Fasern entbehren, so entgehen diese bei Anwendung der Methode vollkommen der Kenntnisnabme. Aber so sehr diese Mängel für den Embryologen und den normalen Histologen von Bedeutung sein mögen, für den pathologis chen Anatomen kommen sie kaum in Betracht." - Muss es also einerseits zugegeben werden, dass die Fürbemethoden, die sich auf die gesteigerte Basophilie des Gliaprotoplasmas grïnden, uns einen gewissen Aufschluss von der Ausdehnung und dem Grade der progressiven Veränderungen des Gliagewebes im einzelnen Falle bringen können - was sicher einen grossen Fortschritt bedeutet - so ist es andererseits offenbar, dass diese Methoden uns keine Aufklarung über das Verhaltnis zwischen dem progressiv veränderten Protoplasma und den Gliafasern geben. Ebensowenig können sie uns über die frühesten resp. geringfügigsten pathologischen Veränderungen der Gliazellen informieren. Es muss nümlich der pathologische Prozess (oder die ihn hervorrufende Schädlichkeit) erst eine gewisse Intensität erreicht haben, um die Basophilie des Protoplasmas mit Sicherbeit hervortreten zu lassen.

Dass auch bei der Anwendung der speziellen Neurogliafärbemethoden die soeben erwähte Basophilie die Darstellung des pathologisch veränderten Gliazellprotoplasmas erleichtert bezw. ermöglicht, ist eine bekannte Tatsache. So wird von einer Reihe von Methoden behauptet, dass sie sich zwar für das Studium des gereizten Gliaprotoplasmas eignen, aber nicht oder nur in geringem Maße für das normaler protoplasmatischer Bestandteile. (Methoden von Eisath, Merzbacher, teilweise auch diejenigen von Weigert und Benda nebst den Modifikationen derselben.) Nun kann jedoch bezüglich der Anwendung der betreffenden Methoden beim pathologischen Materiale derselbe Einwand gemacht werden, wie bei den einfachen Anilinfärbemethoden. Denn es bedarf erst eines gewissen Grades der Basophilie des gereizten Gewebes, damit sie überhaupt einigermassen verwertbare Resultate geben; bei den gelindesten, eben anfangenden 
Graden pathologischer Veränderungen aber erweisen sie sich als unzureichend.

Durch das Studium der Neurogliaveränderungen bei der experimentellen Gehirntuberkulose wurde auch ich von der bedeutenden Rolle, welche die Veränderungen der protoplasmatischen Substanzen des Gliagewebes dabei spielen, wie auch ron der Unzulänglichkeit der einschlägigen Farrbemethoden überzeugt. Ich bin deshalb seit langem bestrebt gewesen, ein Verfahren zu finden, welches einerseits ein Studium des normalen Baues und der Beschaffenheit des Neurogliagewebes erlaubte, andererseits es uns aber ermög!ichte, pathologische Gliaveränderungen schon von Anfang an durch alle Stadien successive zu verfolgen.

Anfangs arbeitete ich auf der Basis der alten Methoden, speziell der Bendaschen, und versuchte dabei durch eine Veranderung der Differenzierungsverfahren ausser den Gliafasern auch den protoplasmatischen Teil des Gliastützgewebes zu Gesicht $\mathrm{zu}$ bringen. $\mathrm{Zu}$ diesen Versuchen wurde ich durch die Resultate veranlasst, welche schon $\mathrm{Hardesty}$ (27) durch Anwendung der $\mathrm{Hu}$ bertschen (35) Modifikation der gewöhnlichen Bend a-Methode erzielte. Indessen waren meine Bemühungen nach dieser Richtung hin erfolglos. Dasselbe war der Fall mit einer Menge anderer Farbungsmethoden, welche ich $\mathrm{zu}$ dem angegebenen $\mathrm{Zwecke}$ prüfte und weiter auszuarbeiten versuchte.

Erst seitdem ich bei meinen Experimenten Material ver-

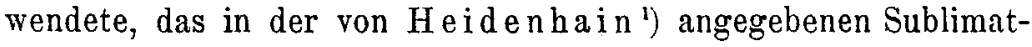
trichloressigsäuremischung fixiert worden war, erzielte ich einige verwertbare Resultate und konnte dann auf diesem Wege mit einem gewissen Erfolg weiter arbeiten. Meine Versuche mit Gliafärbung an Material, das mit Sublimattrichloressigsăure fixiert wurde, gingen von der Beobachtung aus, dass dem Gliagewebe durch Einwirkung dieser Flüssigkeit eine gewisse Basophilie verliehen wurde, wodurch nicht allein das Gliaprotoplasma in der unmittelbaren Nähe der Kerne, sondern auch das Gliastützgewebe in seiner Gesamtheit sogar bei Farbung mit banalen Färbe-

1) Die Zusammensetzung der Fixierungsflüssigkeit warde mir im Frühling 1908 ron Privat-Dozent Dr. Axel Wallgren, der von Herrn Professor Heidenhain darauf mündlich aufmerksam gemacht worden war, mitgeteilt. Später hat $\mathrm{H}$ eide $\mathrm{nh}$ a in (28) in einem anderen Zusammenhange diese von ihm als "Subtriessig " bezeichnete Fixierungsflüssigkeit empfuhlen. 
methoden, z. B. nach van $G$ i es on, ziemlich deutlich hervortrat. Von dieser Feststellung ausgehend, machte ich Versuche, eine elektive Gliafärbung mit der Eisenhämatoxylinmethode von $\mathrm{He}$ idenhain, die ich für meinen besonderen Zweck zu modifizieren suchte, $z u$ erhalten. Nach langen Vorversuchen gluickte es mir schliesslich, Priparate zu erhalten, welche s tellenw e is e eine elektive Gliafärbung zeigten und die gleichzeitig eine Färbung sowohl der Gliafasern wie des Gliaprotoplasmas darboten. Aber wie gesagt, nur stellenweise. Hierbei war ich ausserdem genötigt, die Präparate so intensiven Nachbehandlungen und Oxydationsprozeduren (Behandlung im Thermostat mit einer Mischung von Lugolscher Lösung und Trichloressigsăure mit Zusatz von kleinen Mengen Wasserstoffsuperoxyd) auszusetzen, dass die feineren Strukturen, speziell in der Rindenschicht des Gehirns, teilweise zerstört wurden. Hiermit war also nichts gewonnen.

Seitdem $\mathrm{Heidenhain} \mathrm{(28)} \mathrm{abermals} \mathrm{die} \mathrm{Aufmerksamkeit}$ auf die Färbung mit Vanadiumhämatoxylin, die ja schon früher für verschiedene $Z$ wecke in der histologischen Technik angewandt wurde, gelenkt hatte, und dieselbe speziell für Material, das in Sublimattrichloressigsåure fixiert worden war, geeignet gefunden, beschloss ich nachzusehen, ob die für das Vanadiumbämatoxylin charakteristische Polychromasie möglicherweise auch am Zentralnervensystem sich geltend machen würde, insofern als die gliösen Gewebselemente der polychromen Färbemischung gegenüber sich anders verhalten würden, als die rein nervösen. Die ersten Versuche mit Vanadiumbämatoxylin gaben ein Resultat, das nicht sehr ermunternd war. Später gelang es mir indessen, seitdem ich das von $\mathrm{Heidenhain}$ angegebene Verfahren bei der $\mathrm{Zu}$ bereitung der Fürbeflüssigkeit teilweise modifiziert hatte, die gliösen Gewebselemente speziell das Gliaprotoplasma, auch im normalen Gehirn zu Gesicht zu bringen. Aus meinen Versuchen ging hervor, dass die Verschiedenheiten der Affinität, welche das Gliagewebe und die Achsenzylinder der markhaltigen Fasern der polychromen Färbemischung gegenüber zeigten, ziemlich gering waren. So konnte eine differente Färbung der beiden soeben genannten Gewebe nur bei einem bestimmten Oxydationsgrad der Farbemischung erhalten werden. Dieser war aber bei dem von Heidenhain angegebenen Oxydationsverfahren unter Einfluss 
des atmosphärischen Sauerstoffs schwer zu erreichen. Dagegen konnte die Farbeflüsigkeit durch Zusatz von Wasserstoffsuperoxyd in bestimmten Quantitäten unmittelbar nach der Zubereitung in der Weise verändert werden, dass sie für den betreffenden Zweck verwendbar wurde. $\left.{ }^{1}\right)$ Doch waren die Resultate auch hier nicht besonders günstig. In solchen Präparaten ist die Differenz zwischen der Glia und dem Achsenzylinder nicht so gross, dass man mit Sicherheit unter allen Umständen Verwechslungen zwischen diesen beiden Gewebsteilen entgehen könnte. Und was noch schlimmer ist, die Neurogliafasern können nur äusserst unvollständig oder gar nicht dargestellt werden. Ausserdem kann die Färbung für pathologische Zwecke auf Grund der sebr dunkeln Farbe, welche die Glia dabei schon normalerweise annimmt, kaum angewendet werden. Dagegen dürfte die Methode einigermassen bei dem Studium der Gliasubstanzen in der Rinden-

1) Für diejenigen, die vielleicht mit Vanadiumhämatoxylin für Gliafärbung einen Versuch machen wollen, soll das Verfalıren, das ich am zweckmässigsten gefunden habe, in Kürze hier angeführt werden:

1. Fixierung in Sublimattrichloressigsäure 24 Stunden.

2. Nachhärtung in $96 \%$ Alkobol mit oftmaliger Erneuerung des Alkohols während ca. 3 Tagen. Alkohol abs.

3. Paraffineinbettung.

4. Nach Entfernen des Paraffins aus den Schnitten, welche ziemlich dünn sein müssen (höchstens $4-5, u$ ), wird das Sublimat in einer weinroten Jodalkohollösung entfernt.

כ. Entfernen des Jods durch eine $0,25 \%$ ige Lösung von Natriumthiosulfat.

6. Auswaschen mit Aqu. dest.

7. Färbung während 5-15 Minuten in einer Färbemischung, die in folgender Weise bereitet wird: zu $20 \mathrm{ccm}$ einer $0,5 \%$ igen Hämatoxylinwasserlösung werden $10 \mathrm{~cm}$ einer $0,25 \%$ igen Lösung von Ammoniumvanadat und allmählich unter Umrühren 28 Tropfen einer frischen Wasserstoffsuperoxydiösung (2 Tropfen Perhydrol-Merck, 48 Tropfen Aqu. dest.) zugesetzt. Um angewendet werden zu können, muss ein Tropfen der Flüssigkeit auf Fliesspapier einen rein schwarz-grauen Fleck zurücklassen; zeigt der Fleck eine bläuliche oder braune Farbe, so ist zu wenig resp. zu viel Wasserstoffsuperoxyd zugesetzt worden.

8. Abwaschen in Wasser. Alkohol in steigender Konzentration. Xylol. Balsam. Färbungsresultate: collagenes Bindegewebe dunkelblau, rote Blutkörperchen und Nucleolen gelb, Gliaprotoplasma schwarzbraun, Achsenzylinder braungelb. Das Kernchromatin wird nur teilweise und schwach gefärbt. Die Neurogliafasern treten nicht oder in etwas dunklerer Farbe nur undeutlich gegenüber dem Gliaprotoplasma hervor. 
schicht des normalen Gehirns angewendet werden können. Doch ist die Methode auch hier, auf Grund der wenig spezifischen Fürbung, für feinere Untersuchungen kaum genügend. Indessen scheinen mir die Resultate mit Vanadiumbämatoxylin theoretisch interessant in der Beziehung, als sie zur Genüge zeigen, dass eine differente Fürbung der Gliabestandteile und der rein nervösen Gewebselemente wenigstens unter gewissen Bedingungen durch Verwendung von polychromen Farbemischungen erreicht werden kann.

Ermuntert durch die Versuche mit Vanadiumhämatoxylin, die wenigstens in theoretischer Hinsicht bis zu einem gewissen Grade glücklich ausgefallen waren, wandte ich mich zu den übrigen polychromfärbenden Hämatoxylinlösungen, in erster Linie zu dem schon seit langem mit Vorteil angewandten Phosphorwolframsiuurehämatoxylin (Mallory). Ich kam bald zu der Überzeugung, dass dieser Fürbestoff sich gut für den hier in Frage kommenden Zweck eignete und blieb nach einigen Versuchen mit in verschiedener Weise zusammengesetzten Lösungen bei der von Mallory (43) selbst angegebenen, die ich als die zweckmässigste fand. Schon bei einer direkten (progressiven) Färbung mit dieser Iıösung konnte eine differente Färbung von Achsenzylindern und Gliagewebe erhalten werden. Ebenso war das collagene Gewebe von der Glia gut zu unterscheiden. Von den gliösen Gewebsbestandteilen wurden sowohl die Fasern, wie das Gliaprotoplasma an normalem Gehirnmaterial gefärbt und zwar in einer Ausdehnung, die anscheinend den tatsächlichen Verbăltnissen entsprach. Indessen konnte die Glia nur durch eine weniger intensive Färbung different dargestellt werden, bei stärkerer Farbung dagegen zeigten die Achsenzylinder der markhaltigen Nervenfasern die Neigung, in demselben Tone gefärbt zu werden. Ausserdem zeigten die Präparate eine Neigung ziemlich schnell abzublassen, wodurch die Farbedifferenzen weniger deutlich hervortraten. Die Methode musste somit dahin geändert werden, dass das progressive Verfahren durch Überfärbung mit nachfolgender Differenzierung - also ein regressives Verfahren - ersetzt wurde. Es gelang mir auch in einer alkoholischen Ferrichloridlösung ein Differenzierungsmittel zu finden, das sich für den Zweck gut eignete. Dass diese noch mit Feblern und Mängeln behaftet ist, davon bin ich vollständig überzeugt. Indessen habe ich, obgleich ich eine Menge verschiedener besonders sauer reagierender Metallsalzlösungen ver- 
sucht habe, bis heute keine für meinen Zweck besser geeignete finden können. Da ich ausserdem mit der erwahnten Differenzierungsmethode zumeist recht gute Prăparate erhalten und weiter gefunden habe, dass eventuelle Nachteile in allen wesentlichen Punkten vermieden werden können, glaube ich dieselbe empfehlen zu können.

Ich werde nunmehr eine Beschreibung der von mir sowohl an normalem wie an pathologischem Material angewandten Methode geben, um dann über die Resultate, die am normalen Gewebe mit derselben gewonnen wurden, zu berichten.

\section{Eigene Methode.}

Kleine Stücke, die $2 \mathrm{~mm}$ Dicke und $1 \mathrm{~cm}$ Breite und Länge nicht überschreiten dürfen, werden von dem noch warmen Gehirne in $\mathrm{Heidenhains} \mathrm{Sublimattrichloressigsäuremischung,} \mathrm{welche}$ folgende Zusammensetzung hat, fixiert.

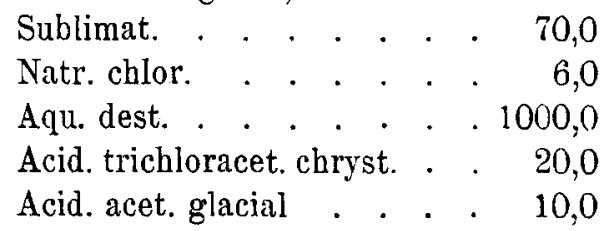

Es empfieblt sich, bei der Fixierung selbst kleiner Stücke ziemlich grosse Mengen Flüssigkeit zu verwenden, wo dieselben auf einer Grundlage von Watte oder Löschpapier verweilen. Nach ca. 12 Stunden wird die Fixierungsflüssigkeit, in der die Stückchen im ganzen 24 Stunden bei Zimmertemperatur liegen bleiben, gewechselt. Die Stücke werden dann mit Löschpapier abgetupft und direkt in $96 \%$ Alkohol, ebenfalls auf einer Unterlage von Watte oder Löschpapier, übergeführt. Hierbei ist zu beachten, dass nicht zu viele Stücke in ein und demselben Gefäss untergebracht werden, jedenfalls muss der Alkohol überall freien Zutritt haben. Der Alkohol wird während der ersten 12 Stunden jede zweite Stunde gewechselt und wenn möglich, werden die Gefässe ziemlich oft etwas umgeschüttelt. Später wird der Alkohol zweimal täglich gewechselt. Ich möchte auf eine sorgfältige Nachbehandlung mit Alkohol in der erwăhnten Weise ganz besonders anfmerksam machen; nach einer weniger sorgfaltigen Alkoholbehandlung ist es nicht allein schwieriger, eine gute Färbung zu bekommen, sondern es können auch gewisse Kunstprodukte, 
Fixierungsartefakte, entstehen, welche ich niemals in Präparaten, die aus gut behandelten Stücken stammten, beobachtet habe. Diese Kunstprodukte sind zweifacher Art. Entweder erscheint die Neuroglia eigentümlich klumpig, ein homogenes Netzwerk bildend, welches nichts von der zierlichen Struktur des normaien Gliagewebes zeigt, oder es treten in der Marksubstanz grössere oder kleinere unregelmässige Hohlrăume auf, die vermutlich durch ein Zusammenballen des Myelins entstanden sind. Wie gesagt, können jedoch diese Artefakte leicht vermieden werden. ${ }^{1 j}$ In dem 96\%igen Alkohol verweilen die Stücke 5-7 Tage und kommen dann auf 2-3 Tage in absoluten Alkohol. Als Übergangsmedien bei der Paraffineinbettung, von der ich ausschliesslich Gebrauch gemacht habe, habe ich Cedernöl und Ligroin nach der von Pranter angegebenen Methode verwendet. Aus dem absoluten Alkohol kommen die Stücke also in mit dünntlüssigem Cedernöl unterschichteten Alkohol, nach 24 Stunden in reines Cedernöl, nach weiteren 24 Stunden in Ligroin und dann in eine gesättigte Ligroin-Paraffinlösung (Paraffin $52^{\circ}$ Schmelzpunkt). Nachdem sie zur Verdunstung des Ligroins einige Tage im Thermostat $\left(37^{\circ}\right)$ gestanden haben, werden die Stücke in Paraifin vom Schmelzpunkt $52^{\circ} \mathrm{C}$ eingebettet, wobei beachtet werden

1) Es verdient besonders hervorgehoben zu werden, dass Alkohol von stärkerer Konzentration sich für die Behandlung nicht eignet. Bei Nachhärtung in absolutem Alkohol sind die von Markscheiden umgebenen Achsenzylinder schwieriger zu entfärben, wodurch elektiv gefärbte Präparate ab und zu nicht erhalten werden können. Ausserdem wird das Protoplasma der Nervenzellen dank der in diesem Falle wohl beibehaltenen $\mathrm{N}$ is s l schen Körperchen so dunkel gefärbt, dass das pericelluläre Gliagewebe nur schwer oder gar nicht zu untersuchen ist. Wie ich schon hier bemerken will, ist das gar nicht oder in viel geringerem Grade der Fall bei Nachhärtung mit 96\% igem Alkohol. Im Gegenteil wird dabei das Protoplasma der Ganglienzellen und deren Fortsätze meistens entfärbt, von kleinen Resten abgesehen; wahrscheinlich ist hier eine Auflösung der chromophilen Bestandteile der Ganglienzellen vor sich gegangen. Es muss jedoch darauf hingewiesen werden, dass die $\mathrm{N}$ i s s l schen Körperchen oft auch bei einer solchen Alkoholbehandlung in einzelnen Ganglienzellen oder fleckenweise in den Präparaten gut erhalten und dunkel gefärbt sind. Es leuchtet ein, dass dergleichen Stellen sich für das Studium der pericellulären gliösen Netzwerke nicht. eignen. Diese Reste des nervösen Protoplasmas habe ich durch Behandlung mit ammoniakalischem Alkohol nach Beth e zu entfernen oder der nachfolgenden Färbung unzugänglich zu machen versucht, habe jedoch vorläufig keine befriedigenden Resultate erzielt. 
muss, dass dieselben nicht länger als notwendig höheren Wärmegraden und zwar höchstens 12 Stunden $56^{\circ} \mathrm{C}$ ausgesetzt werden dürfen. Beim Schneiden, das, trotzdem das Sublimat nicht entfernt worden ist, keine Schwierigkeiten darbietet, muss sich die Dicke der Schnitte nach dem Objekt der Untersuchung richten. Beim Studium der Glia der weissen Substanz kommt man mit Schnitten von $5 \mu$ sehr gut aus. Will man aber den Verlauf der einzelnen Gliafasern verfolgen, dann muss man natürlich dickere Schnitte wählen. Umgekehrt sind bei der Untersuchung der grauen Substanz mit ihrer dichten Gliastruktur möglichst dünne Schnitte erforderlich. Die Praparate werden nach der japanischen Methode aufgeklebt. Nachdem das Paraffin entfernt worden ist und die Objektgläser in absolutem und $96 \%$ igem Alkohol abgewaschen sind, kommen sie während einer Stunde in Jodtinktur (Jodi clryst. 1,0, Alkohol $96 \%$ 10,0). Nachdem der Überschuss von Jod durch $96 \%$ igen Alkohol entfernt worden ist, werden die letzten Jodreste mit $0,25 \%$ Natriumthiosulfatlösung aufgenommen, worin die Schnitte verweilen, bis sie vollständig weiss geworden sind. Sie werden jetzt mit Aqu. dest. abgewaschen, das zwei- bis dreimal gewechselt werden muss. Dann werden sie vorsichtig mit Löschpapier abgetupft und kommen in die Phosphorwolframsäurehämatoxylinlösung von Mallory:

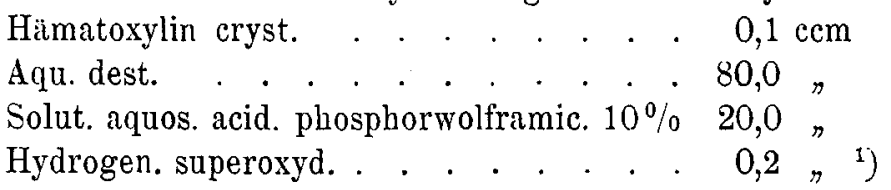

Die besten Resultate habe ich erhalten mit einer alteren (vieljährigen) Farblösung, doch kann die Färbungsflüssigkeit auch frisch angewendet werden, nur färben die frischen Lösungen bedeutend schwächer. Nach 12-24 Stunden werden die Objektträger mit Löschpapier abgetupft und in die Differenzierungsflüssigkeit übergeführt, die $\mathrm{f} r$ is ch bereitet werden muss. Diese besteht aus einer $10 \%$ igen Lösung von Ferrichlorid in absolutem Alkohol (Ferri sesquichlorat. sicc. pur. 5,0, Alkohol abs. 50,0 ). In der alkoholischen Ferrichloridlösung verweilen die Objektträger mit den Schnitten nach unten, bis die Achsenzylinder und das collagene Bindegewebe vollständig entfärbt sind und eine gelbgraue

1) Wasserst off superoxyd (Merck), 10 Vol.-Prozent $=3$ Gew.Prozent Wasserstoffsuperoxyd enthaltend. 
Farbe angenommen haben, was gewöhnlich erst nach einer bis mehreren Stunden der Fall ist; der Verlauf der Differenzierung muss mit dem Mikroskope kontrolliert werden. Ist der richtige Grad der Differenzierung erreicht, so lässt man die Ferrichloridlösung vom Objektträger abträufeln, trocknet diesen mit Löschpapier und wäscht ihn schnell in einem Gefäss mit destilliertem Wasser ab; die graublau gefärbten Schnitte nehmen hierbei eine schöne hellblaue Farbe an. Nach nochmaligem Abwaschen in destilliertem Wasser werden die Schnitte sorgfältig mit absolutem Alkohol behandelt, um die letzten Spuren des Ferrichlorids zu entfernen. Ich pflege dabei in der Weise vorzugehen, dass ich die Schnitte auf 24 Stunden in absolutem Alkohol liegen lasse, den ich wahrend der Zeit einmal wechsle. Dann kommen die Schnitte durch Origanumöl in Xylol und Balsam. Die Behandlung mit Origanumöl, die ich selbst gern anwende, weil sie den Präparaten eine hellere blaue Farbe zu verleihen scheint, kann natürlich fortgelassen werden. Was die Haltbarkeit der Präparate betrifft, kann ich nur sagen, dass dieselbe, wenn die Behandlung mit Alkohol nach der Differenzierung sorgfältig gemacht wird, gut zu sein scheint. Wenigstens haben meine in dieser Weise behandelten Präparate sich mehrere Monate gehalten, ohne abzublassen. Für eine noch länger dauernde Haltbarkeit kann ich aber nicht einstehen.

In aller Kürze gestaltet sich also die Methode folgendermassen :

1. Fixierung in Sublimattrichloressigsăure.

2. Nachbehandlung mit Alkohol $(96 \%)$ in oben angegebener Weise.

3. Einbettung in Paraffin (5 $2^{\circ}$ Schmelzpunkt) nach der Pranterschen Methode mit Hilfe von Cedernöl und Ligroin.

4. Behandlung der Schnitte (nach Entfernen des Paraffins und Passage durch absoluten Alkohol) mit Jodalkohol $(1: 10)$ wahrend einer Stunde.

5. Entfernen des Jodes durch Alkohol und Natriumthiosulfat $(0,25 \%)$.

6. Abwaschen in destilliertem Wasser.

7. Färbung mit Phosphorwolframsäurehämatoxylinlösung nach Mallory wăhrend $12-24$ Stunden. 
8. Abtrocknen mit Löschpapier.

9. Differenzierung in einer frisch bereiteten Lösung von Ferrum sesquichlor. sicc. in absolutem Alkohol (1:10) während einer bis mehrere Stunden unter mikroskopischer Kontrolle.

10. Abtropfenlassen der Differenzierungsflüssigkeit. Abtupfen mit Löschpapier.

11. Abwaschen mit destilliertem Wasser.

12. Gründliche Behandlung mit absolutem Alkohol resp. Liegenlassen in einmal gewechseltem absolutem Alkohol während 24 Stunden.

13. Origanumöl, Xylol, Balsam.

Färbungsresultat: Kernchromatin, Neurogliafasern tief blau; Gliaprotoplasma hellblau bis graublau; Achsenzylinder und collagenes Bindegewebe graugelb; Elastin gelblichbraun; rote Blutkörperchen schmutziggelbgrau, Nucleolen gelb bis gelbbraun (vergì. Taf. VI und VII). Alle diese Farben beziehen sich auf künstliche Beleuchtung (elektrisches Glühlicht).

Auf die Resultate, zu denen ich mittels der soeben beschriebenen Methode an pathologischem Material gekommen bin - meine diesbezüglichen Untersuchungen betreffen die hämatogene experimentelle Gehirntuberkulose - werde ich an dieser Stelle nicht eingehen. ${ }^{1}$ ) Hier möchte ich nur auf Grund meiner Präparate eine Beschreibung des Baues und der Anordnung des Neurogliagewebes im normalen Hundegehirn geben. Da meine Untersuchungen mich zu einer Auffassung geführt haben, die in gewisser Hinsicht von den landläufigen Anschauungen abweicht, ist es nicht zu vermeiden, auf einige Detailfragen einzugehen. Schliesslich muss hervorgehoben werden, dass die unten gegebene Beschreibung, wenn nicht anders ausdrücklich bemerkt wird, ausschliesslich die Rinde und die darunter liegende weisse Substanz (Centrum semiovale) des Grosshirns betrifft.

Betrachtet man an Präparaten, die in der erwähnten Weise gefarbt wurden, zunachst das Neurogliagewebe der weissen

1) Diese Untersuchungen sollen binnen kurzem im Bd. 3 Heft 2-3 von den "Arbeiten aus dem Pathol. Institut der Universität Helsingfors", herausgegeben von Prof. Dr. E. A. Homén, veröffentlicht werden. 
Substanz, so findet man, dass die Kerne derselben in zwei Gruppen eingereiht werden können, von welchen eine jede-obgleich natürlich auch weniger ausgeprägte Typen und Übergangsformen vorkommen - eine Menge charakteristischer Eigenschaften darbietet. Die Kerne, welche zu der einen Gruppe gehören, haben eine länglich ovale Gestalt, selten sind sie rund oder kugelförmig; sie haben meistens eine Länge von 7 à $8-10 "$ und eine Breite von $6-7$ à $8 \mu$, obgleich diese Zahlen natürlich Variationen unterworfen sind. Der Kern zeigt in seiner Gesamtheit eine bellblaue Farbe; im Innern desselben findet sich in der Regel ein oft exzentrisch gelegenes dunkler gefäbtes Kernkörperchen, das ein etwas helleres, gelbbraun gefarbtes Zentrum aufweist. Dies ist von einer schalenförmigen dunklen peripheren Schicht umgeben, die von dicht aneinander liegenden, tiefblau gefärbten Cbromatingranula gebildet wird. Die betreffenden Kerme sind an gefärbtem Chromatin ziemlich arm, nur hie und da werden kleinere Chromatinklïmpchen wahrgenommen, stellenweise in Reihen angeordnet, die auch ganz nahe del Membran vorkommen. Von einem Kerngerüst ist im übrigen nichts zu sehen. (Taf. VI, Fig. 1 und 4, Taf. VIII, Fig. 2, Taf. IX, Fig. 1.)

Die Kerne des anderen Typus zeigen eine viel dunklere Färbung, die durch den unvergleichlich reichlicheren Chromatingehalt bedingt wird. Die Form ist gewöhnlich rund, selten etwas länglich oder unregelmässig. Der Diameter beträgt gewölnnlich $\overline{5}, \tilde{\jmath}-8 \mu$. Das Chromatin ist, wie gesagt, ziemlich reichlich, zu ungleich grossen, dicken Klumpen angehüuft, welche stellenweise so dicht gelegen sind, dass sie den Fermen eine mehr oder weniger deutlich hervortretende netzförmige Struktur verleihen (Taf. VI, Fig. 3, Taf. VIII, Fig. 2). Ein Nucleolus kann in diesen nicht nachgewiesen werden.

Wie schon angedeutet wurde, kommen ziemlich reichlich atypische Kernformen vor, welche in sich gewisse Eigenschaften beider oben geschilderten Typen vereinigen. Was die relative Zahl und die Verteilung der beiden Formen betrifft, so finden wir bedeutende regionäre Differenzen. Stellenweise kommen ziemlich dicht aneinandergereihte Kerne des kleinen dunklen Typus vor, an anderen Stellen trifft man in begrenzten Gebieten ausschliesslich Kerne der anderen Form, besonders scheint dies in Gegenden der Fall zu sein, wo zwei oder mehrere nach ver- 
schiedenen Richtungen verlaufende Bündel von Nervenfasern sich treffen. Im allgemeinen kann man jedoch behaupten, dass die kleinen, an gefärbtem Chromatin reichen Kerne die grosse Majorität bilden.

Gleichzeitig mit den Verschiedenheiten der Kerne scheint auch eine verschiedene Beschaffenheit und Verteilung sowohl der protoplasmatischen wie der faserigen Gliasubstanz sich geltend zu machen. Die grossen, mit Nucleolen versehenen oder an gefärbtem Chromatin armen Kerne sind von einer ziemlich reichlichen Menge hellblau gefürbtem Protoplasma umgeben, das homogen oder wenigstens ohne auffallende Struktureigentümlichkeiten erscheint. Durch das Protoplasma, oft anscheinend eine Grenze desselben bildend, verlaufen deutlich hervortretende, dunkelblau gefärbte Fasern, die Weige r tschen Neurogliafasern. Diese scheinen von allen Richtungen gegen die umgebenden Protoplasmaanhäufungen zu konvergieren, welche sie entweder in der umittelbaren Nähe des Kernes oder auch etwas davon entfernt durchkreuzen. Ein Teil der Fasern zeigt bierbei einen geladlinigen Verlauf, andere beschreiben Kurven mit der Konvexitat an der Stelle, wo sie dem Kern am nächsten kommen, gegen denselben gerichtet, wieder andere weisen unregelmässige Biegungen und Knickungen auf (Taf. VI, Fig. 1 u. 4, Taf. VII, Fig. 1, Taf. VIII, Fig. 2). Die Fasern sind während ihres ganzen Verlaufes von derselben Stărke, wenigstens soweit ich sie verfolgen konnte, und bieten auch in der Nähe der Kerne keine Absplitterung dar. Sie machen also auch mit der betreffenden Färbung den Eindruck von Bildungen, die chemisch vom Protoplasma differieren; wenigstens ist dies in der Näbe der Kerne der Fall. Untersucht man einen Gliakern der betreffenden Art nebst der ilun umgebenden Protoplasmaanhäufung und den daselbst verlaufenden Gliafasern bei schwächeren Vergrösserungen, so imponiert das ganze beim ersten Blick als ein wohl abgegrenztes Zellindividuum, wobei die Fasern, welche bogenförmig an dem Kern vorbeiziehen, oft den Eindruck von Zellgrenzen machen. Bei stärkeren Vergrösserungen (1000 mal) dagegen ändert sich das Bild wesentlich. Es zeigt sich, dass das hellblaue Protoplasma keineswegs auf die unmittelbare Nahe des Zellkerns beschränkt ist, sondern dass es sehr weit vom Kerne in den Interstitien zwischen den markhaltigen Nervenfasern verfolgt werden kann. 
Die Gliazellen von diesem Typus sind also mit Fortsätzen von protoplasmatischer Beschaffenheit versehen. Diese Fortsatze sind mehrfacher Art. Entweder sind sie an der Basis ziemlich dick, nach dem Ende zu ausgezogen, an Form also konisch, oft an den Rändern mit Gliafasern versehen. Oder sie bestehen aus feinen Protoplasmafäden, welche von der den Kern umgebenden Protoplasmaanhäufung sich nach verschiedenen Richtungen erstrecken, am meisten radiär ausstrablend, teilweise deutlich miteinander anastomosierend und oft eine echte Gliafaser umhüllend. Schliesslich sieht man nicht selten dünne, abgeplattete, lamellöse Fortsätze, an Breite und Ausdehnung sehr variierend, welche sich von der zentralen Protoplasmaanbäufung zwischen den markhaltigen Nervenfasern erstrecken und oft in verschiedenen Richtungen verlaufende Gliafasern einschliessen. Oft sind die erwähnten Lamellen an den Rändern von Gliafasern begrenzt. Wenn diese, wie es in der Regel in der Höhe des Kernes der Fall ist, von hier aus divergierend verlaufen, dann bietet eine zwischen denselben ausgespannte Protoplasmalamelle Ähnlichkeiten mit einer Schwimmhaut dar. Mit Hilfe der Fig. 1 u. 4, Taf. VI kann man sich eine Vorstellung von den verschiedenen Arten der Protoplasmafortsätze in den Gliazellen der betreffenden Art bilden. Die Bilder der Gliazellen bieten natürlich zahllose Variationen dar, je nachdem die Ausläufer, die von den kernführenden Protoplasmazentren ausgehen, überwiegend konisch, fädchenartig oder lamellös sind, je nach den verschiedenen Richtungen, die sie einschlagen, und je nach dem grösseren oder kleineren Gehalte an Gliafasern. Zieht man überdies in Betracht, dass auch dje Gestalt des Zellkörpers selbst, d. h. die dem Kerne am nächsten liegende Protoplasmaanhäufung, von Zelle zu Zelle äusserst wechselnd ist und überhaupt sich nach den Interstitien zwischen den in verschiedenen Richtungen verlaufenden Markscheiden und nicht am wenigsten nach der zufálligen Schnittrichtung richtet, so wird man sich vielleicht eine Vorstellung davon machen können, welche Mannigfaltigkeit von Zellformen man hier antrifft. Dieser unendliche Formenreichtum trotzt allen Versuchen einer Klassifizierung. Durch eine solche wäre wohl auch kaum etwas wesentliches zu gewinnen.

Es wurde oben erwähnt, dass die protoplasmatischen Ausläufer der Gliazellen ziemlich weit von dem Zellkörper selbst 
verfolgt werden können und dass die feinen fädchenförmigen Fortsätze oft miteinander anastomosieren. Diese Anastomosen kommen indessen nicht allein zwischen den Ausläufern eines und desselben Zellkörpers vor, sondern auch zwischen nahe gelegenen oder sogar voneinander ziemlich weit entfernten Zellindividuen und betreffen nicht nur die feinen fädchenförmigen, sondern auch die gröberen konischen und die lamellösen Ausläufer. Fig. 1, Taf. VI dürfte dieses Verhältnis illustrieren. Sie zeigt die Neuroglia der weissen Substanz eines jungen Hundes an einer Stelle, wo die in verschiedenen Richtungen verlaufenden myelinhaltigen Nervenfasern einander kreuzen und wo die Gliazellen ziemlich dicht liegen. Man sieht die lamellösen Ausläufer der verschiedenen Zellen teils breit, teils durch schmälere Brücken miteinander zusammenhängen (links unten und rechts oben im Bilde). Andererseits findet man eine Menge fädige Protoplasmaauslaufer, teilweise mit Gliafasern besetzt und aus verschiedenen Zellen stammend, miteinander anastomosieren (links oben im Bilde). Schliesslich kann auch beobachtet werden, wie die feinen Protoplasmafortsätze in Gegenden, welche grösserer Gliaprotoplasmaanhiuufungen entbehren (Mitte des Bildes), ein zierliches Netzwerk zwischen den Markräumen bilden, indem sie sich miteinander vereinigen und ineinander übergehen. Wie gesagt, stammt die in der Fig. 1, Taf. VI abgebildete Stelle aus dem Gehirne eines jungen Hundes und man könnte vielleicht einwenden, dass wir es hier mit einem noch in der Entwicklung stehenden Gliagewebe $\mathrm{zu}$ tun haben, dessen verschiedene Zellindividuen sich von dem gemeinsamen Verbande noch nicht emanzipiert haben, was aber vielleicht der Fall bei einem vollständig entwickelten Gliagewebe sein könnte. Dieser Einwand ist nicht stichhaltig. Es ist leicht, an einem erwachsenen Tiere zu konstatieren, dass eine solche Emanzipation aus dem Zellenverbande niemals vor sich geht, sondern dass die Beschaffenheit des normalen Gliagewebes auch hier überall in entsprechenden Teilen des Gehirns im Prinzip dieselbe ist. Bei Untersuchungen dieser Art ist es natürlich notwendig, die Prăparate gegen die Tiefe hin zu mustern und von der Mikrometerschraube fleissigen Gebrauch zu machen. Wenn man in der Weise vorgeht, wird man mit I,eichtigkeit den allmăhlichen Übergang des einen Protoplasmabalkens in den anderen verfolgen können. Man wird somit nicht umhin können, ein allgemein aus- 
gebreitetes protoplasmatisches Gliareticulum anzunehmen, wovon die einzelnen „Gliazellen " nur integrierende Teile sind. Die klassischen Gliazellen sind also aus ihrem anatomischen Zusammenhange ausgerissene Teile eines gemeinsamen Syncytiums, keine eigentlichen Zellindividuen. Der von Hardesty (27) und Held (32) beschriebene protoplasmatische Zusammenhang $z$ wischen den Gliazellen, das sogenannte Gliasyncytium, kann somit auch mit meiner Methode nachgewiesen werden.

Die in der weissen Substanz sich findenden Kerne des zweiten Typus werden, wie erwähnt, durch einen reichlicheren Chromatingehalt und dadurch bedingte dunklere Farbe sowie durch ihre runde Form und kleineres Volumen gekennzeichnet. Sie sind von einer geringen Menge Protoplasma umgeben, das oft nur die eine Seite des Kernes begrenzt, denselben halbmondförmig umfassend. Auch zeigt dasselbe in der Regel eine bedeutend dunklere Farbe als das Protoplasma der grossen hellen Kerne. Die dunkle Protoplasmafarbe scheint hauptsächlich durch das Vorhandensein einer Menge dicht gelagerter tiefblau gefärbter feiner Körnchen bedingt zu sein, welche fast die ganze halbmondförmige oder unregelmässige Protoplasmaanhäufung in der Nähe des Kernes einnehmen. Im Gegensatz zu den eingangs beschriebenen Gliazellen bieten diese also in der Regel eine deutlich feinkörnige Struktur des Protoplasmas dar, obgleich man natürlich stellenweise Zellen trifft, wo diese Körnelung weniger hervortritt und das Protoplasma eine hellere Farbe darbietet. Von der beschriebenen Protoplasmaanhäufung geben Fortsătze nach verschiedenen Richtungen aus, die Zelle mit dem allgemeinen protoplasmatischen Glianetzwerke verbindend. Diese Ausläufer oder Vereinigungsbalken sind im allgemeinen von einer viel feineren Beschaffenheit als die Fortsatze der erst beschriebenen Gliazellen und bestehen oft ausschliesslich ans feinen Plasmafäden, welche in der Regel keine echten Gliafasern einschliessen. Stellenweise trifft man aber auch gröbere Ausläufer (Taf. VI, Fig. 3). Die betreffenden Zellen sind also durch die erwahnten feinen Protoplasmafäden in dem Glianetzwerke sozusagen aufgehängt. Oft wird rings um die kleine Protoplasmamasse ein Hohlraum beobachtet, wo die "Zellen" teilweise frei liegen. Dieselben bieten dann eine gewisse Ähnlichkeit mit Lymphocyten dar. Man kann 
sich jedoch leicht davon überzeugen, dass solche Bilder als Artefakte aufzufassen sind, indem durch Schrumpfung das Zellprotoplasma mit dem eingeschlossenen Kerne sich etwas von der Umgebung retrahiert hat, sodass die feinen plasmatischen Vereinigungsbrückchen teilweise abgerissen worden sind. Es wurde oben erwähnt, dass die Ausläufer dieser Zellen in der Regel keine echten Gliafasern führen, und in der Tat scheint dies eine ziemlich konstante Erscheinung zu sein. Die kleinen dunklen, mit reichlichem Chromatin versehenen Kerne sind also mit den schon von Weigert (62) beschriebenen zu identifizieren, „in denen das Chromatin eine bomogene dunkle Masse darstellt" und die nur ausnahmsweise, vielleicht auch gar nicht, "in charakteristischer rüumlicher Beziehung “ zu den Gliafasern stehen. ${ }^{1}$ )

Das Neurogliagewebe der weissen Substanz besteht somit aus einem überall sich erstreckenden kontimuierlichen Gliasyncytium mit hie und da hervortretenden grösseren, mit Kernen versehenen Protoplasmaanhäufungen. Auf eine năhere Beschreibung sümtlicher Zwischenformen von Gliaprotoplasmaanhäufungen oder Gliazellen, die $z$ wischen den beiden schon geschilderten Typen sich finden, muss ich verzichten. Lässt man sämtliche Eigentümlichkeiten, welche dazu beitragen, den Gliazellen ihr charakteristisches Aussehen zu verleihen, die Beschaffenheit des Kernes, die Grösse und Färbungsintensităt des Protoplasmas und die Beschaffenheit der Auslaufer zwischen den beiden Extremen, die von den oben beschriebenen Typen vertreten werden, wechseln, so kann man leicht sïmtliche möglichen Zwischenformen konstruieren oder sich wenigstens von denselben eine gewisse Vorstellung bilden. Allzu zahlreich scheinen diese $\mathrm{Zwischenformen}$ nicht zu sein, die überwiegende Mehrzahl der Gliazellen kann man ohne den Tatsachen Gewalt anzutun, auf den einen oder anderen der beiden beschriebenen Typen zurückführen.

Zur Beleuchtung der viel diskutierten Frage, ob die Neurogliafasern von den Gliazellen „räumlich getrennt", als eine wirkliche Intercellularsubstanz oder als intraplasmatische Differenzierungsprodukte zu betrachten sind, dürfte die Anwendung meiner Methode, dankibres Vermögens, auch die protoplasmatischen Gliabestandteile darzustellen, ron einer gewissen Bedeutung sein. In der Tat ist es leicht $z u$ konstatieren, dass die Gliafasern

I) Loc. cit. S. 30/31. 
wenigstens zum allergrössten Teile intraplasmatisch, d. b. innerhalb des oben beschriebenen, netzförmig überall ausgebreiteten Gliaprotoplasmas verlaufen. Hierbei sind die Fasern entweder an allen Seiten von einem hellblau gefärbten Plasmamantel umgeben - was oft bei den massiveren Ausläufern oder den Vereinigungsbalken der Fall ist - oder sie werden an beiden Seiten von dem Gliaprotoplasma umgeben, wie in den lamellösen Ausläufern (Taf. VII, Fig. 1, Taf. VI, Fig. 1), schliesslich bilden die Fasern auch die äussere Begrenzung eines lamellösen Vereinigungsbalkens (Taf. VI, Fig 1, Taf. VII, Fig. 1-3). Dass die Gliafasern hierbei oft an der Oberflache oder der ausseren Begrenzung der Balken des Glianetzwerkes verlaufen, ist natürlich, in jedem Falle stehen sie doch in intimer Verbindung mit dem darunterliegenden Protoplasma, Ob ausserdem isoliert verlaufende Gliafasern vorkommen, ist nicht so leicht zu entscheiden. Bei einer flüchtigen Durchmusterung der Präparate bekommt man zuerst den Eindruck, dass solche nackte, isoliert verlaufende Fasern keine seltene Erscheinung sind. Untersucht man aber genauer unter Verwendung von stärkeren Vergrösserungen, dann wird man einen dünnen Protoplasmaauslaufer finden, der die Gliafaser an der anscheinend nackten Stelle begleitet oder man wird auch bei Anwendung der Vikrometerschraube eine dünne Plasmalamelle beobachten können, die sich der betreffenden Gliafaser unmittelbar anschliesst. Je genauer man die Präparate studiert, umso seltener sind nackte Fasern zu beobachten; jedenfalls finden sie sich in einer verschwindenden Minorität vor. Hierbei ist es selbstverstïndlich keineswegs ausgeschlossen, dass das Vorbandensein auch dieser geringen Menge von wenigstens stellenweise von Protoplasma unbedeckten Fasern einer gewissen Unvollkommenbeit der Farbungsmethode in bezug auf die Darstellung der subtilsten Protoplasmastrukturen oder auch Observationsfehlern zuzuschreiben ist. Jedenfalls kann man nachweisen, dass die Gliafasern innerhalb oder an der Oberfläcbe des allgemeinen gliösen protoplasmatischen Netzwerkes verlaufen; sie imponieren also als ein intraplasmatisches Differenzierungsprodukt von einer besonderen chemischen Beschaffenheit. Die Möglichkeit, dass die Gliafasern stellenwe is e nackt sind und während kürzerer Strecken ihres Verlaufes von den Balken des Gliaplasma- 
netzwerkes getrennt verlaufen, muss zugegeben werden, obgleich ein solches Verhalten sich nicht nachweisen lässt.

Es erübrigt noch mit einigen Worten das Verhalten des Gliagerüstwerkes zu den in ihm eingeschlossenen Markscheiden resp. Achsenzylindern, ebenso wie die Gliaformationen rings um die in der weissen Substanz verlaufenden Blutgefässe zu berühren.

Die Gliahülle rings um die Markscheiden wird von einem feinen protoplasmatischen Netzwerke gebildet, das teils aus längs verlaufenden, teils quer oder schräg verlaufenden, meist feinen Protoplasmafäden zusammengesetzt ist (Taf. VI, Fig. 1, links oben im Bilde). Die Gliafasern, die ein năheres Verhalten zu den Markscheiden zeigen, ziehen bis auf wenige Ausnahmen in der Richtung der Nervenfasern, scheinen jedoch stellenweise mehr oder weniger von derselben abzuweichen; sie sind von feinen Protoplasmafïden eingeschlossen (Taf. VI, Fig. 1, Mitte des Bildes). Stellenweise, wo das umgebende Protoplasma nicht hervortritt, resp. vermisst wird, scheinen die verschiedenen in der Lüngsrichtung verlaufenden Gliafasern mit feinen Protoplasmafïden verbunden zu sein (Taf. VI, Fig. 1, links oben im Bilde). Die Anzahl der Gliafasern, die einen Markraum umgebend, parallel zu ihm verlaufen, scheint im allgemeinen bedeutenden Variationen unterworfen zu sein (Taf. VI, Fig. 1, Mitte des Bildes). Hie und da werden zwischen den Markräumen quere Gliafasern, meistens von einer dünnen Schicht von Protoplasma umgeben, gesehen (Taf. VI, Fig. 1, links oben). Auch die Dichte des die Markrüume umgebenden Netzwerkes, d. h. die Grösse und Form der Maschen wechselt bedeutend. Wo das Netzwerk lichter ist, sieht man oft in hinreichend dünnen Schnitten zwei quergetroffene Achsenzylinder von einer gemeinsamen Gliahülle umgeben (Taf. VI, Fig. 1). An den Grenzen der Marksegmente tritt das umgebende Gliagewebe in unmittelbare Berührung mit den Achsenzylindern, unter Bildung von Gliaschnürringen. Auf Taf. VII, Fig. 1 habe ich versucht, einen solchen Schnürring abzubilden. Aus dem die Markscheide unmittelbar umgebenden Glianetzwerk treten feine Plasmabalken oder - was uns gewöhnlicher erscheint - Protoplasmalamellen hervor, welche dem Achsenzylinder zustreben und sich rings um denselben zu einer kreisförmigen Bildung vereinigen, die teils eine netzförmige, teils bei reichlicherem Protoplasma eine kompakte Beschaffenheit zeigt. Gliafasern von der Umgebung 
tragen oft zur Bildung des Schnürringes bei; sie ziehen nicht selten in dem Marksegmentinterstitium dicht bei dem Achsenzylinder quer über denselben oder beschreiben auch Kurven um den Achsenzylinder und verlaufen dabei in dem Protoplasma, das den Schnürring bildet. Die Gliaschnürringe erscheinen also als Teile des allgemeinen Gliagerüstwerkes, speziell der die Markräume zunachst umgebenden Gliahülle. Weiter kann oft nachgewiesen werden, dass das Netzwerk rings um die Marksegmente in der Nahe ibrer Grenzen dichter erscheint; die Balken des Netzwerkes scheinen miteinander zu dünnen Lamellen zusammenzuschmelzen, sodass die Markraume stellenweise in der Năhe der Segmentgrenzen von dünnen Protoplasmamembranen umgeben sind (Taf. VII, Fig. 1).

Bezüglich des Verhaltens der Glia zu den in der weissen Substanz verlaufenden Blutgefässen kann als allgemeine Regel festgestellt werden, dass die perivascularen Gliaformationen hinsichtlich ihrer Art und Zusammensetzung von der Grösse der Blutgefässe unabbängig sind. An den Arterien, Capillaren und Venen verhält sich das marginale Gliagewebe prinzipiell gleich. Zur Bildung desselben tragen auch hier protoplasmatische Bestandteile mit eingeschlossenen Kernen und eine wechselnde Menge von Gliafasern bei. Bezüglich der protoplasmatischen, d. h. nicht besonders differenzierten perivascularen Gliaelemente verdient in erster Linie erwähnt zu werden, dass eine Grenzmembran, eine Membrana limitans gliae perivascularis, nachgewiesen werden kann als eine dünne hellblau gefärbte Schicht, welche die Gefässadventitia oder - wenn es sich um ein Capillargefäss handelt - das Endothel umgibt. ${ }^{1}$ ) Zur Bildung dieser Membran, die, was Aussehen, Struktur und Farbenreaktionen betrifft, dieselbe Beschaffenheit wie die Gliaprotoplasmabildungen, speziell die lamellösen Ausläufer der Gliazellen (vgl. Taf. VI, Fig. 1 und Taf. VII, Fig. 2 und 3) zeigt und somit nicht den Grenzmembranen (Membranae limitantes) anderer Organe gleichzustellen ist, tragen erstens die Auslănfer der Gliazellen, die in der unmittelbaren Nähe des Gefässes oder etwas mehr entfernt davon liegen, zweitens die Balken des das Gefäss unmittelbar umgebenden

1) Bei der Beschreibung des Baues des marginalen Gliagewebes bin ich sowohl hier wie im folgenden der $\mathrm{H}$ eld schen Nomenklatur, die mir die zweckmässigste scheint, gefolgt. 
Gliagerüstes und schliesslich die nahe der Membran selbst oder innerhalb derselben gelegenen Gliazellen mit ihrem Protoplasmakörper bei. Man kann sagen, dass die Grenzmembran von einer lokalen Zusammenschmelzung des Protoplasmas dieser sämtlichen Gliabestandteile herstammt. Zugegeben werden muss, dass die Darstellung und das Studium der perivascularen Gliamembranen schwierig sind. Um dieselben zu veranscbaulichen, bedient man sich am besten solcher Präparate, wo gewisse Artefakte, und zwar die sogenannten $\mathrm{H}$ isschen Raume, zu seben sind. Hierbei wird das Gliagewebe mit den eingeschlossenen markhaltigen Nervenfasern zur Retraktion von der Adventitia gebracht, wobei die Membrana limitans perivascularis in der Regel, wenn auch nicht immer, mit dem nervösen Gewebe und der Glia verbunden bleibt, sodass zwischen dem erwahnten Gewebe und der Adventitia ein grösserer oder kleinerer Zwischenraum entsteht. ${ }^{1}$ ) Obgleich in Präparaten, die nach der oben beschriebenen Methode gewonnen wurden, $\mathrm{Hissche}$ Räume nicht beobachtet wurden, gelingt es zuweilen im Zentrum grösserer Stücke oder in solchen, die weniger sorgfalltig in Alkohol nacbgehärtet wurden, solche Bilder zu erbalten. Fig. 2 und 3, Taf. VII, zejgen die perivasculare Grenzmembran von der Gefassadventitia isoliert (die von den Membranen eingeschlossenen Gefusse sind nicht abgebildet), und zwar Fig. 2 an einer Stelle, wo das Gefäss beinahe tangential, Fig. 3 an einer Stelle, wo Gefäss und Grenzmembran ziemlich in der Längsrichtung des Gefässes getroffen wurden. Die sogenannten Gliafüsse werden von dickeren Ausläufern gebildet, welche man deutlich bis zu Gliazellen, die in der unmittel-

3) Ich spreche von den $\mathrm{H}$ is schen Räumen als Artefakte, obgleich mir die verschiedenen Meinungen, die bezüglich der Deutung derselben herrschen, wohl bekannt sind. Dass die perivasculären Räume dieser Art wirklich Schrumpfungsphänomene darstellen, dafür sprechen mehrere Umstände. Es zeigt sich $u$. a., dass die ceteris paribus nmsoweniger hervortreten, je besser die Fixierung ist. Durch eine sorgfältige Fixierung und Nachbehandlung kann das Auftreten der erwähnten Räume i m m e r vermieden werden. Auch das Aussehen der äusseren Fläche der Adventitia, die die innere Begrenzung der $H$ is schen Räume bildet und aufgefranst, mit losgerissenen, in den Raum hineinragenden Bindegewebsfasern erscheint usw., spricht für dieselbe Auffassung. Andererseits kann kein Beweis für die Ansicht erbracht werden, dass die $\mathrm{H}$ is schen Räume wirkliche Lymphräume sein sollen. Ich kann auf diese Frage, die ausserhalb des Rahmens dieser Arbeit liegt, hier nicht näher eingehen. 
baren Nähe des Gefassses oder etwas mehr entfernt davon gelegen sind, verfolgen kann (Taf. IX, Fig. 1), oder auch von dünneren Balken, welche dem syncytialen Glianetzwerke entspringen (Taf. VII, Fig. 3). In beiden Fallen führen die betreffenden Ausläufer in der Regel Gliafasern. Die gröberen sind oft mit mehreren Fasern versehen, die meist an den Rändern verlaufen und zwischen sich eine geringe Menge von hellblau gefïrbtem Protoplasma einschliessen (Taf. VII, Fig. 2 und 3). Die dünneren, besonders diejenigen, die direkt aus dem Glianetzwerke entspringen, enthalten gewöbnlich nur eine einzige Gliafaser, die von einer dünnen Schicht Protoplasma umgeben wird, das jedoch auch gelegentlich vermisst werden kann. In der Năhe der Grenzmembran divergieren die Fasern, wenn sie in der Melurzahl vorhanden sind, nach verschiedenen Richtungen hin und das zwischen denselben gelegene Protoplasma bildet eine konische Anbiufung, die mit ihrer Basis direkt in die Membrana limitans übergeht. Auch die dünneren Balken zeigen beim Übergang in die Grenzmembran Anschwellungen von derselben Form. Die Gliafasem, die frei zu verlaufen scheinen, verlieren oft in der Nahe der Grenzmembran ihre dunkle Farbe, breiten sich zu einem schmalen Gliafusse von anscheinend protoplasmatischer Beschaffenheit aus und verschmelzen mit der Grenzmembran (Taf. VII, Fig. 3). Übrigens verhalten sich die Fasern in den Gliafüssen verschieden. Teils laufen sie in die Membrana limitans aus und schlagen hier eine im Verbăltnis zum Gefäss longitudinale oder quere Richtung ein, oder können ein Stückchen weiter in die Grenzmembran, wo sie eine gegenüber dem Gefässe schräge Richtung innehalten, verfolgt werden. Die Fasern der Membrana limitans bilden somit ein Netzwerk mit oft ziemlich regelmassigen Maschen; die stärlisten Fasern scheinen in der Regel einen longitudinalen Verlauf zu haben (Taf. VII, Fig. 2). Teils verlieren die Fasern oft schon innerhalb des Gliafusses, noch öfter aber wabrend ihres Verlaufes innerbalb der Membrana perivascularis ihre charakteristische Farbe, splittern sich in feine Fibrillen auf, welche stellenweise abgebrochen erscheinen und schliesslich nur durch eine Anzahl in Reihen angeordneter feiner Körnchen angedeutet sind (Taf. VII, Fig. 3). Man kann also konstatieren, dass ein Teil der Gliafasern in der Membrana limitans perivascularis aufhör. Oben wurde erwabnt, dass gewisse 
mit Kernen versehene Gliaplasmaanhäufungen, Gliazellen, auch zur Bildung der perivasculären Grenzmembran beitragen. Sie liegen entweder unmittelbar unter der Membrana limitans, d. h. an der dem Gefäss gegenüberliegenden Seite derselben, oder bilden einen integrierenden Bestandteil der Membran in der Weise, dass die Kerne in oder an derselben liegen oder derselben angelagert sind, kleine Ausbuchtungen gegen die Adventitia hervorrufend; das letztere scheint selten zu sein, kommt aber ab und zu vor. In beiden Fällen geht das Protoplasma breit in die Membrana limitans über, welche dann, wenigstens in den dem Kerne angrenzenden Partien, den Eindruck eines lamellösen Ausläufers des Zellprotoplasmas macht (Taf. VII, Fig. 3). Schliesslich sei bemerlit, dass die perivasculären Grenzmembranen, wo sie gut dargestellt und untersucht werden können, als kontinuierliche Membranen obne Löcher oder Öffnungen erscheinen; die Möglichkeit, dass solche jedoch in derselben yorkommen, kann natürlich nicht ausgeschlossen werden, solange sümtliche perivasculären Gliabüllen in ihrer ganzen Ausdehnung nicht haben nachgewiesen werden können.

Wenn wir jetzt zur Betrachtung des in der grauen $\mathrm{Sub}$ stanz sich findenden Gliagewebes meiner Präparate übergehen, so können wir zuerst feststellen, dass die für die Marksubstanz charakteristische Anordnung des gliösen Gewebes in einigermassen typischer Form nur in sehr beschränkten Abschnitten der Rinde uns entgegentritt und zwar in der subpialen marginalen Neuroglia und beim Übergange der grauen und weissen Substanz. Im Gegensatze hierzu zeigt der allergrösste Teil der Gehirnrinde bezüglich der Beschaffenheit und Anordnung der Gliasubstanzen ganz eigenartige Verhaltnisse. Hier treten Strukturen auf, welche nicht beim ersten Blick und ohne weiteres als dem nicht nervösen $Z$ wischengewebe angehörig erkannt werden können. Um uns zuerst an das marginale Gliagewebe $\mathrm{zu}$ halten, das die meisten Analogien mit der zentralen Glia in der weissen Substanz zeigt, so verdient besonders hervorgehoben zu werden, dass eine subpiale Grenzmembran, Membrana limitans gliae superficialis, nachgewiesen werden kann. In vertikal auf die Gehirnrinde geführten Schnitten kann die Grenzmembran als eine stellenweise ganz dünne hellblau gefärbte Bildung be- 
obachtet werden. An anderen Stellen, wo dieselbe Gliafasern in sich schliesst, tritt sie als ein etwas dunklerer blauer Streifen gegenüber dem hellen graugelben Piagewebe scharf hervor; die äusserste Grenze des Gliagewebes bildend. An schrägen (Taf. VI, Fig. 5) oder mehr tangentialen Schnitten der Hirnrinde können die Struktur und Zusammensetzung der Membran leichter studiert werden. Es zeigt sich, dass dieselbe aus einer hellblau gefärbten Substanz besteht, die in jeder Beziehung an das Gliaprotoplasma erinnert und stellenweise in verschiedenen Richtungen verlaufende Gliafasern, an anderen Punkten dagegen eine feinkörnige Beschaffenheit zeigt. Ibrem Aussehen nach erinnert die subpiale Grenzmembran somit an die perivasculären Gliamembranen der weissen Substanz, welche ebenfalls, wie schon erwăhnt, den Eindruck von Membranen von undifferenziertem Gliaprotoplasma machen. Die erwăhnte Ähnlichkeit tritt auch in dem Verhalten der subpialen Gliamembran gegenüber nahe gelegenen Gliazellen und deren Auslaufern, ebenso wie gegenüber dem unmittelbar unter derselben liegenden Gliasyncytium hervor. Auch hierbei tragen Ausläufer von näher oder entfernter gelegenen Gliazellen, Balken von dem unterliegenden syncytialen Netzwerke (Taf. VI, Fig. 6, Taf. VIII, Fig. 1) und schliesslich Gliazellen, die in oder gleich unter der Membran liegen (Taf. VI, Fig. 5), zur Bildung der Grenzmembran bei. Anch bezüglich des Verhaltens der Gliafüsse zu der subpialen Gliamembran, ebenso wie der Eigentümlichkeiten, welche die differenzierten Gliafasern bei ihrem Übergange von den zuführenden Gliafüssen in die Grenzmembran zeigen, herrscht eine so vollständige Übereinstimmung mit der schon beschriebenen perivasculären Grenzglia der weissen Substanz, dass ich auf diesen Gegenstand hier nicht näher einzugehen brauche. Betreffs der in der Grenzmembran verlaufenden Fasern verdient erwähnt zu werden, dass sie die verschiedensten Richtungen einzuschlagen scheinen, wodurch sie polygonale Felder abgrenzen, die an gewissen Stellen, besonders in der Tiefe der Furchen zwischen den Gyri, eine ziemlich regelmässige Form zeigen. Die in den Gliafüssen verlaufenden Fasern zeigen gelegentlich schon innerhalb derselben, zuweilen aber erst während ibres Verlaufes in der Grenzschicht, eine Aufsplitterung in feine Fibrillen, welche allmählich undeutlicher werden und schliesslich nur durch Reihen von feinen Körnchen angedeutet sind. Ein Teil der Glia- 
fasern findet also in der Membrana gliae superficialis ihr Ende. Andere laufen in die Grenzmembran durch einen Gliafuss hinein und biegen dann eine Strecke weiter wieder in einen angrenzenden oder etwas entfernteren Fuss aus ('Taf. VI, Fig. 6).

Bezüglich des marginalen Gliagewebes besteben ziemlich in die Augen springende regionäre Verschiedenbeiten. An einigen Stellen ist es in sehr geringer Menge vorhanden und erscheint ohne auffallende Struktureigentümichkeiten. Besonders ist dies der Fall an der höchsten Konvexität der Gyri. In der Tiefe del intergyralen Furchen dagegen tritt die marginale Glia in imponierender Mächtigkeit auf und zeigt eine besonders eigenartige Struktur and Anordnung. Fig. 6, Taf. VI zeigt die Glia in der Tiefe einer Furche an einem Vertilalschnitt der Gehirnrinde. Der rechts gelegene Rand des Bildes entspricht der tiefsten Stelle der Furche. Was der Glia in diesen Gegenden ihr charakteristisches Geprăge verleiht, ist die Mächtigkeit der hier gegen die Pialfläche geordneten Protoplasmabalken, welche Gliafüsse bilden. Sie verlaufen oft in ziemlich regelmissigen Abstanden voneinander und können meistenteils deutlich gegen die Tiefe hin bis $z \mathfrak{u}$ den entsprechenden Gliazellen verfolgt werden. Auch diese zeigen an den betreffenden Stellen gewisse charakteristische Eigenschaften. Sie haben eine mehr oder weniger deutlich ausgesprochen sternförmige Gestalt, welche durch die nach allen Seiten ausstrahlenden Protoplasmanusläufer bedingt ist. Letztere sind zum Teil mit typischen Gliafasern versehen, teilweise entbehren sie derselben jedoch. Manche Ausläufer kömnen ziemlich weit verfolgt werden, andere teilen sich nach einer kurzen Strecke in eine Anzahl feiner Protoplasmabalken, welche mit ahniichen Bildungen von angrenzenden Zellen zusammenhängen, sodass ein feines protoplasmatisches Netzwerk mit unregelmässigen Maschen entsteht. Die von den Zellkörpern nach oben in radiărer Richtung ziehenden Ausläufer zeigen oft eine bedeutende Dicke, sie erscheinen dabei als direkte Fortsetzung des Zellkörpers. Sie enthalten in der Regel - obgleich nicht immer - Gliafasern, und geben gleichfalls feine protoplasmatische Seitenfortsătze $a b$, welche hier mit analogen Gebilden benachbarter Hauptfortsätze verschmelzen (Taf. VI, Fig. 6, Taf. VIII, Fig. 1). Dadurch, dass diese sekundären Fortsătze eine transversale, der Pialfläche parallele 
Richtung innehalten, bekommt die Grenzschicht der Glia in diesen Bezirken ein charakteristisches Aussehen (Taf. VI, Fig. 6, Taf. VIII, Fig. 1). Die betreffenden der Pia parallelen Vereinigungsbalken scheinen ab und zu, obgleich nicht grade oft, feine W e ige r t sche Fasern zu führen. Die vertikalen oder radiären Pfeiler, ebenso die sekundären Balken, welche erstere verbinden, können entweder eine feinere fadenförmige oder breitere lamellöse Beschaffenbeit haben. Wenn erstere überwiegt, zeigt die Grenzschicht eine lichtere, zierlichere Anordnung (Taf. VI, Fig. 6). Sind sămtliche oder die meisten Balken, die das oberflachliche Gliasyncytium bilden, von membranöser Natur, so resultiert daraus ein mehr oder weniger ausgeprägter wabenartiger Bau der Gliagrenzschicht ('Taf. VIII, Fig. 1). Solche kleinen Gliakammern kommen überall in der Grenzschicht vor, scheinen jedoch, soviel ich beurteilen kann, besonders angehäuft und prägnant an den Seitentlächen der Gyri bervorzutreten. Die sternförmigen Zellen, welche die Knotenpunkte des in der Grenzschicht vorhandenen syncytialen Systemes bilden, sind in einer einfachen Reihe angeordnet und litngen zum Teil durch ein bellblaues mattkörniges Protoplasma breit miteinander zusammen (Taf. VI, Fig. 6). Die Kerne dieser Gliazellen zeigen in allem wesentlichen dasselbe Aussehen wie die grossen, an gefärbtem Chromatin armen und mit Nucleolen versehenen Kerne des Gliagewebes der Marksubstanz. Unmittelbar unter den erwähnten Gliazellen, oft in den protoplasmatischen Fortsătzen derselben verlaufend, oft aber ohne nähere Beziehung zu denselben, laufen schräg gegen die Oberfläche Weigertsche Gliafasern, welclue hier meist nur in geringer Menge vorkommen, gelegentlich aber zahlreicher sind ("Rindenschicht der Glia").

Verfolgt man das marginale Gliagewebe von der Tiefe der Furchen gegen die freien Flächen der Gyri, so sieht man es an Mächtigkeit abnehmen. Die Grenzschicht, d. h. der radiär strukturierte Teil der marginalen Glia, der zwischen Membrana gliae superficialis und den reihenartig angeordneten sternförmigen Gliazellen liegt, erscheint weniger ausgeprägt. Die gegen die Grenzmembran gerichteten Hauptbalken verlaufen scbräg oder unregelmassig und sind hier viel spärlicher zu sehen. Auch die sekundären, mit der Pia parallelen Balken verschwinden mehr und mehr. Die in der Tiefe der Sulci so charakteristischen sternförmigen Zellen verlieren ihre typische Form und erscheinen 
als mehr oder weniger platte, unregelmässige Gebilde mit etwas abgeplattetem, meist ovalem Kern (Taf. VI, Fig. 5). Die erwähnten Zellen gehen stellenweise mit ihrem Protoplasmakörper breit in die oberflächliche Grenzmembran über. Infolge des Schmälerwerdens der Grenzschicht nähert sich die "Rindenschicht" mit ihren tangential oder schräg verlaufenden Gliafasern der Membrana limitans (Taf. VI, Fig. ō). In den gegen die freie Hirnoberfläche gelegenen Abschnitten der marginalen Glia oder in den obersten angrenzenden Partien der Sulci trifft man dagegen ab und zu Zellen, die man höchstens ausnahmsweise in der Tiefe der Furchen findet. Diese Zellen scheinen einen integrierenden Bestandteil der oberflachlichen Grenzmembran zu bilden, mit welcher ihr Protoplasma vollständig verschmilat. Die Kerne, die also in der Membran selbst oder in einer geringen Verdickung derselben liegen, zeigen dieselben Eigentümlichkeiten wie in den übrigen Gliazellen der Grenzschicht.

Es wurde oben erwähnt, dass die Gliazellen der Grenzschicht in ihren nach allen Richtungen ziehenden Ausläufern Gliafasern führen. Einige von diesen Fasern können nach innen in die Hirnrinde ein Stückchen in die Molekularschicht verfolgt werden. Auch eine Anzahl der tangential oder schräg verlaufenden Fasern biegt nach innen um und lïsst sich eine kleine Strecke weit in dieser Schicht nachweisen. Im allgemeinen kann festgestellt werden, dass nur die oberflächlichsten Teile der Molekularschicht Weigertsche Gliafasern besitzen. Ausser den aus der Grenzschicht und der Rindenschicht stammenden Fasern kommen hier stellenweise solche vor, welche typische Beziehungen zu den Gliazellen der Molekularschicht darbieten. Diese Zellen bestehen aus kleinen Protoplasmaanbäufungen rings um einen ziemlich kleinen runden Kern, der ziemlich reichlich gefärbtes Chromatin in Form von gröberen oder feineren Klumpen und meistens keinen nachweisbaren Nucleolus enthalt. Am Kern dieser Zellen vorbei ziehen in bogenförmigen Buchten einzelne Gliafasern, die nur eine kurze Strecke vom Kerne verfolgt werden können.

Während also die Weigertschen Fasern schon in den oberHächlichen Lagen der Molekularschicht mehr und mehr zurücktreten, zeigt dagegen das protoplasmatische Gliasyncytium eine immer mehr in die Augen springende Mächtigkeit und wird schon 
hier ganz und gar dominierend. Es sind zwei Eigenschaften des Syncytiums, welche bedingen, dass dasselbe in den Präparaten sich durch eine auffallend dunkle Farbe hervorhebt: einerseits die Dichtigkeit des Glianetzwerkes, andererseits die tiefe Farrbung seiner Balken, während im übrigen das faserfreie Gliaprotoplasma bei der von uns angewendeten Methode lichter erscheint. Die Dichtigkeit des Glianetzwerkes, $d$. b. die relative Enge der Maschen desselben geht Hand in Hand mit einer Abnahme der Stärke der Balken. Diese zeigen sich als ăusserst dünne Protoplasmafäden. Ihr tiefer Farbenton wird nicht durch eine diffuse Farbung des Protoplasmas selbst bedingt, sondern durch eine Menge in demselben eingeschlossener feiner Körnchen, die bei der betreffenden Färbung eine tiefblaue Farbe annehmen und sich somit in gleicher Weise wie die Weigertschen Gliafasern färben.

Das Aussehen und die Beschaffenheit dieses feinen körnigen Netzwerkes wird am besten an sehr dünnen Schnitten studiert. Besonders eignen sich für feinere Beobachtungen solche Stellen, wo gröbere Dendritverăstelungen sich finden, welche sowohl in den unteren Abschnitten der Molekularschicht ais in der Pyramidenzellenschicht zahlreich vorkommen. An solchen Stellen (Taf. VII, Fig. 4 und 5) machen die ungefürbten Protoplasmafortsaltze der Nervenzellen den Eindruck von runden oder länglichen (je nachdem sie quer oder schräg getroffen sind) Lücken oder auch von gröberen oder feineren, verasstelten Kanălen, (wenn der Schnitt mit der Längsrichtung zusammenfiel). In beiden Fallen bietet der diesen Hohlräumen oder besser gesagt den Dendriten unmittelbar anliegende Teil des Glianetzwerkes ein gutes Feld für Studien. Hat man z. B. einen tangential getroffenen gröberen Dendrit vor sich, so treten die Einzelheiten des pericellulären resp. peridendritischen Netzwerkes mit voller Deutlichkeit hervor (Taf. VII, Fig. 5 und Taf. IX, Fig. 2, die Pyramidenzelle in der Mitte des Bildes). Man findet dann, dass die Maschen des Netzwerkes in der Form unregelmăssig viereckig oder polygonal mit abgestumpftem Winkel sind. Ihre Grösse scheint nicht besonders grossen Schwankungen unterworfen zu sein. Gibt man sich die Mühe, den Diameter der Maschen in verschiedenen Richtungen zu messen, so findet man, dass derselbe gewöhnlich etwa $1 \mu$ mit geringen Oscillationen nach beiden Seiten hin betrăgt. Die Balken des Netzwerkes zeigen eine komplizierte Struktur und bestehen 
aus einer hellblau gefärbten Grundsubstanz, die dunkel gefärbte Körnchen in sich schliesst, deren Grösse ebenso wie die Stärke der Balken etwas variiert. Oft werden nebeneinander und in einem und demselben Balken verschieden grosse Körnchen gefunden. In jedem Falle hălt sich die Starke der Balken und die Grösse der Körnchen unter der Grenze des mikroskopisch sicher messbaren. Ebenso wie die Grösse der Körnchen wechselt auch ihre Farbe. Neben tiefgefärbten kommen etwas lichtere, ja sogar solche vor, die kaum von der umgebenden lichten protoplasmatischen Balkensubstanz unterschieden werden können. Diese Körnchen, die nach der hier angewendeten Methode zu schliessen ein konstant vorhandenes Zellelement des Gliagewebes der Gelirnrinde darstellen, bezeichne ich bis auf weiteres der Kürze wegen als Gliosomen.

Als eine Konsequenz des reichlichen Vorkommens dieser Gliosomen in den schmalen Balken des Netzwerkes geht ohne weiteres ihre Anordnung in längeren oder kürzeren Reihen hervor. Gelingt es in den oberen Abschnitten der Molekularschicht eine von den hier spärlich vorkommenden Weigertschen Fasern ihren ganzen Verlauf entlang zu verfolgen, so kann man, auch wenn die Faser anscheinend in der Richtung des Schnittes verläuft und eine Knickung ausgeschlossen werden kann, gelegentlich beobachten, wie die Faser aufhört, wăhrend eine Serie reihenartig angeordneter Gliosomen eine Fortsetzung derselben bilden.

Um zu dem feinen pericellulären Netzwerk zurückzukehren, verdient als für dasselbe charakteristisch noch erwähnt zu werden, dass die Knotenpunkte durch Verschmelzung von in der Regel drei, gelegentlich vier Balken gebildet werden. Mehr als vier zusammenstossende Balken habe ich nicht mit Sicherheit beobachten können. Wie schon angedeutet wurde, ist dieses feine Netzwerk mit den eingeschlossenen Gliosomen diffus über die ganze graue Substanz ausgebreitet. Es erstreckt sich von der Oberfläche des einen Dendriten zum anderen, von der Oberfläche der einen Nervenzelle kann dasselbe durch das dazwischenliegende Gewebe zu der Oberfläche einer anderen verfolgt werden, von der Molekularschicht durch die Pyramidenschicht bis zu der Grenzschicht zwischen Rinde und Marksubstanz. Bezüglich des Verhaltens des pericellulären Netzwerkes zum Innern der Dendriten und dem Körper der Ganglienzellen, resp. dem nervösen 
Protoplasma sei erwähnt, dass irgend ein Zusammenhang zwischen diesen Teilen nicht nachgewiesen werden kann. Die Begrenzungen der Ganglienzellen und ihrer Dendriten sind ganz scharf. Eine Fortsetzung der Balken des Netzwerkes in das nervöse Protoplasma hinein kommt nicht vor (Taf. VII, Fig. 4 und 5). Auch in den Făllen, wo das Ganglienzellenprotoplasma nicht vollständig farblos oder gar zerstört ist, was doch meistens der Fall zu sein scheint, und wo grössere oder kleinere schwach gefärbte Reste davon vorhanden sind (Taf. VII, Fig. 5), können keine anderen Beziehungen zwischen dem Gliaplasmanetzwerk und dem nervösen Protoplasma konstatiert werden als solche, die sich auf eine obelHảchliche Anlagerung beschrănken.

Die Kerne, die in der grauen Rindensubstanz vorkommen und nicht zu den nervösen Zellen, sondern zu der nicht nervösen Zwischensubstanz gehören, zeigen gewisse charakteristische Eigenschaften. Sie sind im allgemeinen ziemlich klein, messen gewöhnlich $5-7 \mu$ im Diameter, sind von runder Form, gelegentlich etwas abgeplattet und zeigen meist einen ziemlich reichlichen Gehalt in gefärbtem Chromatin, in Form von grösseren Klumpen oder feineren Körnchen.

Bezüglich des Chromatingehaltes kommen gewisse Variationen vor. In einem Teile der Zellen erscheint das gefürbte Chromatin als gröbere Klumpen, die eine netzförmige Anordnung haben und durch ihre bedeutende Menge dem Kerne eine dunkle Farbe verleihen, so dass derselbe bis $\mathrm{zu}$ einem gewissen Grade einem Lymphocytenkern ähnlich ist (Taf. VII, Fig. 6). Andererseits lommen Kerne vor, welche eine geringere Quantität von gefärbtem Chromatin aufweisen, das gewöhnlich in Form von Körnchen oder Klumpen, die im Innern des Kerns zerstreut sind, angeordnet ist, oft ohne scheinbaren Zusammenhang miteinander (Taf. VI, Fig. 2). In diesem Falle erscheint der Kern natürlich im ganzen lichter. Ein Nucleolus kann in diesen Kernen ebensowenig wie in den erstgenannten beobachtet werden. Kerne der beiden Typen, ebenfalls wie solche von $Z$ wischenformen $z$ wischen beiden, sind über die ganze graue Substanz zerstreut. Hierbei kann irgend eine regelmässige oder typische Anordnung in der Beziehung, dass verschiedene Arten von Kernen in verschiedenen Abschnitten der Rinde vorkommen, nicht nachgewiesen werden. Ebensowenig besteht bezüglich des Gehaltes an gefärbtem Chro- 
matin, der Grösse usw. irgend ein prinzipieller Unterschied zwischen den Kernen, die in gewisse räumliche Beziehungen zu den nervösen Zellen z. B. in Form von Begleitkernen treten und solchen, die anscheinend frei in dem Rindengewebe liegen.

Grösseres Interesse bietet zweifellos das Studium der Verhältnisse zwischen diesen Kernen und dem umgebenden Protoplasma einerseits, wie zu dem überall vorhandenen, gliosomenführenden Netzwerk andererseits. Es kann nicht geleugnet werden, dass hierbei eine gewisse Unvollkommenheit meiner Methode an den Tag tritt. Man trifft nämlich in den Präparaten Stellen, wo die betreffenden Kerne anscheinend ziemlich isoliert im Gewebe liegen, von demselben durch eine schmale Lücke getrennt und nur von einer schmalen Zone Protoplasma umgeben, das bald unregelmässig erscheint, bald den Kern balbmondförmig umgibt. Man kann sich leicht davon überzengen, dass die betreffenden Lücken Schrumpfungsräume sind. Erstens werden nämlich in diesen feine, teilweise Gliosomen führende Fäden angetroffen, welche das Protoplasma des Kernes mit dem Netzwerke verbinden. Zweitens können leicht Stellen gefunden werden, wo diese Schrumpfungsartefakte nicht vorhanden sind. Solche Stellen, die uns natürlich einen richtigeren Aufschluss über das Verhalten der Gliazellen der grauen Substanz zu dem Gliafadennetz geben, zeigen unzweideutig, wie das den Kern umgebende, ziemlich spärliche, im ganzen dunkel gefärbte, feinkörnige Protoplasma oft schon in der Nähe des Kernes sich in eine Menge feiner protoplasmatischer fadenförmiger Fortsätze auffranst, die nach allen Richtungen hinziehen und in die Balken des feinen Glianetzwerkes übergehen (Taf. VII, Fig. 4, Taf. VI, Fig. 2). Mit grosser Deutlichkeit tritt diese Erscheinung in dem Protoplasmakörper der „Begleitzellen“ hervor, die mit ihren feinen Ausläufern zur Bildung des pericellulären Glianetzwerkes beitragen (Taf. VII, Fig. 6). Es wurde erwähnt, dass das Protoplasma der betreffenden Gliazellen eine feinkörnige Struktur aufweist. Dass diese nicht durch eine Anhäufung von Gliosomen bedingt wird, geht wohl aus den Zeichnungen deutlich hervor (Taf. VI, Fig. 2, Taf. VII, Fig. 4 und 6), obgleich natürlich auch Körnchen vorkommen können, die, was Grösse und Farbe betrifft, den Körnern des Glianetzwerkes ähneln; indessen ist dies nur vereinzelt der Fall. Was besonders hervorgehoben zu 
werden verdient, ist, dass sow ohl die kleinen Gliazellen mit dunkel gefärbtem Kerne als diejenigen mit lichterem Kerne in der Rinde des Grosshirns einen Protoplasmakörper baben, der zahlreiche feine, fadenförmige Fortsatze besitzt, welche sich stark verästeln, miteinander anastomosieren und direkt in das gliosomenführende, protoplasmatische Glianetzwerk der grauen Substanz übergeben, wobei die Gliazellen mit ihrem verhăltnismässig kleinen Zellkörper wie in diesem Netzwerk aufgehängt erscheinen.

Es bleibt noch übrig, das Verhalten des Gliagewebes der grauen Substanz zu den daselbst sich findenden mesodermalen Bildungen, Blutgefässe und deren Adventitia, zu berücksichtigen. Verfolgt man ein Blutgefasss von der Pia bis in die Molekularschicht, dann kann man beobachten, wie die oberflächliche Grenzmembran allmählich in die perivasculatre Gliamembran übergeht, die das Gefüss wăhrend des Verlaufes durch die ganze Rinde umgibt. Beim Eintritt des Gefässes in die Rindensubstanz indert das marginale Gliagewebe, das als eine direkte Fortsetzung der subpialen marginalen Schicht das Gefäss entlang nach innen verfolgt werden kann, ziemlich schnell sein charakteristisches Ausseben. Die groben Fortsătze, die hier radiär zum Gefäss angeordnet sind, ebenso wie die gröberen Gliafüsse nebmen an Zahl und Stärke $a b$ und schwinden schliesslich ganz. Ebenso verlieren sich die Weigertschen Fasern, welche noch in den oberflächlicheren Lagern der Molekularschicht zu der Bildung der Limitans perivascularis beigetragen hatten, in den tiefer gelegenen Abschnitten der Rinde. In diesen Teilen der grauen Substanz stellt sich die Grenzmembran als eine dünne und - soweit man dies aus den Praparaten schliessen kann - zusammenhängende kontinuierliche Schicht von hellblauer Farbe (Taf. VII, Fig. 7) dar. Diese Schicht tritt in zweierlei Weise mit dem umgebenden Glianetzwerke in Verbindung. Erstens bestehen diese Verbindungen aus feinen gliosomenführenden Protoplasmafäden, welche von dem umgebenden Gewebe durch den sog. Rothschen Raum gegen die Membran hin ziehen und sich mehr oder weniger vertikal an derselben befestigen, während das Protoplasma des Balkens sich zu einem Fusse von minimalen Dimensionen verbreitet (Taf. VII, Fig. 7). Ausser durch diese feinen Balken 
werden die Verbindungen zwischen Limitans perivascularis und dem umgebenden Glianetzwerke von einer Anzahl perivascular gelegener Gliazellen vermittelt, welche in den betreffenden Abschnitten der Rinde eine ziemlich gewöhnliche Erscheinung sind. Charakteristisch für die erwähnten Zelien, die ihre Lage dicht unter der Membrana limitans haben, ist, dass sie mit ihrem Protoplasmakörper in die Membran mehr oder weniger breit übergehen oder, was häufiger der Fall zu sein scheint, dass sie eine Menge feiner fădchenartiger Protoplasmafortsätze aussenden, welche gegen die Membrana limitans Linziehen, wo sie in typischer Weise unter Bildung eines Fusses ihr Ende finden. Andererseits hängen die Zellen, die bezüglich des Kernes und der Beschaffenheit des Protoplasmakörpers vollständig den übrigen ausserhalb des Gefüssgebietes liegenden Gliazellen ähneln, mit feinen Fortsätzen in gewöhnlicher Weise mit dem Glianetzwerke zusammen.

Hinsichtlich des Auftretens und der Frequenz dieser perivasculïren Gliazellen bestehen offenbar in denselben Abschnitten der Rinde bedeutende Differenzen. An gewissen Stellen sind sie spärlich, so dass die Gefässe gelegentlich in verbältnismässig weiten Strecken der Rinde verfolgt werden können, ohne dass man solche Zellen trifft. An anderen können sie nahe aneinander in einer Zahl von zwei, drei oder mehr gelngert sein. Grössere Gefässe zeigen oft ein stärkeres perivasculires Gliagewebe mit zahlreichen eingestrenten Gliazellen als die kleineren bezw. die Capillaren. Dies ist jedoch keineswegs immer der Fall. Überhaupt scheinen die Gefässe der tiefereu Rindenschichten von zahlreicheren perivascularren Gliazellen begleitet zu werden als die oberflachlicheren, obgleich auch in dieser Beziebung bedeutende Variationen vorkommen.

Das Studium des perivascularen Gliagewebes der grauen Substanz ist mit gewissen Schwierigkeiten verbunden, welche zum Teil einer Mangelhaftigkeit der Methode zugeschrieben werden müssen. Es ist mir nämlich nicht gelungen, in meinen Präparaten dem Entstehen der perivasculären Schrumpfungsräume zu entgehen, die zwischen der Membrana limitans und dem umgebenden Gewebe in der Gehirnrinde liegen. Diese sogenannten Rot $\mathrm{h}$ schen Räume, welche trotz einer sorgfältigen Nachbehandlung mit Alkohol in einzelnen Teilen der Priparate vorkommen, erschweren 
natürlich bis zu einem gewissen Grade die Beobachtungen über das Verbältnis zwischen Limitans perivascularis und dem umgebenden Gliagewebe. Doch findet man Stellen, wo solche durch Schrumpfung entstandenen perivasculären Räume fehlen. Durch die Roth schen Räume werden die tatsăchlichen Verhältnisse in der Beziehung entstellt, dass die breit in die Membrana perivascularis übergehenden Gliazellen mit der Membran in Verbindung bleiben, während die feineren Ausläufer von den etwas entfernter gelegenen Gliazellen ebenso wie die gegen die Gefassmembran ziehenden Gliabalken an vielen Stellen zerreissen (Taf. VII, Fig. 7). Dass andererseits aber die Rothschen Raume in bedeutendem Grade das Studium der Struktur und der Beschaffenheit der Membranil limitans erleichtern, ist klar.

Bezüglich dieser Grenzmembran wurde oben erwathnt, dass sie als eine protoplasmatische Bildung anzusehen ist. Es sind zwei in derselben vorkommende Gewebselemente, die ihr gewisse Struktureigenheiten verleihen: körnige Bildungen und Weigertsche Gliafasern. Die Körnchen, die mit den Gliosomen isomorph sind, kummen nicht gerade zahlreich vor und zeigen auch hier eine deutliche Neigung, sich in Reihen zu ordnen. Gelegentlich sind sie so dicht aneinander gelagert, dass die Zwischenräume nicht oder nur mit Schwierigkeit wahrgenommen werden können (Taf. VII, Fig. 7). In diesem Falle machen sie den Eindruck von kurzen Stücken der Weigertschen Fasern. Andererseits sieht man eine solche Gliosomenreihe in eine Gliafaser übergehen oder richtiger gesagt, die direkte Furtsetzung derselben darstellen (Taf. VII, Fig. 7), oder man sieht eine Gliosomenreihe mehr oder weniger deutlich gegen die Befestigungsstelle eines Gliafusses hinziehen und sich mit dessen Körnern vereinigen. Von den Weigertschen Fasern der Membrana perivascularis in diesen Teilen der Rinde ist nicht viel zu sagen. Sie kommen hauptsächlich in den untersten Schichten, ebenso in den oberen Lagern der Molekularschicht vor, können aber gelegentlich auch höher hinauf in der Rinde angetroffen werden (Taf. VII, Fig. 7), in Gegenden, wo das umgebende Gliagewebe solche zu entbehren scheint. - Diese Erscheinung berubt wahrscheinlich darauf, dass einzelne feinere Fasern des Glianetzwerkes durch die dicht gelagerten dunkel gefärbten Gliosomen und durch die Dichte des Gewebes sich der Beobachtung entziehen. Jedenfalls zeigen sie, 
wo sie überhaupt in der Grenzmembran vorkommen, einen teils longitudinalen, teils transversalen Verlauf und bewirken so gelegentlich eine Feldbildung.

An der Grenze zwischen Mark und Rinde sieht man die oben beschriebene, für die graue Substanz typische Anordnung, allmählich schwinden. In den tiefsten Schichten der Rindensubstanz, besonders in der Schicht der polymorphen Nervenzellen, kommen die Weigertschen Gliafasern zum Vorschein, anfangs nur vereinzelt, später in reichlicherer Anzahl. Gleichzeitig ändert das Gliasyncytium selbst sein Aussehen. Das Netzwerk wird lichter, die Maschen erweitern sich, um die schon hier in grösseler Anzahl vorkommenden Markscheiden aufzunehmen, die Gliosomen schwinden allmählich. In den oberflächlichsten Abschnitten des Warkes treten schon die mit grossem lichten, nucleolushaltigen Kern und reichlichen protoplasmatischen Fortsätzen versehenen Gliazellen auf, die mit den Gliafasern dem Glianetzwerke die für die weisse Substanz charakteristische Beschaffenheit verleihen.

Ehe ich die Beschreibung des Gliagewebes der Gehilnsubstanz verlasse, möchte ich noch die Aufmerksamkeit auf einen besonderen Umstand lenken. Es wurde in einem anderen Zusammenhange angedeutet, dass das nicht nervöse Zwischengewebe der Rindensubstanz eine Anordnung und ein Aussehen darbietet, die dasselbe nicht beim ersten Blick und obne weiteres als eine gliöse Bildung erkennen lassen. Wie aus meinen Ausführungen hervorgehen dürfte, ist das feinmaschige, zierliche, mit Körnchen versehene Netzwerk, das in so vielen Hinsichten vom Ausseben typischen Gliagewebes abweicht, doch zweifelsohne gliöser Natur. Der Übersicht wegen werde ich hier die Umständè, welche für diese Auffassung sprechen, kurz zusammenfassen.

Ich halte das feine Netz der grauen Substanz für eine Gliabildung:

1. weil dasselbe kontinuierlich nach oben bis zu dem marginalen subpialen Gewebe verfolgt werden kann und ebenso an der Grenze $z$ wischen Mark und Rinde in einem kontinuierlichen $\mathrm{Zusammenhange} \mathrm{mit} \mathrm{dem} \mathrm{Glia-}$ gewebe der Marksubstanz steht; 
2. weil dasselbe in deutlicherkontinuitat mit dem Protoplasma der Gliazellen der grauen Substanz steht;

3. weil es ebenso einen unzweideutigen Zusammenhang mit den Grenzmembranen der grauen Substanz zeigt, welche als dünne Scbichten von undifferenziertem Protoplasma erscheinen;

4. weil dasselbe bezüglich der Farben reaktionen von den nervösen Bildungen abweicht, dagegen dieselben Reaktionen wie das Gliagewebe im übrigen zeigt, speziell ist dies der Fall bei den Gliosomen, welche in derselben Weise wie die Weigertschen Gliafasern gefürbt werden; und schliesslich

5. weil kein Umstand angeführt werden kann, der für eine nervöse Beschaffenheit desselben sprechen könnte.

Aus der oben gegebenen - wie ich fürchte, ein wenig ermüdenden - Beschreibung dürfte in der Hauptsache hervorgehen, welche Aufschlüsse die von mir angegebene Yethode über Bau und Anordnung des Gliagewebes in dem Teile des normalen Hundegehirnes, den ich zum Gegenstand meiner Untersuchungen gewahlt, geliefert hat. Bei einem Vergleich $z$ wischen diesen Resultaten und der Auffassung über den normalen Bau des Gliagewebes, der durch die Anwendung der üblichen Färbemethoden gewonnen wurde, findet man, dass die Anschauungen in gewissen Punkten voneinander abweichen. Zwar sind in meinen Präparaten Strukturen dargestellt, welche ohne weiteres mit den früher gekannten Gliabildungen identifiziert werden können; dies ist besonders der Fall bei den Weigertschen Gliafasern. Andererseits scheint mir aber die Methode zu Resultaten $z u$ führen, die mehr oder weniger von der gewöhnlichen Auffassung, besonders betreffend gegenseitigen Verhaltens der Gliazellen, abweichen. Ausserdem scheint sie mir etwas neues gebracht $\mathrm{zu}$ haben in der Beziehung, dass meine Prăparate Strukturen zeigen, welche keine Übereinstimmung mit den Gliabildern zeigen, die mit den klassischen Methoden dargestellt werden können. Die Verbălt- 
nisse, welche die Methode aufgedeckt hat, können indessen, wie ich selbst besonders bemerken will, nicht ohne weiteres als feststehende wissenschaftliche Tatsachen angesehen werden, ebensowenig wie die beschriebene Methode von vornherein als für die histologische Technik definitiv verwertbar angesehen werden kann. Es machen sich natürlich hier dieselben Umstände wie bei anderen neuen Methoden überhaupt geltend, die zu Resultaten führen, welche mehr oder weniger von früheren Auffassungen in der Histologie abweichen. Um ihre Anwendbarkeit für die histologische Teclnik darzutun, scheint mir eine neue Methode $z$ wei Bedingungen erfüllen $z u$ müssen. Erstens müssen wir gewisse Garantien dafür besitzen, dass das neu Dargebrachte nicht auf Artefakten bezw. auf einer unrichtigen oder missgedeuteten Darstellung von früher bekannten Strukturen berubt. Zweitens dürfen Tatsachen, welche wissenschaftlich fest gesichert sind, nicht verletzt werden. Ich muss also rusehen, inwieweit meine Methode diesen beiden Forderungen entspricht.

Was zunächst den ersten Punkt betrifit, so stellen die Bildungen, welche in meinen Präparaten unzweifelbaft als Bestandteile des Gliagewebes erscheinen, aber doch möglicherweise als Artefikte gedentet werden könnten, protoplasmatische Brücken dar. welche die verschiedenen Gliazellen untereinander verbinden oder das plasmatische Gliareticulum in seiner Gesamtheit sowohl in der grauen wie in der weissen Substanz. Dies Glianetzwerk könnte möglicherweise als die Folge einer Koagulation der Gewebstlüssigkeit gedeutet werden. Ich möchte dies besonders in Erwägung ziehen, weil ein ăhnlicher Einwand von Ramon y Cajal ${ }^{1}$ ) gegen die von Bethe gegebene Deutung der Netzwerke in Präparaten, die nach der Methode des letzterwähnten Forschers gefärbt wurden, gemacht worden ist. In der Tat gibt diese Methode besonders von den pericellulären Netzwerken der grauen Substanz Bilder, welche, wie wir sehen werden, in mehreren Beziehungen mit den meinigen übereinstimmen. Durch kleinere Abänderungen des von mir beschriebenen Verfahrens können Präparate erhalten werden, in welchen die Ähnlichkeit mit denjenigen von Bethe noch mehr hervortritt. Durch eine von der oben angegebenen etwas abweichende Alkoholbehandlung - man braucht nur die

1) Vergl. Marinesc 0, G.: La cellule nerveuse. Paris 1909, Tome I S. $206-207$. 
in Sublimattrichloressigsäure fixierten Stücke in absoluten Alkohol überzuführen, der wăhrend der ersten 24 Stunden nicht gewechselt wird - und durch nachfolgende Färbung entweder mit Hämatoxylinwolfram oder Hämatoxylinvanadium erhält man oft Bilder, welche offenbar eine grosse Ähnlichkeit mit den Betheschen haben. Leider habe ich keine eigene Erfahrung von der Betheschen Methode, sondern muss mich auf die von ihm gelieferten Abbildungen und seine Beschreibung von den Färbungsresultaten beziehen. In jedem Falle zeigen in der erwähnten Weise behandelte Präparate pericellulare und diffuse Netzwerke in der grauen Substanz, welche eine grössere Ähnlichkeit mit den Betbeschen Golginetzen darbieten, als dies durch Anwendung meiner Methode erhalten werden kann. Diese Netzwerke scheinen von dicken, intensiv gefarbten homogenen Balken zusammengesetzt zu sein, vielleicht sind die Balken sogar noch stärker als diejenigen des Betheschen Netzwerkes. Sie scheinen weiter in ein gröberes etwas lichter gefärbtes Netzwerk der weissen Substanz kontinuierlich überzugehen, das in allem wesentlichen dem $B$ e t b eschen .F Fullnetz" zu entsprechen scheint, doch ist vielleicht auch dies von noch stïrkeren und intensiver gefürbten Balken zusammengesetzt. Die erwähnten Netzwerke machen beim ersten Blick den Eindruck von Artefakten, die durch eine netzförmige Koagulation der Gewebstüssigkeit zustande gekommen sind. Untersucht man indessen das Netzwerk der weissen Substanz näher, so findet man an den Knotenpunkten des Netzes oder an den Stellen, die klumpiger und dicker erscheinen, eingeschlossene Kerne. Die dem Kerne anliegende Anhäufung von intensiv gefärbter Substanz stellt sich als Zellprotoplasma heraus, und die feineren Balken des Netzwerkes enthüllen sich in der Tat als miteinander stark anastomosierende Ausläufer von Gliazellen - denn nur von solchen kann hier die Rede sein. Auch hier handelt es sich also nicht um eine netzartige Koagulation der Gewebshlüssigkeit, sondern um entstelltes Gliagewebe der weissen Substanz.

Kann man also schon bei diesen Präparaten, welche doch wie gesagt eine mehr oder weniger entstellte Gliastruktur zeigen, schwerlich die Hypothese von einer netzförmig koagulierten Gewebsflüssigkeit aufrecht erhalten, so ist dies noch weniger der Fall bei dem netzförmigen Zusammenhange zwischen den Gliazellen in Präparaten, die unter Beobachtung von oben gegebenen 
Vorschriften angefertigt wurden, und in denen Kunstprodukte von der erwähnten Art nicht vorkommen. Das hellblau gefärbte Protoplasma in der Nähe des Kernes, das oft ein deutliches Mikrocentrum aufweist, ${ }^{1}$ ) sieht man in unseren Präparaten sich in eine Menge Ausläufer teilen, welche in kontinuierlicher Weise verfolgt werden können, entweder bis zu einer nabeliegenden Zelle oder zu Ausläufern, mit denen sie deutlich verschmelzen. Will man also den Zusammenhang zwischen den Gliazellen bzw. das Netzwerk als ein Kunstprodukt auffassen, so muss auch das Zellprotoplasma als ein Artefakt erklärt werden, denn irgend eine Grenze zwischen dem Zellprotoplasma und dessen Fortsätzen, bzw. den Balken des Glianetzwerkes kann nicht nachgewiesen werden. Offenbar können keine Gründe für eine solche Annahme erbracht werden. Ausserdem spricht gegen evtl. Artefakte die ausserordentlich komplizierte zierliche Struktur, die man überall beobachten kann (Taf. VI, Fig. 5 und 6). Diese kann kaum in einer artefiziellen Weise bei der Einwirkung unserer Reagentien entstanden sein. Wenn dies zugegeben werden muss bei der marginalen Glia und dem Gliagewebe der weissen Substanz, wo die Verhältnisse gewissermassen übersichtlicher sind, so kann man schwerlich belaupten, dass andere Verhältnisse innerhalb des Gliagewebes der grauen Substanz sich geltend machen sollten. Das Vorkommnis von Artefakten erwähnter Art kann also, wie ich glaube, aus guten Gründen ausgeschlossen werden und wir haben also keinen Grund zu befürchten, dass die Bilder des Gliagewebes, soweit sie den gegenseitigen Zusammenhang der Gliazellen und das protoplasmatische Glianetzwerk betreffen, nicht durch tatsächliche anatomische Verbältnisse bedingt werden sollten. Die Frage von der Existenz der Gliosomen und von der biologischen Rolle, die diese Bildungen eventuell spielen, werde ich unten näher erörtern. Zwar stellen meine Präparate, wie ich schon oben erwäbnte, einige Kunstprodukte dar. Diese sind jedoch derartig, dass sie teils als solche leicht erkannt werden, teils die oben erwähnten Resultate nicht beeinflussen können, (Rothsche Räume, pericelluläre Räume).

1) Dass die Centriolen der Mikrocentra der Gliazellen durch die betreffende Methode dargestellt werden können, davon kann man sich leicht überzeugen. Indessen habe ich im Vorhergehenden diesem Umstand keine Aufmerksamkeit gewidmet, weil wir mehrere Methoden besitzen, welche sich füx diesen Zweck besser eignen. 
Scheint mir also die Sublimattrichloressigsäurehämatoxylinwolframmethode wenigstens von dem Gesichtspunkte verwendbar, dass sie nicht Strukturen oder Bildungen darstellt, welche als Artefakte gedeutet werden müssen oder können, so bleibt noch nachzuweisen, dass die erreichten Resultate nicht in offenbarem Gegensatz zu den bisherigen Erfahrungen auf dem Gebiete der Gliaforschung stehen. Bei der Beurteilung dieses Verhăltnisses muss sich natürlich eine gewisse Subjektivität geltend machen, denn was dem einen als wissenschaftlich bewiesen gilt, wird oft von dem anderen als mehr oder weniger unsicher oder ganz und gar bypothetisch gehalten. Wenn man mit grösstmöglicher Objektivität kurz die Resultate auf dem Gebiete der Gliaforschung, die als völlig feststehend betrachtet werden müssen, zusammenfassen will, so kann man m. E. nur zu den folgenden Schlüssen kommen. Als völlig bewiesen muss gelten:

1. dass die Gliazellen einen protoplasmatischen Körper von variierender Grösse haben, der mit einer wechselnden (gewöhnlich sehr reichlichen) Anzahl von nach verschiedenen Richtungen ausstrahlenden Ausläufern versehen ist, die, was die Stärke, Form und Länge betrifft, grosse Verschiedenheiten aufweisen und die sich wahrend ihres Verlaufes teilen können (Golgi, Cajal, Kölliker, van Gehuchten, Lenhossek, Lawdowsky a.a.);

2. dass im Zentralnervensystem faserige Differenzierungsprodukte vorkommen, die zu der nichtnervösen Zwischensubstanz gehören und die an gewissen Stellen charakteristische răumliche Beziehungen zu den Kernen der Gliazellen zeigen und auch im übrigen eine Verteilung und Anordnung aufweisen, die für verschiedene Absclunitte des Zentralnervensystems konstant und charakterist isch ist (Ranvier, Weigert, Krause, Aguerre, Huber u. a.).

Wenn ich die Resultate meiner Methode mit Rücksicht auf eine eventuelle Übereinstimmung mit diesen Tatsachen prüfe, so komme ich $\mathrm{zu}$ einem Schlusse, der als nicht ungünstig angesehen werden kann. Ein besonderes Verdienst der Methode ist ihr Vermögen, die Weigertschen Gliafasern unter gleichzeitiger Darstellung der Golgischen Strukturen zu fărben. Gewisse gliöse Bildungen in meinen Präparaten stellen sich nämlich als isomorph mit denjenigen der Golgi schen Silberimprägnations- 
methode dar. Bezüglich der grossen, mit grösserem, lichteren, nucleolenfübrenden Kerne versehenen Gliazellen der weissen Substanz verweise ich nur auf die Taf. VIII, Fig. 2 und Taf. IX, Fig. 1, welche in allem Wesentlichen die Ähnlichkeit zwischen diesen Zellen und den langstrahligen Astrocyten demonstrieren. Ein Jeder, der mit den Golgimethoden gearbeitet hat, wird mir wohl zugeben, dass wir es bier mit isomorphen Zellenformen zu tun haben. Aber auch die anderen Zellentypen, die durch die letzterwahnte Methode dargestellt werden, die kurzstrahligen Astrocyten, deren Deutung, wie bekannt, der ausgesprochenen Weigertschen Auffassung bedeutende Schwierigkeiten bereitet hat, finden sich in meinen Präparaten wieder. Ich zögere also nicht, sie mit der Gliazelle der grauen Substanz zu identifizieren, die mit ihren fadenförmigen, feinen protoplasmatischen Ausliufern zur Bildung des gliösen Netzwerkes beitrügt. Als Beweis der Berechtigung einer solchen Identifizierung möchte ich hier nur die schon vor 15 Jahren von Lenhossek (38) ${ }^{1}$ ) gegebene Charakteristik der betreffenden Zellformen anführen: "Denn was sie hauptsăchlich auszeichnet, das ist die Kürze ihrer Ausläufer; sie verhalten sich zu den Langstrahlern wie Zwerge zu normalen Individuen. Aber die Äste sind nicht nur sehr kurz, sondern auch sehr zart; sie erscheinen weniger strahlenförmig, als vielmehr in der Form eines die Zelle umgebenden, dichten Rasens, eines echten Buschwerkes. Dabei sind sie zu Varikositäten geneigt, wodurch die ganze Zelle mit ibrer Verastelung manchmal einen merkwürdig körnigen Habitus erbait, der allerdings sehr oft noch durch eine unvollkommene Imprägnation gesteigert wird. Denn diese Zellen schwärzen sich, wie auch Kölliker bemerkt, selten so rein und tadellos, wie die Langstrahler. Ein weiteres Charakteristikum besteht hier noch darin, dass die Ästchen oft verzweigt sind, und dass sie sich gegen ihre Spitzen hin allmählich verdünnen."

Schon das soeben Angeführte ist wohl zweifelsohne hinreichend, um darzutun, dass die Auffassung, die einem durch die Hämatoxylinwolframmethode beigebracht wird, nicht im geringsten gesicherte Tatsachen von fundamentaler Bedeutung für die Gliaforschung beeinträchtigt. Ich kann jedoch nicht unterlassen zu bemerken, dass selbst gewisse Detailstrukturen,

1) loc. cit. S. 194. 
welche schon früher von Golgi und anderen, die von den Methoden des berühmten italienischen Forschers Gebrauch gemacht haben, gefunden wurden, und später teils von Weigert selbst, teils von seinen Anhängern entweder vollständig vernachlässigt oder auch als Kunstprodukte erklärt wurden, doch mit gliafaserfärbenden Methoden dargestellt werden können. Ich will nur an die Ansicht Golg is und seiner Schüler von den subpialen Grenzmembranen erinnern. Zur Beleuchtung dieser Auffassung fübre ich wieder Lenhossek $(38)^{1}$ ) an: "Alle diese Fasergebilde, mögen es nun radiäre Fortsätze tiefer befindlicher Zellen oder tangentiale Ausläufer der oberflichlichen peridymalen Astrocyten sein, finden, wie schon erwïhnt, mit kleinen Verdickungen ibr Ende. Diese Knötchen treten auf der freien Oberfläche des Markes mosaikartig zu einer offenbar lückenlosen, kompletten, iusserst feinen Grenzmembran zusammen, einer Art Cuticula (Vembrana limitans meningea, $\mathrm{His}$ ), die gegen die Pia mater hin das ektodermale Rückenmark vollkommen abschliesst." $\mathrm{Zu}$ dieser Beschreibung habe ich meinerseits ${ }^{2}$ ) nur $\mathrm{zu}$ bemerken, dass die mosaikartige Anordnung der Gliafüsse in meinen Präparaten als eine Zusammenschmelzung hervortritt; im übrigen liann sie ohne weiteres auf die marginale Glia der Hirnrinde angewendet werden.

Aber auch in einer anderen Beziebung scheint ein Vergleich $z$ wischen gewissen Golgibildern und einigen von den meinigen Interesse zu haben, weil vielleicht gewisse Anhaltspunkte für die Beurteilung der Bedingungen des Eintretens der Silberreaktion gewonnen werden können. Wie schon oben angeführt wurde, kann man den typischen lkurzstrahligen Astrocyt als identisch mit dem Typus der Gliazellen betrachten, welcher hauptsächlich in der grauen Substanz zu finden ist und mit seinen dünnen Protoplasmaausläufern zur Bildung des feinen Glianetzwerkes beiträgt. Wenn dies richtig ist - und darüber kann $\mathrm{m}$. E. kein Zweifel bestehen - so geht daraus hervor, dass die Ausläufer der Astrocyten in Golgipräparaten nicht, wie dies oft geschehen ist (vergl. Weigert [62]), mit Gliafasern identifiziert werden

1) loc. cit. S. 204.

2) Dass die Identifizierung dieser Membran mit der $H$ is schen Membrana limitans meningea eigentlich auf einem Missverständnis der $\mathrm{H}$ isschen Bezeichnung beruht, ist schon fruher ron $\mathrm{Hel}$ d hervorgehoben worden (32). 
können, sondern wenigstens $\mathrm{zu}$ einem grossen Teile von den Protoplasmafortsätzen der Zelle gebildet werden. Andererseits ist es eine bekannte Tatsache, was übrigens auch der oben zitierten Stelle bei Lenhossek (38) zu entnehmen ist, dass die Kurzstrahler eine unvollständigere, oft lichtere Imprägnation als die Langstrahler aufweisen. Hieraus scheint hervorzugehen, dass das Vorkommnis von Gliafasern in oder nahe bei der Zelle, wenigstens bis zu einem gewissen Grad, das Auftreten der Silberreaktion erleichtert oder befördert. Unter solchen Umständen könnte man vielleicht vermuten, dass die körnigen Bildungen der Glianetzbalken, unsere Gliosomen, welche gegenüber Hämatoxylinwolfram dieselben Reaktionen wie die Fasern zeigen, auch ebenso wie diese in grösserem oder geringerem Grade nicht allein das Auftreten der Reaktion befördern, sondern auch bis $z u$ einem gewissen Grade dem definitiven Silberbilde ein charakteristisches Geprïge aufdrücken sollten. In der Tat scheint dies auch der Fall zu sein: „Dabei sind sie zu Varikositäten geneigt, wodurch die ganze Zelle mit ihrer Verästelung manchmal einen merkwürdig körnigen Habitus erhält. ${ }^{1}$ )" Durch die Anteilnahme des Gliaprotoplasmas an der Silberreaktion werden auch gewisse Figentümlichkeiten bei den Ausläufern der langstrahligen Astrocyten erklürt. So müssen die Verästelungen derselben, welche bisweilen in Golgipräparaten vorkommen, wahrscheinlich als Imprägnationen von protoplasmatischen Seitenbalken des Glianetzwerkes gedeutet werden, die von den oft gliaführenden protoplasmatischen Ausläufern abgehen oder mit ihnen zusammenhängen. Die eigentümlichen Verdickungen und Varikositaten, welche gelegentlich längs der Fortsätze der Astrocyten beobachtet werden können, machen nicht den Eindruck von Fällungen, sondern von kleineren Gliaplasmaanhäufungen, bezw. Knotenpunkten des protoplasmatischen Glianetzwerkes, welche die imprägnierten Fortsätze während inres Verlaufes von der Zelle passieren. Weiter wird obne weiteres die verschiedene Stärke der Ausläufer erklärt, die oft deutlich bei der Golgi schen Schwarzfärbung hervortritt: "Einzelne Fasern zeichnen sich allerdings manchmal durch auffallende Breite aus. $\left.{ }^{2}\right)^{4}$

1) Lenhossek (38), loc. cit. S. 194.

2) Lenhossek (38), loc. cit. S. 182. 
Dieser Vergleich zwischen Resultaten der Golgimethoden und der hier befürworteten würde $z$ weifelsohne nach vielen Richtungen hin vervollständigt werden können. Die oben erwähnten Tatsachen genügen aber wohl nicht nur, um die Anwendbarkeit der Methode überhaupt darzutun, sondern auch um zu zeigen, dass dieselbe bezüglich der Resultate in vielen Hinsichten geeignet ist, frühere Methoden, in erster Linie diejenigen von Golgi und Weigert, zu vervollständigen.

Es zeigt sich also, dass die Sublimattrichloressigsäurehämatoxylinwolframmethode zur Genüge die beiden oben aufgestellten Forderungen erfüllt. Einerseits ruft sie nicht Artefakte oder verkehrte Strukturen hervor, andererseits beeinträchtigt sie in keinel Weise die feststehenden Tatsachen der bisherigen Gliaforschung, sondern scheint vielmehr die geläufigen Methoden zu ergänzen. Dies gibt meines Erachtens gewisse Garantien dafür $a b$, dass die Methode zuverlüssig ist, auch hinsichtlich der Ergebnisse, bei denen eine Kontrolle durch bisherige Methoden nicht möglich ist. Es scheint mir angemessen - teils um eine richtige Beurteilung meiner Methode und der damit erreichten neuen Gesichtspunkte zu gewinnen, teils um den Forschern Gerechtigkeit widerfahren $\mathrm{zu}$ lassen, welche früher $\mathrm{zu}$ einem mehr oder weniger ähnlichen Resultate gekommen sind, - die Angaben in der Literatur zu besprechen, die sich auf diese früher im allgemeinen nicht beobachteten 'Teile des normalen Gliagewebes beziehen.

Um mit dem Gliagewebe der weissen Substanz des Zentralnervensystems $\mathrm{zu}$ beginnen, verdient erwăhnt $\mathrm{zu}$ werden, dass Reinke ( 56 ) schon 1897 die protoplasmatischen Verbindungen zwischen den verschiedenen einander nahegelegenen Gliazellen des Rückenmarkes beim Menschen beobachtet zu haben scheint. Obgleich Reinke in seiner Arbeit diese Protoplasmabrücken nicht ausdrücklich erwähnt und noch weniger von einem Gliasyncytium spricht, hat er in einer seiner Figuren (Taf. VI, Fig. 4) eine Bildung dargestellt, welche nicht anders gedeutet werden kann, als eine solche Brücke von Gliaprotoplasma. Auch scheint mir Reinke in seinem Versuche, die Golgische und die Weigertsche Auffassung $\mathrm{zu}$ vereinigen, im wesentlichen das 
Richtige betrefts des Verhaltens der Gliafasern zu dem Gliaprotoplasma getroffen zu haben.

Im Jahre 1902 wurde von Hardesty (27) eine Arbeit über das Gliagewebe im Rückenmark des Elefanten publiziert. An diesem für derartige Untersuchungen offenbar günstigen Materiale konnte das Verhalten der Gliazellen zueinander von Hardesty mit Erfolg studiert werden. Er bediente sich dabei der von $\mathrm{Huber}(3 \overline{0})$ modifizierten Bendamethode. Hardesty beschreibt den protoplasmatischen Zusammenhang der Gliazellen nnd gebraucht hierbei die Bezeichnung Gliasyncytium. Ebenso schildert er den Verlauf der Fasern im Zellprotoplasma und in den die Zellen miteinander verbindenden Fortsätzen.

Um das Studium des Gliasyncytiums und der hierhergehörigen Fragen hat indessen zweifelsohne Held, dessen ausgezeichnete Arbeit „Über den Ban der Neuroglia" im Jahre 1904 erschien, das grösste Verdienst. Eine năbere Erörterung seiner Auffassung von dem Bau und der Anordnung des Gliagewebes kann hier nicht stattfinden. Teils darf wohl vorausgesetzt werden, dass diese Publikation ersten Ranges allgemein bekannt ist, teils würde ein Referat des Inhaltes in vielen Punkten nur eine Wiederholung des Obengesagten werden. Indessen besteht doch ein wesentlicher Unterschied zwischen meiner und der H $\mathrm{H}$ eld schen duffassung, und zwar in betreff des Banes und der Struktur der Grenzmembranen, sowohl der perivasculüren wie der oberHiachlichen. Wie bekannt, huldigt Held noch in allem wesentlichen der alten Auffassung dieser Bildungen, wozu man hauptsächlich durch die Silberimprägnationsmethode gekommen ist, und beschreibt sie als von kleineren Feldern zusammengesetzt, die mehr oder weniger unregelmässig begrenzt sind. Einem jeden derselben entspricht ein Gliafuss, der gewöhnlich sich in der Mitte des Feldes zu befestigen scheint. Diese sind miteinander durch Kittlinien verbunden. Ith gebe hier einen Teil der Beschreibung wieder, die $\mathrm{Held}$ (32) von der betreffenden Membran gegeben hat: ${ }^{1}$ ) „Die einzelnen Fussflächen sind durch Kittlinien verbunden, welche hier infolge der $\mathrm{Heidenhainschen} \mathrm{Methode}$ (bei bestimmter Fixierung) schwarz gefarbt geblieben sind. Die Grenzhaut selber, welche im Durchschnitt wie eine feine, glatte Linie erscheint, die nach innen in zahIreiche konische

i) loc. cit. S. 256. 
Zapfen sich verlängert, sieht im Flächenbild mattgekörnt aus, wenn man sehr wenig oder gar nicht differenzierte Praparate untersucht. Auch an den grossen Gefässen, in den oberflächlichen Hirnschichten, habe ich eine gleiche Felderung gesehen." „An den Kapillaren habe ich deutliche Flächenbilder bisher nicht darstellen können. Die Grenzhaut und ihre Kittlinien sind offenbar so fein, dass sich keine sicheren Differenzierungsbilder durch solche Methode gewinnen lassen." Vergleicht man diese Beschreibung mit dem von mir S. 41 angeführten Zitat aus der Arbeit von Lenhossek, so geht ohne weiteres die Ähnlichkeit der Auffassungen von der Zusammensetzung der Grenzmembranen daraus hervor. Im Gegensatz zur Ansicht der Golgischen Schule làsst $\mathrm{Held}$ die "mosaikartig“ angeordneten Gliafüsse, welche sümtlich die Grenzhaut bilden, durch eine Kittsubstanz voneinander getrennt werden, welche in Form von Kittinien dargestellt werden kann. Über die in der Grenzmembran befindlichen Gliafasern sagt Held (32) in der Beschreibung der von ihm angegebenen Typen von Gliafüssen: ${ }^{1}$ ) „Die $z$ we ite Ha utform zeigt eine Gliafaser oder einzelne bei einem Bündel, welche als solche durch den Fuss selber hindurchziehen und in der betreffenden Grenzhaut flach weiterlaufen. Meistens können sie, weil abgeschnitten, nicht weiter in ihrem Verlauf verfolgt werden; mitunter aber habe ich doch beobachtet, wie sie nach kürzerer Strecke blass in derselben aufhören. Es entsprechen also diese Angaben denjenigen von Retzius, wonach hakenförmige Umbiegungen der Gliafasern an der Intima Piae vorkommen." Über den weiteren Verlauf der Fasern in der Grenzhaut, besonders bezüglich ihres Verhaltens zu den Kittlinien, das für uns ein besonderes Interesse darbieten würde, habe ich keine näheren Angaben weder in der oben zitierten, noch in einer spateren Arbeit von Held (33) über die marginale Glia im Grosshirn des Menschen gefunden.

Bezüglich der soeben angeführten Ausführungen von $\mathrm{Held}$ soll erwăhnt werden, dass es mir trotz grösster Mühe nicht gelungen ist, die von $\mathrm{Held}$ beschriebenen Kittlinien darzustellen. Ich habe dabei Fixierungen in verschiedenen sublimathaltigen Flüssigkeiten, besonders in Zenkerscher Flüssigkeit und Sublimattrichloressigsäuremischung, angewendet. Als Färbemittel benutzte

1) loc. cit. S. 250. 
ich dabei das Eisenhämatoxylin von Heidenhain. Diese Technik liefert, wie bekannt, bei analogen Bildungen, z. B. den Kittlinien des Darmepithels, in der Regel ausgezeichnete Resultate. Man könnte ja einwenden, dass meine resultatlosen Versuche mangelnder Technik zuzuschreiben wären, oder dass, wie dies Held selbst meint, "bestimmte Fixierungen" nötig sind, um überhaupt die Kittlinien zu Gesicht bringen zu können. Ich würde auch der Sache keine allzu grosse Bedeutung beilegen, wenn nicht der Verdacht durch einige Punkte der $\mathrm{Heldschen}$ Arbeiten nahegelegt würde, dass die Existenz dieser Kittlinien doch nicht absolut sichergestellt ist. Betrachtet man nämlich diejenigen Figuren von Held, welche als Beweise für die Existenz der Kittlinien beigegeben sind (Fig. 33b, 35, 36, 40 in der früheren [32], Fig. 31 und 322 in der letzteren Arbeit [33]) naher, so ist der Vangel bezw. die geringe Zahl der Fasern in den Grenzmembranen ganz besonders auffallend; and doch stammen die in den Figuren wiedergegebenen Teile der Grenzmembran aus solchen Abschnitten des Gehirns, in denen, wie ich mich überzeugen konnte, zablreiche We igertsche Fasern nicht allein dort vorkommen, sondern auch teilweise in der Grenzmembran selbst sich finden. Eine Ausnalume macht vielleicht Fig. 31 in der Arbeit über die marginale Glia, weil dieselbe möglicherweise einer fasernarmen Region der Hirnrinde entstammt; doch finden sich hierüber keine näheren Angaben. Ein anderer Umstand, der verdient hervorgehoben zu werden, ist, dass nach den eigenen Angaben von $\mathrm{Held}$ (32) die Kittlinien teils in der Grenzhaut der Oberflache, teils in der Limitans perivascularis, in den oberflachlichsten Schichten der Cortex dargestellt werden können: „Auch an den grossen Gefässen in den oberflächlichen Hirnschichten babe ich eine gleiche Felderung gesehen." ${ }^{1}$ ) Es kann also festgestellt werden, dass die $\mathrm{Held}$ schen Kittlinien in der perivasculären Grenzhaut in den tieferen Schichten der Rinde nicht nachgewiesen werden können nur so kann ich die Angaben von Held auffassen - also in Gegenden, die anerkannt arm an Gliafasern sind. Noch einen dritten Umstand möchte ich hervorheben. Mehrere der Heldschen Figuren, besonders Fig. 36 in der oft zitierten Arbeit von 1904, zeigen in unzweideutiger Weise, wie die in die Gliafüsse von der Grenzmembran hineinlaufenden Gliafasern eine direkte Fortsetzung

I) loc. cit. S, 256 .

Archir f. mikr. Anat. Bd. 76 , 
der Kittlinien der Membran sind. Ich möchte besonders bemerken, dass die in der Fig. 36 dargestellten Verhältnisse, welche die oberflächliche Grenzmembran im Grosshirn des Menschen betreffen, mir durch das Studium der entsprechenden Regionen des Hundegehirns wohl bekannt sind. Wie eine ähnliche Anordnung gedeutet werden muss, darüber habe ich bei $\mathrm{H}$ eld keinen Aufschluss finden können. Soll man sich vorstellen, dass die Gliafasern in der die Kittlinien konstituierenden Masse weiter verlaufen? Diese Annahme stimmt nicht mit dem Verhalten der Gliafasern zu dem Gliaprotoplasma überhaupt überein, von dem Held selbst eine so mustergültige Beschreibung geliefert hat.

Stellt man sämtliche oben erwähnten Angaben von Held über die Kittlinien der Grenzmembran zusammen und zieht in Betracht, dass die Grenzmembranen auch in solcheu Gebieten, wo Gliafasern sonst vorkommen, dieselben vermissen lassen oder wenigstens faserarm sind, dass Kittlinien mit Sicherheit nur in den über faserreicheren Regionen ausgebreiteten Grenzhäuten dargestellt werden können und schliesslich, dass die Kittlinien als die Fortsetzung der in den Gliafüssen verlaufenden Fasern erscheinen, so scheint mir, trotz der Autorität, die $\mathrm{Held}$ in diesen Fragen zuerkannt werden muss, die Existenz der Kittlinien nicht über jeden Zweifel erhaben, da eine Verwechslung mit den in den Grenzmembranen verlaufenden Fasern nicht mit Sicherheit ausgeschlossen werden kann. Wie ich schon früher hervorgehoben habe, kann man andererseits mit Hilfe der Hämatoxylinwolframmethode - die Eisenhämatoxylinfärbung nach $\mathrm{H}$ e i d e $\mathrm{n}$ h a in gibt übrigens in dieser Beziehung in allem wesentlich dasselbe Resultat - nachweisen, dass die in den Gliamembranen, und zwar sowohl in den oberflächlichen wie in den perivasculären, verlaufenden Fasern eine „Feldbildung “ derselben zustande bringen. Die in verschiedenen Richtungen verlaufenden und einander kreuzenden Gliafasern, welche diese Felder voneinander abgrenzen, sind oft beim ersten Blick solchen „Kittlinien" nicht gerade unähnlich; besonders ist dies der Fall an Stellen, wo die Felder mehr regelmässig sind, und wo die Fasern sich in die Grenzmembran $\mathrm{zu}$ verlieren beginnen. An solchen Stellen wieder, wo die Fasern schliesslich nur durch mehr oder weniger deutlich hervortretende Körnchenreihen angedeutet sind, hängt es natürlich oft von der subjektiven Anschauung der einzelnen Untersucher 
ab, ob man an den Knotenpunkten der Felder die "Fasern" sich als solche unter Kreuzung fortsetzen lasst, oder ob man einen Übergang der einen Faser in die andere, bezw. eine Anastomose zwischen ihnen annimmt.

Ich bin hier etwas näher auf die Frage von den Kittlinien der gliösen Grenzmembranen eingegangen, weil die eventuelle Existenz derselben mir in mehreren Beziehungen wichtig erscheint. Die Anerkennung dieser Kittlinien würde nämlich die Auffassung von den normalen Gliastrukturen erheblich erschweren, weil es sich dann zeigen würde, dass nicht alle Gliafüsse, welche zur Bildung der Grenzbïute beitragen, unter solchen Umständen als gleichwertig angeseben werden könnten. Teils bestehen die Gliafüsse aus breiteren lamellenartigen Ausläufern, bezw. Balken, welche nicht die von den Kittlinien angegebenen Grenzen zu respektieren scheinen, teils werden dieselben von feinen Protoplasmafitden gebildet, welche in grosser Zahl an demselben Feld der Grenzmembranen sich befestigen. Die Schwierigkeiten, die bei der Beurteilung dieser Bildungen sich darbieten, werden von Held (33) in treffender Weise charakterisiert: ${ }^{1}$ ) „Ich kann nur darauf hinweisen, dass alle die feinen Faserchen, welche aus dem Reticulum der umgebenden Substanz sich lösen und der Limitans perivascularis sich anheften und oft mit geringerer Verbreitung in sie übergehen, sich nicht dem Begriff eines oberflächlïchen Gliafusses ohne weiteres einordnen lassen. Denn ob dieser rein protoplasmatisch ist oder aus einer Gliafaser hervorgeht, immer liefert er ein umschriebenes Feld in der Limitans Gliae. Das ist bei den fraglichen feinen Füserchen $\mathrm{nicht}$ der Fall. Von ihnen inserieren viele an einem einzigen Feld der Limitans. Diese Schwierigkeit der Homologisierung ist aber nicht die einzige." . . . .

Beiläufig möchte ich bemerken, dass es auch für die Auffassung der pathologischen Prozesse, welche innerhalb der perivasculären Glia sich abspielen und bei denen, wie bekannt, ein Austreten der einzelnen Gliazellindividuen ans dem Zellverbande vorkommt, nicht gleichgültig ist, ob man in den, den Gefässen am nächsten gelegenen Gliazellen verhältnismassig selbständige, durch Kittsubstanz wenigstens teilweise miteinander verbundene Zellindividuen, oder ein gemeinsames Syncytium sieht.

1) loc. cit. S. 392 und 393. 
Von späteren Forschern, welche bezüglich des normalen Gliagewebes zu einer Auffassung, die mehr oder weniger mit der Heldschen übereinstimmt, gekommen sind, muss Eisath (20) genannt werden. Mit einer von ihm selbst ausgearbeiteten Methode ist es Eisath gelungen, einen Teil des Gliaprotoplasmas wie auch die Gliafasern darzustellen, was als ein bedeutender Fortschritt gegen früher angesehen werden muss. Bei der Betrachtung der Eisathschen Abbildungen und noch mehr bei einem näheren Studium seiner Arbeit gewinnt man indes die Überzeugung, dass die voll ihm angewandte Methode in zwei Beziehungen ungenügend ist. Teils kann nur ein Teil der Gliafasern sichtbar gemacht werden, teils zeigt sich das Gliaprotoplasma zweifelsolune zum grossen Teil nicht gefärbt. Auch bei Versuchen mit der Methode von Eisatb bin ich zu dieser Auffassung gekommen. Die Schlussfolgerungen von Eisath können infolgedessen m. E. nur als teilweise richtig anerkannt werden. So kann z. B. die von ihm gegebene Einteilung der Gliazellen nicht zatreffend sein, indem die Eis ath schen "runden Gliazellen ohne Fortsătze und Fasern" nach meinen Untersuchungen nicht existieren, wenigstens nicht im Hundegehirn. Wenn Eis ath (20) iber die von Held angewandte Methode aussagt:1) "Nur hat, wie aus den Bildern hervorgeht, die Heldsche Firbeart einen ahnlichen Mangel wie die Nisslfatrbung, denn sie macht aucir nur einen Teil des Gliazelleibes ersichtlich, und zwar nur denjenigen, welcher aus der Körnchensubstanz gebildet wird, während die eigentliche Grenzlinie, welche im weiteren Umkreise der Gliakörnchen die helle Grundsubstanz der Zelle einsäumt, nicht zur Darstellung gelangt ${ }^{\star}$, so ist dies eine Bemerkung, die nach meinem Dafürhaiten mit noch grösserem Rechte auf die Methode von $E$ isath selbst angewendet werden kann. Indessen bleibt es doch das Verdienst dieses Forschers, eine spezifisch gliafärbende Methode gefunden zu haben, die eine Darstellung der Fasern und des Gliaprotoplasmas, wenigstens teilweise, zulässt.

In letzterer Zeit, d. h. nach der Publikation der Held schen Arbeit, haben auch einige Pathologen auf Grund von Beobachtungen, die an pathologischem Material gemacht wurden, sich für die Hardest $y-\mathrm{H}$ eld sche Lebre von dem syncytialen Zusammenhang der Gliazellen auch unter normalen Verhältnissen ausgesprochen

s) loc. cit. S. 13. 
Auf die Arbeiten dieser Forscher, unter denen in erster Linie Nissl (49, 50, 51) und Spielmeyer (59) genannt werden müssen, kann ich an dieser Stelle nicht näher eingehen.

In den obigen Erörterungen bezüglich der in der Literatur niedergelegten Beobachtungen über den Bau des Gliagewebes, die in grösserem oder kleinerem Grade den meinigen ähneln, habe ich die Gliastrukturen der grauen Substanz grösstenteils unberücksichtigt gelassen. Dies schien mir zweckmässig zu sein nicht nur um in die Darstellung dieses gewissermassen verworrenen Gebietes der normalen Histologie wenn möglich etwas Klarheit zu bringen, sondern auch, weil die Beobachtungen, die ich hierbei zunächst im Auge habe, gar nicht oder nur mit wenigen Ausnahmen vom Gesichtspunkte der Neuroglialehre diskutiert worden sind. In der Tat scheinen die Beobachtungen über die netzförmigen Strukturen der grauen Substanz ein besonderes Kapitel der Histologie des Centralnervensystems zu bilden. Ich kann es nicht unterlassen, die betreffenden Beobachtungen, insofern sie die von mir gemachten mehr oder weniger berühren, hier zu besprechen.

Soweit ich aus der einschlägigen Literatur ersehen kann, hat Golgi (24) zuerst Beobachtungen über die betreffenden Bildungen angestellt. In seiner 1893 veröffentlichten Arbeit über den Ursprung des IV. Cerebralnerven ${ }^{1}$ ) erwïhnt er das Vorkommen "einer feinen Bekleidung, wahrscheinlich aus Neurokeratin bestehend, von netzartiger Form, oder eine fortlaufende Schicht bildend, welche nicht nur die Zellkörper, sondern auch ihre Fortsätze angeht, und auf die ich schon vor längerer Zeit die Aufmerksamkeit gelenkt habe “. ${ }^{2}$ ) In einer kurz darauf elschienenen Arbeit von Golgi und Fusari (26) habe ich diese pericellulären Netzwerke nicht erwäbnt gefunden, denen schon in der soeben erwähnten Publikation Golgis eine isolierende Aufgabe zugeschrieben wurde. Dagegen werden die von Lugaro ${ }^{3}$ ) und $\left.\mathrm{Sala}^{4}\right)$ mittels der Golgimethode nachgewiesenen feinen peri-

i) Wie bekannt, erschien die deutsche Übersetzung der Golgischen Arbeiten im Jahre 1894.

2) loc. cit. S. 272.

3) Lu gar o: Sulla connessioni fra gli elementi nervosi della corteccia cerebellare con considerazioni generali sul significato fisiologico dei rapporti fra gli elementi nervosi. Rivist di frenit. e di medicina leg., T. XX, 1894.

t) Sala, L.: Sulla fina Struttura del Torus longitudinalis nel cervello dei teleostei. Atti della Acad. della Scienze med. e nat. Ferrara, Anno LXIX, 1895. 
cellulären Netzwerke, welche von den erwähnten Forschern als nervöse Bildungen gedeutet wurden, erwähnt. Golgi macht dabei die Bemerkung, dass solche feinen pericellulären Netzwerke in verschiedenen Teilen des Centralnervensystems als eine ziemlich oft vorkommende Erscheinung von ihm nachgewiesen worden sind. Ob Golgi hierbei die von ihm früher erwăhnten aus Neurokeratin bestehenden pericellularen Netzwerke oder andere netzförmige Bildungen meint, geht nicht mit Sicherheit aus seinen Ausführungen hervor. Die Arbeiten von Lugaro und Sala kenne ich nicht im Original und habe mir deshalb keine Meinung über die von ihnen beschriebenen pericellularen Netzwerke, speziell über die Beziehungen zwischen diesen und dem in meinen Präparaten vorkommenden gliösen Netzwerke der grauen Substanz bilden können.

In dem oben erwähnten Aufsatze von Golgi und Fusari finde ich ausserdem eine Arbeit von Paladino ${ }^{1}$ ) erwihnt, welche in mehreren Punkten die uns hier interessierenden Fragen berührt. Auch diese Publikation ist mir im Original nicht zuganglich gewesen, weshalb ich mich an das von Golgi and Fusari gemachte Referat halten muss. Über das Verhalten der Neuroglia zu den Nervenzellen im Rückenmarke heisst es: „Die Nervenzellen sollen in Lücken enthalten sein, in welchen die Neuroglia rarefiziert ist: auf ibrer Obertlache soll man ein Spinngewebe aus Neuroglia bemerken, welches aus äusserst dünnen, verflochtenen Faden besteht". Ob unter diesem "Spinngewebe aus verflochtenen Fäden" ein wirkliches Netzwerk verstanden werden soll, darüber bin ich nicht vollständig im klaren. Wenn dies der Fall sein sollte, ist $\mathrm{Pal}$ a din o vielleicht der erste, welcher die feinen gliösen pericellulären Netzwerke beschrieben hat.

Golgi (25) ist jedoch etwas später auf die von ihm früher beschriebenen pericellulären Netzwerke zurückgekommen. In einem 1895 publizierten Aufsatz gibt er eine Beschreibung von ihnen, die auf ihr Aussehen in Silberimprăgnationsprăparaten basiert ist; er schreibt den Netzwerken eine isolierende Aufgabe zu und ist der Ansicht, dass sie aus "Neurokeratin" bestehen. In jedem Falle müssen die betreffenden Bildungen nach Golgi

1) Paladino, G.: Sui limiti precisi fra la neuroglia e gli elementi nervosi nel midollo spinale e sui alcune questioni istofisiologiche, chi vi si riferiscono. Boll. dell. $\mathrm{R}$ accad. med. di Roma, Anno XIX, fasc. 1. 
$\mathrm{zu}$ den nicht nervösen $Z$ wischensubstanzen gerechnet werden, was besonders hervorgehoben werden soll.

Die năchste hierher gehörige Arbeit ist diejenige von Se mi Meyer (47) im Jahre 1899. Der Verfasser gibt hier eine Beschreibung über die von ihm mit Hilfe der vitalen Methylenblaumethode dargestellten Neuritenverästelungen in verschiedenen Teilen des Centralnervensystems (Endkern des Vestibularis, hintere Vierhügel und obere Olive beim Kaninchen und Meerschweinchen); diese "Neuritenendigungen", welche teilweise aus feinen Netzwerken, teilweise aus gröberen „kelchartigen Endigungen" bestehen, werden betreffs ihrer Bedeutung mit den von ihm $(45,46)$ früher mit derselben Methode dargestellten Achsenzylinderendverästelungen identifiziert; ebenso hält er dieselben für identisch mit den von Golgi (25) 1898 beschriebenen pericellulären Netzwerken und mit den $\mathrm{Heldschen}(29,30)$ "AchsenzylinderendHïchen". Bezüglich der Identităt der von ihm selbst beobachteten Bildungen mit den Auerbachschen Endapparaten (6) drückt sich Semi Meyer vorsichtiger ans ("vielleicht dasselbe Gebilde“). ${ }^{1}$ )

Kurz nach der Publikation Semi Meyers erschien die bekannte Arbeit von Bethe (13). Diesem Forscher war es gelungen, mit Hilfe einer von ihm selbst ausgearbeiteten, ziemlich komplizierten Methode nicht allein die Neurofibrillen der Ganglienzellen, sondern auch so gut wie überall in den grauen Substanzen des Centralnervensystems feine netzartige Bildungen nachzuweisen. Diese werden von Bethe für nervöse gehalten; er identifiziert sie mit der von Golgi gefundenen und nennt sie Golginetze. Weiter hält Bethe dieselben für identisch mit den von Held $(29,30)$, Semi Meyer $(45,46,47)$, Auerbach $(6,7)$ und Donaggio ${ }^{2}$ ) früher beschriebenen. Die Resultate von Bethe

1) loc. cit. S. 298 .

*) Don aggio, A: Contributo alla conoscenza dell intima struttura della cellula nervosa nei verte. Riv. speriment. di Frenitaria XXIV. 2. 1898. Derselbe: Nuove osservazione sulla struttura della cellula nervosa. Ibidem XXIV. 3. 4. 1899. Diese Arbeiten, welche von B eth e angeführt werden, sind mir nicht im Original zugänglich gewesen. Von den kurzen Referaten darüber in dem "Jahresber. über die Leistg. und Fortschr. auf dem Gebiete der Neurologie und Psychiatrie aus den Jahren 1898 bzw. 1899 scheint hervorzugehen, dass die netzförmigen Strukturen D on ag gios von ihm als den peripheren Teilen der Ganglienzellen, also dem Nervenzellenprotoplasma zugehörig, gedeutet warden; ob es sich hier um Netze handelt, welche mit den Golg inetzen gleichzustellen sind, geht aus der Darstellung nicht hervor. Es soll hier bemerkt werden, dass $\mathrm{Cajal}$ die wirklichen G olgi netze in derselben Weise aufgefasst hat, wie Donaggio. 
unterscheiden sich in nennenswertem Grade von den früheren, die mit der Imprägnationsmethode nach Golgi oder mit der vitalen Methylenblaufärbung erhalten wurden. Teils konnten die feinen Netzwerke mit der Betheschen Methode als pericelluläre Netzwerke nicht allein in der nächsten Umgebung der Ganglienzellen, sondern auch im übrigen Teile der grauen Substanz, sich darin diffus ausbreitend, nachgewiesen werden; teils wies Bethe mit derselben Methode eigenartige Strukturen in der Marksubstanz nach, die aus einem gröberen Netzwerke, von Beth e Füllnetz genannt, bestehen. In molybdängefärbten Präparaten erscheint es etwas blasser, verbreitet sich in den Interstitien zwischen den Markscheiden und geht auch in die grauen Substanzen über, ohne jedoch mit den Golg ischen Netzen zusammenzuhängen. Schliesslich soll erwähnt werden, dass Bethe einen kontinuierlichen Zusammenhang zwischen den Golgi netzen und feinen „endenden“ Achsenzylinderausläufern beschreibt und abbildet, wobei er doch ausdrücklich hervorhebt, dass solche Beobachtungen nicht absolut beweisend sind.

Es soll noch eine Arbeit von $\mathrm{Held}$ (31) aus dem Jahre 1902 erwälant werden, die einer Kritik der pericellularen Netze gewidmet ist und in vielen Beziehungen aufklärend wirkt. Held hat zur Beleuchtung der Frage von der Beschaffenheit dieser Bildungen sich sämtlicher zu Gebote stehender Methoden bedient und gelangt dabei zu dem Schlusse, dass unter dem Namen von Golginetzen oder pericellularen Netzen Formationen von verschiedener physiologischer Bedeutung beschrieben wurden. Die von Golgi beschriebenen, ebenso wie die von Bethe und Semi Meyer nachgewiesenen Netze werden von Held miteinander identisch und gliöser Natur gehalten. Als ihrer Natur nach mit diesen gleichwertig betrachtet $\mathrm{Held}$ einen Teil der von ihm selbst früher als nervöses pericelluläres Terminalnetz aufgefassten Bildungen. Von einer ganz anderen Beschaffenheit ist nach $\mathrm{Held}$ der grössere Teil der von ihm selbst als netzförmig verzweigt, bezw. zusammenhängend beschriebenen "Achsenzylinderendflächen" ebenso wie die Auerbachschen (7) Endnetze, welch letztere als wirkliche nervöse Terminalnetze aufgefasst werden müssen. Das „Füllnetz ${ }^{\prime}$ von Bethe wird von Held als ein Gliareticulum anfgefasst, welches in Bethepräparaten mehr oder weniger deutlich hervortritt, und dessen kontinuierlicher Übergang in die Golgi- 
netze nachgewiesen wird. Weiter hebt $\mathrm{Held}$ die tiefe Färbung derjenigen Substanz hervor, die Gliaschnürringe bildet, die also bei der Betheschen Methode dieselben Eigenschaften und Färbereaktionen wie die Golginetze zeigt, und weist auch hier die Kontinuität zwischen den die Gliaschnürringe zusammensetzenden Balken und dem Füllnetze nach. In seiner Arbeit von 1904 kommt Held (32) zu einem vollkommen ahnlichen Resultate bezüglich der Natur der Betheschen Strukturen.

Zwei Jahre später veröffentlichte Donagg io ${ }^{1}$ ) eine Arbeit, aus der hervorzugehen scheint, dass es ihm mit einer komplizierten Methode gelungen ist, ein pericelluläres Netzwerk rings um die Ganglienzellen darzustellen, das er mit den Netzwerken von Golgi, Semi Meyer und Bethe identifiziert. An der Bildung der von Donaggio beschriebenen Netzformationen scheinen Bestandteile teilzunehmen, welche teils als rein nervöse, teils als gliöse gedeutet werden müssen.

Es seien hier schliesslich die netzartigen Bildungen erwähnt, die bei Untersuchungen mit der Methode von Bielschowsky gefunden werden. So beschreiben Bielschowsky und Wolff (17) rings um die Purkinjeschen Zellen in der Rinde des Kleinhirns wirkliche Terminalnetze, die durch Verbindungen zwischen zablreichen in verschiedenen Richtungen verlaufenden Axonen gebildet werden. Rings um die Dendriten der Purkinjeschen Zellen sollen ähnliche T'erminalnetze vorkommen, in welchen Achsenzylinder verschiedener Herkunft ihr Ende finden.

Wenn wir jetzt etwas näher auf die Frage eingehen, inwieweit diese früher beschriebenen teils pericellulären, teils diffusen Netzwerke in den grauen Substanzen mit Rücksicht auf ihren Bau und ihre physiologische Bedeutung dem von uns beschriebenen Gliareticulum entsprechen, so können wir sogleich einige von diesen Bildungen ausschliessen, da sie offenbar mit den Glianetzwerken, wie sie sich in Sublimatbämatoxylinwolframpräparaten darbieten, nichts $z u$ tun haben. Hierzu rechne ich die von Held (29) früher beschriebenen Achsenzylinderendflächen, die A u erbachschen Terminalnetze $(6,7)$ und die ron Semi

1) Donaggio, A: Il reticulo fibrillare endocellulare negli elementi nervosi dei vertebrati di fronte a recenti riccerche. Monit. zoolog. ital. anno XV 10. Ref. im Jahresber. über die Fortschr. und Leistg. der Neurologie und Psychiatr., Ber. über das Jahr 1904. 
Meyer (46) im Jahre 1896 beschriebenen Neuritenendigungen. Ob die von Semi Meyer 1897 nachgewiesenen pericellulären "Faserkörbe" mit unseren Glianetzwerken isomorph sind, kann ich nicht sicher entscheiden. Leider vermag ich keinen Vergleich mit den Netzwerken von Donaggio anzustellen, weil wie schon erwähnt die diesbezüglichen Arbeiten mir im Original nicht zugänglich waren.

Von den übrigen hierhergehörigen Bildungen halte ich die mit der Golgimethode nacbweisbaren pericellulären Netzwerke wenigstens teilweise mit unserem feinen Reticulum in der grauen Substanz des Hundehirns isomorph. Für diese Ansicht spricht nicht so sehr die von Golgi (25) gegebene Beschreibung seiner Neurokeratinnetze und die Abbildung, die er beigefügt hat (diese kann, weil bei geringerer Vergrösselung gemacht, keine sicheren Anbaltspunkte für einen Vergleich liefern), als vielmehr diejenigen von den Heldschen (30) Abbildungen der pericellularen Golginetze, die nach derselben Methode hergestellten Präparaten entstammen. Besonders Fig. 5, Taf. XIV der erwähnten Arbeit zeigt eine auffallende Ibnlicbkeit mit meinen Abbildungen; namentlich bietet das pericellulare Grolginetz in der unmittelbaren Nathe des linken Randes der abgebildeten Ganglienzelle, sowohl hinsichtlich der feinen warzigen Balken, als der Grösse und der Gestalt der Maschen in der Hauptsache dasselbe Aussehen, wie das gliöse Netzwerk dar. Man kann also mit guten Gründen belaupten, dass die sogenannten Golginetze, d. h. das mit der Golgimethode nachweisbare pericelluläre Netzwerk, wenigstens teilweise aus Neurogliagewebe besteht - unter der Voraussetzung, dass das Vorkommen von $z$ wei verschiedenen miteinander isomorphen Netzformationen, von welchen die eine nervöser, die andere gliöser Natur ist, ausgeschlossen werden kann. Diese Voraussetzung scheint mir in der Tat zuzutreffen, denn die sicher nervösen Endapparate, wie sie von Held, Auerbach und Cajal beschrieben worden sind - es mag sich dabei um freie oder miteinander durch feine Brücken zusammenhängende Endkolben bandeln - können kaum Bilder liefern, welche mit den hier in Frage kommenden verwechselt werden könnten.

Sch wieriger scheint es mir zu entscheiden, ob Held $(29,30)$ in seinen Arbeiten über die terminalen Netze Verwechslungen dieser Art vollständig entgangen ist. Wenn man auf die von Held angewandte 
Methode (ein Eisenhämatoxylinverfahren nach $\mathrm{H}$ eide $\mathrm{nbain}$ ), welche, wie wir seben werden, bei einer ganzen Reihe verschiedener Fixierungen auch das gliöse Gewebe der granen Substanz sichtbar macht, ebenso wie auf die eigenartigen anatomischen Verhăltnisse Rücksicht nimmt, so scheinen bei einer solchen Arbeit wie der $\mathrm{Hel}$ d schen, Verwechslungen nach der angedeuteten Richtung hin unvermeidlich. Doch finde ich unter den von $\mathrm{Held}$ gegebenen Abbildungen der terminalen Achsenzylinderendkörbe nicht solche, welche mich berechtigen, die von Held beschriebenen Netzwerke als den hier diskutierten isomorph oder identisch anzuseben. Nur das in Fig. 9, Taf. XII (30) dargestellte pericellulare Neuritenendnetz (abgeseben von den früher erwähnten nach Golgi imprägnierten Netzwerken, besonders in Fig. 5, Taf. XIV) ${ }^{\mathbf{1}}$ ) bietet etwas mehr auffallende Ähnlichkeiten mit meinen Glianetzwerken, obgleich ich auch nicht von dieser Figur behaupten kann, dass eine Verwechslung mit gliösen Bildungen stattgefunden habe.

Dagegen liann ich aus guten Gründen die von $S e m i$ Me yer (47) im Jahre 1899 beschriebenen netzförmigen Neuritenendungen, die mit der vitalen Vethylenblaumethode dargestellt wurden, dem mit der Subtriessigbămatoxylinwolframmethode gewonnenen pericellularen Netzwerke isomorph ansehen. Besonders zeigen die Fig. 1 und 3 von Semi Meyer eine sogar bis anf die Details sich erstreckende Ähnlichkeit mit den Bildern, die man mit meiner Methode erhält. Ein Umstand, der besonders hervorgehoben zu werden verdient, ist, dass auch die körnige Beschaffenheit der Balken des gliösen Netzwerkes, die ich früher erwähnt habe, mehr oder weniger deutlich in jenen Abbildungen hervortritt (siebe Fig. 1 bei Meyer, die Zelle linlss). Der Versuch von Semi Meyer, die nervöse Natur dieser Netzwerke zu beweisen, kann nicht als glacklich bezeichnet werden; "ebensowenig wie die Markscheide färbt sich bei der vitalen Methode die Glia, an die Golgi vielleicht auch gedacht hat, so dass also aus einer der isolierenden und stützenden Substanzen die Gitter, die sich mit Metbylenblau so schön färben, nicht bestehen können. Auch die Färbbarkeit mit der Betheschen Fibrillenmethode spricht wohl für die nervöse Natur der Gitter, wenigstens scheint

1) Die in den betreffenden Figuren abgebildeten, mit der Silberimprägnationsmethode dargestellten Netzwerke sind später von Held selbst als gliöse gedeutet worden. 
dies für Bethe nach seinen Äusserungen selbstverständich $z u$ sein." ') Die Unzulänglichkeit dieser Beweisführung ist leicht einzusehen. Erstens kann man doch nicht von vornherein als ausgeschlossen annehmen, dass auch nicht gliöse Elemente gelegentlich bei der vitalen Methode gefärbt werden können, zweitens beweist eine Farbbarkeit durch die Bethesche Methode nichts, weil bis auf den beutigen Tag niemand den Beweis erbracht hat, dass die von Bethe nachgewiesenen Netzwerke wirklich nervöser Natur sind.

Beim Studium der Betheschen Arbeit (13) und der von ihm beigefügten Abbildungen drängt sich im Gegenteil sogleich die Auffassung auf, dass die von dem betreffenden Forscher dargestellten Strukturen, selbstverständlich mit Ausnahme der intracellulären, zum Ganglienzellenprotoplasma gehörenden Neurofibrillen, wenigstens nicht ausschliesslich nervöser Natur sind. Ein Umstand, der schon von vornherein anzudeuten scheint, dass auch das Gliagewebe mehr oder weniger an der Farbenreaktion teilnimmt, ist das Vorkommen des von Bethe so genannten Füllnetzes, das nach ihm in Beziehungen zu Blutgefässen, Gliakernen und Pia mater tritt. Es ist schwer, sich ein anderes Gewebe zu denken, das sich in dieser Weise verbalt, als gerade die Glia. Um auf die Golginetze zurückzukommen, so bieten die mit der Molybdinmethode von Bethe (13) nachgewiesenen Netzwerke, aus seiner Beschreibung wie den Abbildungen zu urteilen, in vielen Hinsichten eine bemerkenswerte Ähnlichkeit mit dem gliösen Netzwerk in meinen Präparaten. Ich verweise nur auf die Fig. 19, 28, 27, Taf. XXX und Fig. 42, Taf. XXXI von Bethe. Von diesen bietet besonders die letzterwähnte, die das Golgi inetz der Molybdänmethode veranschaulicht, insofern gewisse Vergleichspunkte mit meiner Fig. 4, Taf. VII, als zu Grund für beide Zeichnungen entsprechende Abschnitte des Gehirns, und zwar die Molekularschicht der Rinde des Grosshirns liegen. In beiden Figuren zeigen die Maschen des Netzwerkes ungefähr dieselbe Grösse und Form; in den Knotenpunkten stossen gewöhnlich drei, gelegentlich vier Balken zusammen; diese erscheinen ziemlich von gleicher Stärke und haben wenigstens keine grösseren Anschwellungen an den Knotenpunkten; in beiden Figuren kann man weiter beobachten, wie das Netzwerk sich diffus durch die

1) loc. cit. S. 300 . 
graue Substanz von einem Dendriten zum anderen erstreckt. An der Oberflacche der Ausläufer werden mehr oder weniger deutlich hervortretende Pericellulärnetze gebildet, welche also nur die der Nervenzelle oder deren Dendrit unmittelbar anliegenden Teile der diffusen Netzformation sind. In einer Beziehung unterscheidet sich das Bethesche Golginetz von meinem Gliareticulum, indem jenes nämlich homogen oder wenigstens ohne mebr auffallende körnige Bildungen hervortritt. Diesem Umstand kann ich aber keine besondere Bedeutung in dem Sinne beilegen, dass die Betheschen Netze anders als die von mir abgebildeten zu deuten seien. Ich finde nämlich in der Arbeit von $\mathrm{Held}(31)$, der auch mit der Beth e schen Methode gearbeitet hat, Äusserungen, weiche darauf bindeuten, dass die Golginetze in Molybdảnpräparaten wenigstens gelegentlich eine mehr oder weniger körnige Beschaffenheit zeigen. ${ }^{1}$ ) Andererseits habe ich bei Fixierung mit Sublimattrichloressigsăure und Färbung in oben angegebener Weise Präparate erhaiten, in denen die von mir beschriebene Körnelung der Balken des Glianetzes gar nicht oder nur undeutlich hervortrat. Dies hat beobachtet werden können bei einer Nachbehandlung der fixierten Stücke in absolutem Alkohol, der wathrend der ersten 24 Stunden nicht gewechselt wurde. Solche Prïparate erinnern in hohem Grade an die Betheschen, auch was die Golginetze betrifft; vielleicht sind die Baiken in den letzterwahnten etwas graciler, jedoch tritt dieselbe homogene Beschaffenheit der Balken wie in den Betheschen Netzen auch hier hervor. Wit Rücksicht auf das oben Gesagte halte ich mich für berechtigt, die Betheschen Golgi netze als mit den Glianetzen der grauen Substanz isomorph anzusehen; die Betheschen Netze sind also höchstwahrscheinlich gliöser Natur. Eine solche Annahme ist um so eher berechtigt, als Bethe selbst keine Beweise für die nervöse Natur der Golginetze angeführt hat. Denn dass dem kontinuierlichen Zusammenhang $z$ wischen den Achsenzylinderverästelungen and diesen Netzen, der von Bethe beschrieben wurde, in dieser Beziehung keine entscheidende Bedeutung zugeschrieben werden kann, geht wohl schon daraus hervor, dass er selbst seine Beobachtungen in diesem Punkte für nicht völlig beweisend bält.

1) loc. cit. S. 221. 
Aber auch in einer anderen Beziehung bietet ein Vergleich zwischen der Betheschen Methode und der bier beschriebenen ein gewisses Interesse. Ich habe schon früher die Kunstprodukte erwähnt, welche bei Anwendung meiner Methode entstehen können und dabei auf das Vorkommnis eigenartiger Artefakte hingewiesen, die an das Bethesche Füllnetz erinnern und sich vom letzteren nur durch eine stärkere Färbung und vielleicht durck eine gröbere Beschaffenheit der Balken unterscheiden. Wenn es sich herausstelien sollte, dass meine Beobachtungen in dieser Hinsicht richtig sind - wenigstens berechtigen mich meine wiederholten Erfahrungen dazu - so scheinen mir gewisse Möglichkeiten vorhanden zu sein, das eigentümliche Aussehen zu erklären, welches das Gliagewebe bei einer Behandlung nach Bethe annimmt; denn dass die Betbeschen Golginetze und die Füllnetze für Gliagewebe gehalten werden müssen, obgleich bis zu einem gewissen Grade entstellt, habe ich schon an mehreren Stellen hervorgehoben. Solche Bilder fand ich nur bei direkter Übertragung der Stücke von der Fixierungstlüssigkeit in absoluten Alkohol auf 24 Stunden. Bethe wendet ein insofern abuliches Verfahren an, als er nach Fixierung in $3-7 \%$ Salpetersüure die Stücke mit Alkohol $(96 \%)$ ebenfalls während 24 Stunden behandelt, der auch nicht gewechselt wird. Das gemeinsame dieser beiden Verfahren ist also das Übertragen der Organteile von einer stark sauren Wasserlösung in konzentrierten Alkohol auf langere Zeit (24 St.). Es ist also wahrscheinlich, dass wir in dieser Behandlung die Ursache zu suchen haben für das eigentümliche strukturlose Aussehen, das die Neuroglianetzwerke in B ethepräparaten darbieten, obgleich ich mir keine bestimmte rorstellung davon habe bilden können, in welcher Weise die erwähnte Kombination von Alkohol und Säure auf das Gewebe einwirkt. In jedem Falle sprechen auch diese Verhältnisse bis zu einem gewissen Grade für die gliöse Natur der Betheschen Netze.

Bezüglich der mit der Bielschowskyschen Methode nachweisbaren feinen, pericellulären Netzwerke babe ich nur zu bemerken, dass dieselben nicht ohne weiteres als nervöse aufgefasst werden können. Im Gegenteil scheint mir bei der Beurteilung solcher Beobachtungen, mit Rücksicht auf das unzweifelhafte Vorkommen von feinen pericellulären Glianetzen einerseits und auf die 
nicht vollständig elektiven Eigenschaften der Bielschowskyschen Methode andererseits, eine gewisse Vorsicht geboten.

Dass die Silbermethode von $\mathrm{Cajal}$, die im übrigen hinsichtlich der Färbung der Neurofibrillen der Hauptsache nach in derselben Weise wie diejenige von $B i e l s c h o w s k y$ sich verhält, die Golginetze nicht zu Gesicht bringt, ist eine bekannte Tatsache. Neuerdings bat $\mathrm{Cajal}^{1}$ ) seine Methode dahin modifiziert, dass mit derselben, wenn auch nicht regelmässig, eine Färbung auch der pericelluären Netzwerke erhalten werden hann. Es ist für uns von einem gewissen Interesse, zu konstatieren, dass die Methode damit ibre elektiven Eigenschaften eingebüsst hat, da durch dieselbe nicht allein die Golginetze, sondern auch andere, nicht nervöse Gewebselemente, $z$ B. collagene Bindegewebsfasern in der Adventitia der Blutgefïsse dargestellt werden können.

Von den in der Literatur beschriebenen netzförmigen Bildungen in der grauen Substanz des Zentralnervensystems balte ich also die pericellularen Netze von Golgi, die Neuritenendungen von Semi Meyer, insoweit diese von wirklichen Netzformationen gebildet werden, und die Betheschen Golginetze für dem Gliareticulum der Hamatoxylinwolframmethode isomorphe Bildungen, und $z$ war sind diejenigen von Golgi, Semi Meyer und Bethe beschriebenen böchstwahrscheinlich gliöser Natur. Die Berechtigung dieser Annahme geht daraus hervor, dass man bis auf weiteres netzförmige Bildungen von zweifellos nervöser Natur, welche den oben erwähnten vollständig ähneln, nicht kennt, dagegen eine auffallende Formähnlichheit zwischen ihnen und gewissen unzweideutigen Gliasubstanzen in der Rinde des Grosshirns nachweisen kann.

Ich möchte schliesslich bemerken, dass ich bei der Diskussion über diejenigen Resultate der früheren Forscher, welche mehr oder weniger den meinigen ähneln, auf das Tiermaterial, das den einzelnen hierhergehörigen Arbeiten zu Grunde gelegen hat, keine Rücksicht genommen habe. Dies ist geschehen nicht um meine

1) Cajal, S., Ramon, y: Les conduits de Golgi-Holmgren, du protoplasma nerveux et le reseau pericellulaire de la membrane. Trar. Labor. Rech. biol. Univ. Madrid, T. VI, 1908. Ref. Zeitschr. f. wissensch. Mikrosk., Bd. 26, 1909. 
Ausfïhrungen $z \mathfrak{u}$ erleichtern, sondern weil ich an verschiedenem Material (Mensch, Hund, Meerschweinchen) konstatieren konnte, dass prinzipielle Verschiedenheiten mit Rücksicht auf den anatomischen Bau des Neurogliagewebes innerhalb der hier in Frage kommenden Tiergruppen nicht existieren.

Ehe ich die Besprechung der Resultate meiner Methode verlasse, kann ich nicht umhin, noch einen besonderen Umstand zu erörtern. In der Beschreibung des Baues des Neurogliagewebes, die ich oben gegeben habe, ist an mebreren Stellen auf das Vorkommnis von körnigen Bildungen bingewiesen woiden, welche in Aussehen und Anordnung von ziemlich typischer Beschaffenbeit sind. Diese Körnchen die in Grösse und Farbe etwas variieren, sind in das Gliaprotoplasma der Balken des Syncytiums eingeschlossen. Ich habe diese Körnchen als Gliosomen bezeichnet. Es bleibt noch übrig zu untersuchen, ob denselben eine wirkliche Existenz zukommt, oder ob sie als eine Folge der Präparation betrachtet werden müssen. Hierbei muss besonders die Möglichkeit einer durch das Fixierungsmittel entstandenen körnigen Fällung gewisser Teile des Gliaprotoplasmas in Betracht gezogen werden. Ich möchte nun zuerst hervorheben, dass die erwähnten Gliosomen keineswegs nur in Trichloressigsäurehämatoxylinwolframpräparaten vorkommen, sondern dass sie auch bei einer Reihe anderer Methoden auftreten. So sieht man in mit. Eisenhämatoxylin gefärbten Präparaten, die in Zenkerscher Flüssigkeit z. B. oder in anderen sublimathaltigen Fixierungsmitteln fixiert wurden, die grauen Substanzen von körnigen Gebilden wimmeln, die in Grösse und Anordnung mit den Gliosomen vollkommen übereinstimmen. Hierbei darf man natürlich nicht Präparate verwenden, bei denen die Differenzierung zu weit getrieben wurde. Diese Körnchen kennt sicher ein jeder, der Gliacentriolen mit der betreffenden Methode dargestellt hat. Aber dies beweist ja an und für sich nicht, dass die Körnchen nicht durch die Präparationsmethoden in arteficieller Weise dargestellt wurden; besonders ist es ja von den sublimathaltigen Fixierungsmitteln bekannt, dass sie die Neigung baben, den feineren Protoplasmastrukturen eine gewisse 
körnige Beschaffenheit zu verleihen, die zweifelsohne einer feinkôrnigen Fallung oder einer "feinen tropfigen Entmischung" der Eiweissstoffe des Protoplasmas ihre Entstehung verdankt. Mit Rücksicht hierauf ist es also von Interesse, zu konstatieren, dass man nach Alkoholfixierung und mit derselben Färbungsmethode (Eisenhämatoxylin) bei Einhalten eines gewissen Differenzierungsgrades die Körnchen des gliösen Netzwerkes zu Gesicht bringen kann. Am besten werden diese als gliöse Bildungen erkannt, wenn man an solchen Präparaten die feinen Protoplasmabalken, welche die Rothschen Räume durchziehen, untersucht. Hier kann man leicht die rosenkranzartige Anordnung beobachten. Auch bei Alkoholfixierung, Nachbeizung nach Benda und einer nachfolgenden Eisenhämatoxylinfärbung können in wenig differenzierten Prïparaten dieselben Bildungen nachgewiesen werden. Bei allen diesen verschiedenen Behandlungsmethoden sind die Körnchen zu sehen, nur ihre Farbe scheint im Verhältnis zu den übrigen Gewebselementen mehr oder weniger an Intensität zu wechseln. Wenn man also auch bei Alkoholfixierung, die jedoch wie bekannt mit Bezug auf die Protoplasmastrukturen nicht dieselben Eigentümlichkeiten wie die sublimathaltigen Flüssigkeiten zeigt, sondern im Gegenteil die Tendenz hat, dem Protoplasma eine mebr netzförmige oder wabige Beschaffenheit zu geben, das Vorkommen der Gliosomen feststellen kann, so scheint es höchstwahrscheinlich, dass dieselben nicht der Einwirkung des Fixierungsmittels zugeschrieben werden können.

Um weiterhin zu zeigen, wie unabhängig von den Fixierungsmitteln diese Körnchen sind, erlaube ich mir noch anzuführen, dass Held (33) in seiner letzten Arbeit über dì marginale Glia dieselben besonders in dem feinen Gliasyncytium der grauen Substanz beobachtet $\mathrm{zu}$ haben scheint. Ich schliesse dies aus einigen seiner Abbildungen, besonders Fig. 1 und 2, Taf. VIII; die hier abgebildeten feinen Körnchen, die in den Balken des feinfädigen Gliasyncytiums eingestreut sind, kann ich nur als mit meinen Gliosomen identische Bildungen deuten. Held hat für die Fixierung die Müllersche Flüssigkeit mit Zusatz von Sublimat, Eisessig und Formalin benutzt.

Kann man also nachweisen, dass die Gliosomen hinsichtlich ihres Vorkommens oder ihres Aussehens von den von uns angewendeten verschiedenen Fixierungsmitteln unabbängig sind, so 
bleibt nur übrig, diesen Bildungen eine wirkliche Existenz zuzuschreiben und sie als mit übrigen histologischen Gewebselementen ebenbürtig zu betrachten.

Es wäre natürlich von Interesse, die biochemische Beschaffenheit und die biologische Rolle der Gliosomen zu ermitteln. Zwar stehen in diesem Punkte nur sehr unvollständige technische Hilfsmittel zu unserer Verfügung, indem wir dabei ausschliesslich auf ihr Verhalten zu unseren Farbereagentien hingewiesen sind; jedoch gibt ja auch dieses Verfahren bei anderen Geweben und Gewebselementen gewisse Resultate und bezüglich der Gliosomen zeigt es sich ebenfalls wenigstens anwendbar. Es verdient hervorgehoben $\mathrm{zu}$ werden, dass dieselben mit den gewöhnlichen Gliafärbungsmethoden, durch welche man eine differente Farbung der Fasern bezweckt, nicht dargestellt werden können; die Gliosomen müssen also hinsichtlich der Zusammensetzung von den Gliafasern abweichen. Andererseits \%eigen sie Reaktionen, wodurch sie sich von dem undifferenzierten Protoplasma, besonders demjenigen der Gliazellen unterscheiden, indem sie bei der Hamatoxyinwolframmethode eine tiefere, das Protoplasma aber eine hellere Farbe annehmen. Dass diese Realitionsverschiedenheit nur in quantitativer und nicht in qualitativer Hinsicht sich geltend macht, bedeutet hierbei verhältnismässig wenig, da bekanntlich ein grosser Teil der histologischen Reaktionen gerade in einer Verschiedenheit der Färbungsintensität besteht. Gegenüber dem Eisenhämatoxylin zeigen die Gliosomen und das Gliaprotoplasma ein ahnliches Verbalten. Je weiter man die Differenzierung treibt, um so blasser wird das Protoplasma, während die Körnchen verhältnismăssig lange die Farbe behalten, bis scbliesslich auch sie abblassen. Dies spricht dafür, dass die Substanz, welche die Gliosomen bildet, nicht einfach aus Gliaprotoplasma besteht, sondern dass sie von derselben in chemischer Hinsicht wenigstens in gewissen Beziehungen abweicht.

Schwieriger ist es aber, sich eine Vorstellung davon zu bilden, worin diese Verschiedenheit besteht. Man könnte sie vielleicht auf die Resultate der Hämatoxylinwolframmethode beziehen, bei der die Gliosomen dieselbe Farbe annehmen wie die Gliafasern und sie als Differenzierungsprodukte des Protoplasmas gegen die Substanz der Gliafasern hin auffassen. Diese Annahme ist natürlich nicht ohne weiteres richtig, weil bekanntlich 
eine Übereinstimmung der Farbresultate nicht die Identität verschiedener histologischer Gewebselemente beweist. Es gibt aber einige Umstände mehr morphologischer Art, welche dafür sprecken, dass die erwähnte Möglichkeit doch in Betracht gezogen werden muss. Wie ich schon früher angeführt habe, treten nämlich in den Abschnitten der Hirnrinde, wo Gliafasern vorkommen, oft gewisse räumliche Beziehungen zwischen diesen und den Gliosomen hervor. So sieht man nicht selten in der perivasculären Grenzmembran die reihenartig angeordneten Gliosomen anscheinend eine Fortsetzung der Gliafasern bilden. Andererseits kann nachgewiesen werden, dass diese, an der Limitans angelangt, sich auffransen und eine blassere Farbe annehmen, stellenweise abgebrochen erscheinen und gelegentlich nur durch eine Reihe Körnchen angedeutet sind, welche bezüglich Aussehen und Beschaffenheit vollstandig den Gliosomen zu entsprechen scheinen. Auch die Bildungen, die am meisten den Eindruck körniger Fâden machen, die wahrscheinlich durch Ansammlung einer Reihe Gliosomen entstanden sind und die gelegentlich besonders in der perivasculären Grenzmembran der grauen Substanz gesehen werden können, verdienen hierbei erwähnt zu werden.

Diese Beobachtungen und andere ähnlicher Art scheinen den Schluss zu erlauben, dass die Gliosomen doch etwas mit den Gliafasern zu tun haben, wenn sie auch in ihrer Zusammensetzung von ihnen abweichen. Von welcher Art diese gegenseitigen Beziehungen sind, darüber kann man sich bis auf weiteres nur in hypothetjscher Weise aussprechen. Um nur eine Möglichkeit anzudeuten, scheint es mir nicht unmöglich, dass die betreffenden körnigen Differenzierungsprodukte des Gliaprotoplasmas eine gewisse Rolle bei der Neubildung der Gliafasern spielen. Aus dem, was von der Faserbildung im Gliagewebe bekannt ist, scheint hervorzugehen, dass hierbei gewissen körnigen Bestandteilen eine besondere Aufgabe zukommt. Hiervon sagt $\mathrm{Held}(32)$ in seiner Beschreibung über die Entwicklung der Gliafasern im N. opticus der Mäuse: ${ }^{1}$ ) ,Mit diesem Stadium habe ich noch ein etwas früheres, den Nervus opticus eines reifen Mausefötus verglichen; er zeigt zum Unterschied nur ganz vereinzelte Gliafasern in jenen Zellfortsătzen, welche noch 1. 1. S. 238 . 
nicht den Zelleib durchsetzen. Auch ist hier die Substanz des sich bildenden Gliafäserchens noch nicht so fest und homogen, sondern noch etwas körnig, so dass es wie ein matter Strich im Zellprotoplasma erscheint." Als Beweis dafür, dass ähnliche Beobachtungen auch an pathologischem Material gemacht worden sind, möchte ich noch die Arbeit von Spielmeyer (50) zitieren: ${ }^{1}$ ) "Im Heidenhainschen Praparat erkennt man eine zarte grauschwarze Strichelung, die der Differenzierung gegenüber sehr empfindlich ist. Im We ig e rt schen Gliapräparat heben sich von dem rötlich gelben Protoplasmagrunde (Kontrastfärbungen) der Fortsätze und des Zelleibes feine, mattblaue oder graublaue Streifen ab. Mit Hilfe des Apochromaten sieht man ganz deutlich kleinste, etwas stärker blau gefärbte Körnchen in dieser Streifung (Fig. 1). Dass es sich bei diesen Körnchenreihen um die Anfänge der Gliafaserbildung handelt, darf wohl mit Sicherheit angenommen werden." Es ist offenbar, dass es sich bei diesen körnigen Protoplasmadifferenzierungsproduliten, die bei der Neubildung der Gliafasern als ein Vorstadium derselben auftreten, nicht ausschliesslich um mit unseren Gliosomen identische Bildungen handelt, obgleich es andererseits mit Rücksicht auf die gegenseitigen Beziehungen, die die Fasern und Gliosomen unter normalen Verhältnissen zeigen, wahrscheinlicher ist, dass letztere hierbei auch eine gewisse Rolle spielen. Würde es gelingen, zu beweisen, dass die Gliosomen bei der Entwicklung oder der Neubildung der Gliafasern ein Zwischenstadium zwischen dem undifferenzierten Protoplasma und der spezifischen Fasersubstanz bilden, so wäre damit zweifelsohne ein neuer Gesichtspunkt für die Beurteilung der histogenetischen Stellung der gliösen Substanzen der Rinde gewonnen. Das Gliasyncytium der grauen Substanzen mit den eingestreuten Gliosomen würde somit im Vergleich mit dem faserhaltigen Teile des Gliagewebes ein früheres Entwicklungsstadium, wo es noch nicht zur Ausbildung fertiger Gliafasern gekommen ist, repräsentieren. Auch das Vermögen der Gliazellen der Hirnrinde, unter gewissen pathologischen Verhältnissen Gliafasern auch in solchen Gegenden, wo keine Fasern vorkommen, zu produzieren, würde uns sicher leichter verständlich erscheinen.

1) 1. c. S. 308 : 
Wie dem nun auch sei, soviel scheint mir bis auf weiteres mit Sicherheit angenommen werden $z u$ können, dass in dem feinen, die grauen Substanzen durchsetzenden Gliasyncytium körnige Bildungen besonderer Art und charakteristischer Anordnung vorkommen, welche als Differenzierungsprodukte des Gliaprotoplasmas angesehen und somit gewissermassen mit den Gliafasern gleichgestellt werden müssen. Ob man diese Bildungen Gliosomen oder anders nennt, ist natürlich vollständig gleichguiltig.

Im Vorhergehenden habe ich versucht, eine Darstellung der Resultate zu geben, die durch Anwendung der Subtriessighämatoxylinwolframmethode beim Studium des normalen Gliagewebes erreicht werden können, und ich habe auch die Ergebnisse früherer Forscher erwähnt, soweit sie für uns ein grösseres Interesse darbieten. Bevor ich schliesse, bleibt mir noch übrig von der praktischen Verwendbarkeit der Methode und den damit in Zusammenhang stehenden Fragen einige Worte zu sagen. Ganz besonders muss ich mich in aller Kürze mit den theoretischen Voraussetzungen, auf denen sich die Methode gründet, beschaftigen, teils um die Anwendung derselben zu erleichtern, teils um meine diesbezüglichen Erfahrungen denjenigen zugute kommen zn lassen, welche vielleicht die Methode in dem einen oder anderen Punkte mangelhaft finden und event. nach einer Verbesserung oder Ergänzung derselben streben werden.

Hinsichtlich der Fixierungsflüssigkeit und deren Einwirkung auf die Färbungsresultate verdient hervorgehoben $z a$ werden, dass die Trichloressigsăure dabei offenbar eine wichtige Rolle spielt. Die Färbung des Gliaprotoplasmas, welche in bestimmter Weise meine Prapparate kennzeichnet, scheint so gut wie ausschliesslich auf die Rechnung der Trichloressigsäure gesetzt werden zu müssen. Dass diese nicht nur eine physikalische Fällung des Protoplasmas bewirkt, sondern auch dessen chemische Zusammensetzung beeinflusst, also als ein Beizungsmittel wirkt, ist offenbar. Von der Richtigkeit dieser Ansicht kann man sich leicht überzeugen, wenn man Material, das z. B. in einer $5 \%$ wässrigen Lösung von Trichloressigsäure fixiert wurde, in der- 
selben Weise wie dies bei dem betreffenden Färbeverfahren oben beschrieben wurde, behandelt. In solchen Präparaten tritt das Gliaprotoplasma in demselben Farbenton und Umfange hervor, wie nach Fixierung in der von $\mathrm{Heidenhain}$ angegebenen Flüssigkeit. Bei diesem Verfahren können dagegen die Gliafasern nur unvollständig dargestellt werden und nebmen einen Farbenton an, der sich nicht in nennenswertem Grade von dem des Gliaprotoplasmas unterscheidet. Es ist also wahrscheinlich, dass die übrigen Bestandteile, welche die Fixierungsflüssigkeit zusammensetzen, eine Einwirkung auf die Weigertschen Fasern nach derselben Richtung bin wie die Trichloressigsäure auf das Gliaprotoplasma ausüben und sie durch Beizung der nachfolgenden Färbung zugănglich machen. Diese Beizung der Fasern scheint mir, teilweise wenigstens, dem Sublimat zugeschrieben werden zu müssen. Obgleich ich für diese Annahme keinen stichhaltigen Beweis anführen kann, scheint sie mir jedoch wahrscheinlich, weil das Sublimat schon früher mit Erfolg für abnliche Zwecke angewendet wurde, und zwar von $L$ her m it te und Gu c c i o ne (40).

In gewisser Weise mit der Frage vom Sublimat als Beizungsmittel verknüpft ist die Bedeutung der nachfolgenden Jodbehandlung. Ob die Jodierung der Schnitte ausschliesslich dem gründlichen Entfermen des Sublimates dient, oder ob ihr auch eine andere Rolle, z. B. eine Oxydationswirkung zukommt, habe ich nicht entscheiden können. Soviel scheint mir sicher zu sein, dass man durch eine gründliche Jodierung, wie sie oben beschrieben wurde, eine gleichmăssigere und sicherere Farbung der Glia erhält, als durch ein kürzeres Verfahren. Ebenso bewirkt eine Anwendung der in der mikroskopischen Technik geläufigen Oxydationsverfahren an Stelle oder im Verein mit einer Jodbehandlung eher eine Verschlechterung als eine Verbesserung der endgültigen Färbungsresultate.

Bezüglich der Alkoholbehandlung nach der Fixierung habe ich dem oben (S. 12) Angeführten nicht viel hinzuzufügen. Wie gesagt, eignet sich für diese Nachharrtung nicht absoluter Alkohol wegen der Schwierigkeit, mit seiner Hilfe elektiv gefärbte Präparate zu erhalten; Achsenzylinder und Nervenzellprotoplasma werden nach einer solchen Vorbehandlung intensiv gefärbt und halten die Farbe bei der Differenzierung mit grosser Zäligkeit fest. Schwächere Konzentrationsgrade als die vorgeschriebenen, die zwar ebenso- 
wenig wie der $96 \%$ den erwähnten Übelstand darbieten, können aber nicht in Frage kommen, weil sie das Myelin zur Quellung bringen und somit störende Artefakte hervorrufen. Wie die Verschiedenheit der Einwirkung eines absoluten und $96 \%$ Alkohols erklärt werden soll, ist mir vorläufig unklar; vielleicht spielt hierbei die schneller oder langsamer vor sich gehende Auflösung des Myelins nebst Diffusionsverhältnissen zwischen der dem Organteile anhaftenden Fixierungsflüssigkeit und dem Alkohol die bestimmende Rolle.

Die Polychromasie der Malloryschen Farblösung, die der Einwirkung des Wasserstoffsuperoxyds auf die leicht zersetzbare Phosphorwolframsauregruppe zugeschrieben werden muss, wodurch Körper von verschiedenem Sauerstoffgehalte entstehen, die wieder Doppelverbindungen mit dem Hamatoxylin eingeben, macht sich gegenüber dem in beschriebener Weise vorbehandelten Gewebe nach $z$ wei Richtungen hin geltend. Die Farbflüssigkeit wirkt entweder rot- oder blaufarbend, je nach den verschiedenen Affinititen der gebeizten Gewebselemente. Wie schon früher erwïhnt wurde, können also durch ein rein progressives Verfahren gewisse Resultate erreicht werden. Es zeigt sich ausserdem, dass die rotfärbenden Komponenten relativ unecht, die blaufübenden dagegen verhaltnismassig echt fürben. Die Verbindungen $z$ wischen den rotfärbenden Salzen und gewissen Gewebsbestandteilen (collagene Fasern, Achsenzylinder, rote Blutkörperchen) werden von alkoholischer Ferrichloridlösung zersetzt, während die Verbindungen zwischen den blaufärbenden Salzen und den Gewebselementen sich gegenüber diesem Differenzierungsmittel resistent verhalten.

Es wurde früher hervorgehoben, dass die Differenzierungsflïssigkeit frisch zubereitet werden muss. Wenn man nämlich die alkoholische Ferrichloridlösung eine Zeitlang stehen lässt, dann nimmt sie allmäblich eine mehr saure Reaktion an und es tritt gleichzeitig unter Umständen eine-reichliche braune amorphe Fällung ein. Diese besteht offenbar aus colloidalem Ferrihydroxyd, das durch hydrolytische Spaltung des Ferrichlorids in der nunmehr wasserhaltigen Flüssigkeit entstanden ist. Eine solche ältere Lösung ist natürlich für Differenzierungszwecke unbrauchbar und muss, sobald sie sich zu trüben beginnt, durch eine frische ersetzt werden. 
Von den Nachteilen des Verfahrens verdienen diejenigen genannt zu werden, welche durch seine Eigenschaft als eine regressive Methode bedingt werden. Ebenso wie andere ahnliche Methoden überhaupt färbt auch diese elektiv nur beim Einhalten eines gewissen Differenzierungsgrades. Die Färbungsresultate mit meiner Methode sind also im wesentlichen von der Genauigkeit der Differenzierung abhängig. Während dies jedocb nur in geringem Grade ihre Anwendung erschwert, bildet ein anderer damit zusammenhangender Umstand einen etwas grösseren Übelstand. Es kommt gelegentlich vor, dass die Differenzierung nicht vollstăndig gleichmässig verläuft, besonders bei den Achsenzylindern, die teilweise dazu neigen, die Farbe festzubalten. Die Färbung dieser Gebilde ist deshalb gelegentlich nicht vollständig gleichmässig. Neben solchen, welche die typische gelbgraue Farbe angenommen haben, finden sich andere, die etwas dunkler tingiert sind. Immerhin tritt der Farbenunterschied zwischen den Achsenzylindern und Gliafasern auch unter solchen Umstanden so deutlich hervor, dass Verwechslungen wohl vermieden werden können.

Was die Farbung der chromophilen Bestandteile des Ganglienzellenprotoplasmas betrifft, so habe ich mich schon früher (S. 12) darüber geäussert. Dass sich in den Prïparaten Stellen finden lassen, wo eine tiefe Färbung der $\mathrm{Nis}$ ischen Schollen eingetreten und wo die Untersuchung der pericellularen Glia infolgedessen erschwert ist, ist von keiner wesentlichen Bedeutung bei den normalhistologischen Studien, bei denen ja eine Auswabl immer möglich ist. Es leuchtet ein, dass derselbe Umstand beim pathologischen Material eventuell lastig werden kann.

Es bleibt noch die Frage übrig, ob sämtliche Gliafasern oder nur ein Teil die typische Farbenreaktion geben. Es ist natürlich unmöglich, dies zu entscheiden, solange wir nicht eine Methode baben, welche sicher sămtliche Gliafasern färbt und in jedem Falle als Kontrollmethode angewendet werden kann. Sicher ist indessen, dass ich mit Hilfe der Hämatoxylinwolframmethode die Gliafasern besser darstellen konnte als mit den geläufigen Methoden.

Die Nachteile, welche durch Schrumpfungsprozesse in den Prăparaten eintreten können, habe ich schon früher verschiedentlich erörtert.

Trotz der oben erwăhnten Mängel, zu denen eventuell noch andere kommen, die durch Nachprüfungen von anderen Forschern 
an den Tag gebracht werden, scheint mir meine Methode in gewisser Beziehung in sich abgeschlossen und brauchbar. Wenigstens habe ich sie mit grossem Vorteil sowohl an normalem wie pathologischem Material angewendet. Besonders bei meinen Untersuchungen über die hämatogene Entstehung der Gehirntuberkulose hat die verhältnismăssig gleichmăssige Färbung mir grosse Dienste geleistet. Bezüglich der Verwendbarkeit bei verschiedenem Tiermaterial soll nochmals hervorgehoben werden, dass prinzipielle Verschiedenheiten zwischen den Resultaten am Material von Hund, Meerschweinchen und Mensch nicht existieren. Ganz frisches menschliches Material habe ich nicht zur Verfügung gehabt. Das frischeste menschliche Gehirn wurde ca. 15 Stunden p. m. verarbeitet $;^{1}$ ) es handelte sich um einen Paralytiker, der bei der Sektion (ausser den charakteristischen Veränderungen des Gehirns und der Hirnhäute) ausgebreitete Dekubitalgeschwüre und pneumonische Veränderungen der Lungen darbot. Auch bei diesem nicht gerade günstigen Materiale konnte ich recht gute Resultate erreichen, obgleich sie in keiner Weise mit denjenigen von frischem Tiermaterial verglichen werden können.

Wenn ich alles zusammenfasse, scheint mir die Methode eine allgemeinere Beachtung zu verdienen und sowobl für normalhistologische wie pathologische Untersuchungen des zentralen Nervensystems geeignet zu sein. Eventuell wird sie natürlich durch weitere Ausarbeitung vervollkommnet werden können. Jedenfalls dürfte sie berufen sein, neue technische Möglichkeiten zu eröffnen, und weitere Aufschlüsse über die histologischen Elemente des Gliagewebes zur Folge haben.

\section{Zusammenfassung.}

1. Durch Fixierung (Beizung) in Heidenhains Sublimattrichloressigsäuremischung und Färbung mit Phosphorwolframsäurehämatoxylin von Mallory nebst nachfolgender Differenzierung kann das Gliagewebe in elektiver Weise dargestellt werden.

1) Dies Material wurde mir in liebenswürdigster Weise von Professor Dr. Christian Sibelius zur Verfügung gestellt. 
2. Hierbei werden nicht nur die Gliafasern, sondern auch das Gliaprotoplasma gefarbt. Letzteres kann als ein ausgebreitetes Syncytium nachgewiesen werden, das durch die stark verzweigten Auslaufer der Gliazellen, die in kontinuierlichem Zusammenbang miteinander stehen, gebildet werden. Die Hardesty-Heldsche Auffassung von dem syncytialen Bau des Gliagewebes muss also als richtig angeseben werden.

3. Bezüglich des Verhaltnisses der Gliafasern zu dem Gliaprotoplasma kann konstatiert werden, dass erstere entweder an der Oberfläche oder im Innern der Balken des protoplasmatischen Gliareticulums verlaufen und sich in derselben Weise zu dem Protoplasma des Zellenkörpers der Gliazellen verhalten. Die Möglichkeit, dass die Fasern in einer gewissen Ausdehnung ihres Verlaufes nackt verlaufen, kann bis auf weiteres nicht verneint werden.

4. An der Grenze der Gehirnsubstanz gegenüber den mesodermalen Bildungen, sowohl der Pia mater, wie der Adventitiader in der Gehirnsubstanz verlaufenden Gefasse, können Grenzmembranen nachgewiesen werden, welche anscheinend aus Gliaprotoplasma bestehen und überall mit den Balken des Gliasyncytiums zusammenhängen.

5. Auch in der Gehirnrinde kann das Gliagewebe als ein aus feinen fadenförmigen Protoplasmabalken bestebendes Netzwerk nachgewiesen werden. Die von Golgi, Meyer und Bethe beschriebenen pericellularen resp. diffusen Netze müssen als isomorph mit diesem Gliareticulum betrachtet werden und sind somit höchstwahrscheinlich gliöser Natur. 
6. In dem feinen Gliareticulum der grauen Substanz können gewisse körøige Gebilde nachgewiesen werden, welche ich als Gliosomen bezeichnet habe nnd für Protoplasmadifferenzierungsproduktevon besonderer Art ansehe.

Meinem hochverehrten Lehrer und Chef, Prof. Dr. E.A. Homén, der mit lebhaftem Interesse meiner Arbeit gefolgt ist und wahrend derselben mir wertvolle Ratschläge gegeben hat, sage ich an dieser Stelle meinen tiefgefühlten Dank. Auch bin ich Herrn Plivat-Dozent Dr. Axel Wallgren für die Hilfe, die er mir bei der Anfertigung der beigefügten Mikrophotogramme geleistet hat, zu Danke verpflichtet.

Helsing fors, Jannar 1910.

\section{Literatur-Verzeichnis.}

1. Aguerre, J. A.: Untersuchung über die menschliche Neuroglia. Arch. f. mikrosk. Anat., Bd. 56, 1900.

2. Alzheimer, A.: Histologische Studien zur Differentialdiagnose der progressiven Paralyse. Histolog. u. histol.-patholog. Arb. v. Fr. Niss l, Bd. 1, 1904.

3. Anglade, D. et Morel, Ch.: Sur un nouveau procédé de coloration de la neuroglia. Séance de la société de Nenrologie de Paris, 7 févr. 1901. Revue Neurologique, T. 9, 1901.

4. Anglade, D.: La réaction neuroglique dans l'encéphalomalacie. Comptes rend. đ. l. Soc. d. biol., séance d. 18 févr. 1905.

j. A uerbach, L.: Färbung für Achsenzylinder und ihre Endbäumchen. Neurolog. Centralbl., 1897.

6. Derselbe: Nervenendigungen in den Zentralorganen. Neurol. Centralbl., 1898.

7. Derselbe: Das terminale Nervennetz in seinen Beziehungen zu den Ganglienzellen der Zentralorgane. Monatsschrift f. Psych. u. Neurolog., Bd. 6, 1899.

8 Bartel, J.: Zur Technik der Gliafärbung. Zeitschr.f. wissensch. Mikrosk., Bd, 21, 1904.

9. B enda, C.: Erfahrungen über Neurogliafärbungen und eine neue Färbungsmethode Neurolog. Centralbl., 1900. 
10. Benda, C.: Die Mitochondriafärbung und andere Methoden zur Untersuchung der Zellsubstanzen. Verhandl. d. anat. Gesellsch. anf $d$. 15. Versammlung in Bonn 1901.

11. Derselbe: Neurogliafärbung. Encyliop. d. mikr. Techn., 1903.

12. B e ne cke. Über einige Resultate einer Modifikation der W e i g e r t schen Fibrinfärbungsmethode. Centralbl. f. allg. Path. u. path. Anat., Bd. 4, 1893.

13. Bethe, A.: Über die Neurofibrillen in den Ganglienzellen von Wirbeltieren und ihre Beziehungen zu den Golginetzen. Archiv f. mikrosk. Anatomie, Bd. j̃̄, 1900.

14. Derselbe: Allgemeine Anatomie und Physiologie des Nervensystems. Leipzig 1903.

15. Biels chowsky: Färbung der Achsenzylinder. Neurolog. Centralbl., 1902.

16. Derselbe: Die Silberimprägnation der Neurofibrillen. Journ. f. Psychol. u. Neurol., 1904.

17. Bielschowsky und Wolff: Zur Histologie der Kleinhirnrinde. Journ. f. Psychol. u. Neurol., 1904.

18. Bonome, A.: Bau und Histiogenese des pathologischen Neurogliagewebes. Virch. Arch., Bd. 163, 1901.

19. Cajal S. Ramon y: Les conduits de Golgi-Holmgren du protoplasme nerveux et le réseau péricellulaire de la membrane. Trav. labor. biol. univ. Madrid, Bd. 6, 1908. Ref. Zeitschr. f. wissensch. Mikrosk., Bd. 26, 1909.

20. Eisath, G.: Über normale und pathologische Histologie der menschlichen Neuroglia. Monatsschr. f. Psych. u. Neurnlog., Bd. 20, 1906.

21. d a F a n o, C.: Osservazioni sulla fina struttura della neuroglia. Ricerche Labor. anat. norm. d. R. univ. Roma e altri Lab. hist. XII, 1906.

22. Derselbe: Studien über die Ver:̈nderungen im Thalamus opticus bei Defectpsychosen. Monatsschr. f. Psych. u. Neurolog., Bd. 26, 1909.

23. Fischer: Einige Bemerkungen über die Fürbung pathologischer Gliaformationen. Neurol. Centralbl., 1902.

24. Golgi, C.: Untersuchungen über den feineren Bau des zentralen und peripherischen Nervensystems. Jena 1894.

25. Derselbe: Intorno alla Struttura della cellula nervosa. Bollettino della societi medico-chirurgica di pavia. 1898.

26. Golgi und F a sari: Nervensystem in "Ergebnisse der Anatomie und Entwicklungsgeschichte", herausgeg. von Merkel und Bonnet, 1894.

27. Hardesty, Jrwing: The Neuroglia of the Spinal Cord of the Elephant with some preliminary Observations upon the Development of Neurogliafibres. Amer. Journ. of Anat., vol. 2, 1902-3.

28. Heidenhain, Martin: Über Vanadiumhämatoxylin, Pikroblauschwarz und Kongo-Korinth. Zeitschr. f. wiss. Mikrosk., Bd. 25, 1909.

29. Held, Hans: Beiträge zur Struktur der Nervenzellen und ihrer Fortsätze. Arch. f. Anat. u. Physiol., Anat. Abt., 1897.

30. Derselbe: Beiträge zur Struktur der Nervenzellen und ihrer Fortsätze. Arch. f. Anat. u. Physiol., Anat. Abt., 1897, Supplement.

31. Derselbe: Über den Bau der grauen und weissen Substanz. Arch. f. Anat. u. Physiol., Anat. Abt., 1902. 
32. Held, Hans: Über den Bau der Neuroglia und über die Wand der Lymphgefässe in Haut und Schleimhaut. Abhandl. d. math.-phys. Klasse der Kgl. Sächs. Gesellsch. d. Wissensch., Bd. 28, 1904.

33. Derselbe: Über die Neuroglia marginalis der menschlichen Grosshirnrinde. Monatsschr. f. Psych. u. Neurolog., Bd. 26, Ergänzungsheft, 1909.

34. Hoppe: Zur Technik der W eig ertschen Gliafürbung. Neurol. Centralblatt, 1906 .

35. Huber, G.: Studies on the Neuroglia. Amer. Journ. of Anat., vol. I, $1901-2$.

36. Krause, Rud.: Untersuchungen über den Bau des ZentraInervensystems der Affen. Abh. d. Kgl. Alkad. d. Wissensch. zu Berlin, 1899-1900.

37. Krause, R. und Aguerre, J.: Untersuchungen über den Bau des. menschlichen Rïckenmarks mit besonderer Berüclisichtigung der Neuroglia. Anat. Anz., Bd. 18.

33. v. Lenhossek, M.: Der feinere Bau des Nervensystems im Lichte der neuesten Forschungen. Berlin 1895.

39. Lhermitte, J.: Procédé nouveau pour la Coloration des cellules et des fibrilles neurologiques. Revue neurologique, T. XVII, 1909.

40. Lhermitte, J. et Guccione, A.: Procede pour la Coloration des cellules et des fibrilles neurologiques. Semaine medic. 1909.

41. Mallory, F. B.: Über gewisse eigentümliche Färbereaktionen der Neuroglia. Centralbl. f, allg. Path. u. path. Anat., Ba. 6, 1895 ó.

42. Derselbe: On certain improvements in histological technique. Phosphotungstic-acid-hämatoxylin for certain tissue elements. Journ. of exper. medicine, vol. 2, 1897.

43. Derselbe: A Contribution to staining methods a. s. f. Journ. of. experim. medicine, vol. 5, 1900. Ref. Zeitschr. f. wissensch. Milirosk., Bd. 18, 1901

44. Merzbacher, L.: Ein einfaches Verfabren zur Darstellung von Gliastrukturen. Journ. f. Psych. u. Neurolog., Bd. 12, 1908.

45. Me yer, Semi: Über eine Verbindungsweise des Neuronen. Arch. für mikrosk. Anat., Bd. 47, 1896.

46. Derselbe: Über die Funktion der Protoplasmafortsätze der Nervenzellen. Verhandl. d. Kgl. Sächs. Gesellsch. d. Wissensch., 1897, Bd. 49, math.-phys. Klasse.

47. Derselbe: Über zentrale Neuritenendigungen. Arch. f. milirosk. Anat., Bd. $54,1899$.

48. Müller, E.: Studien über Neuroglia. Arch. f. mikrosk. Anat., Bd. 55, 1899.

49. Nis 1 , Fr.: Über einige Beziehungen zwischen Nervenzellenerkrankungen und gliösen Erscheinungen bei verschiedenen Psychosen. Wandervers. südd. Neurologen and Irrenärzte in Baden-Baden 1899. Arch. f. Psych, Bd. 32, 1899.

50. Derselbe: Über einige Beziehungen zwischen der Glia und dem Gefässapparat. Wandervers. süddeutsch. Neurologen und Irrenärzte in BadenBaden 1902. Arch. f. Psych., 1903. 
51. Nissl, Fr.: Zur Histopathologie der paralytischen Rindenerkrankung. Histolog. u. histopatholog. Arb., Bd. 1, 1904.

52. Obersteiner: Zur Histologie der Gliazellen in der Molekularschicht der Grosshirnrinde. Arb. a. d. neurolog. Inst. Wien, Bd. 7, 1900.

53. Pappenheim, A.: Grundriss der Farbchemie. Berlin, 1901.

54. Pollack, B.: Einige Bemerkungen über die Neuroglia and Neurogliafärbung. Arch. f. mikr. Anat., Bd. 48, 1897.

55. Ranvier: De la neuroglia. Comptes rend. de la soc. biol., 1892.

506. Reinke, Fr.: Über die Neuroglia in der weissen Substanz des Rückenmarks vom erwachsenen Menschen. Arch. f. mikrosk. Anat., Bd. ̌0, 1897.

57. Rubaschkin: Studien über Neuroglia. Arch. f. mikrosk. Anat., Bd. 64, 1904.

58. Sabrazès et Letessier: Procédé de coloration de la neuroglia. Arch. gener. d. méd., 1905.

ว9. Spielmeyer, W.: Von der protoplasmatischen und faserigen Stützsubstanz des Zentralnervensystems. Arch. f. Psych., Bd. 42, 1907.

60. Weber, L. W.: Der heutige Stand der Neurogliafrage. Centralbl. für allg. Path. u. path. Anat., Bd. 14, 1903.

61. Weigert, Carl: Zur pathologischen Histologie der Neurogliafasern. Centralbl. f. allg. Path. u. path. Anat., Bd. 1, 1890.

62. Derselbe: Beitrïge zur Kenntnis der normalen menschlichen Neuroglia. Festschrift zum 50jührigen Jubiläum des ärtlichen Vereins zn lirankfurt a. M., 1895 .

63. Derselbe: Neurogliafürbung. Encyklop. d. mikr. Technik, 190;.

64. Wimmer: Om neurogliafarvning. Hospitaltidende, 1906.

65. Yamagiwa, K.: Eine neue Färbung der Neuroglia. Vircl. Arch., Bd. $160,1900$.

\section{Erklärung der Abbildungen auf Tafel VI-IX.}

Die hier wiedergegebenen Abbildungen sind nach Präparaten dargestellt, die nach der von mir angegebenen Methode der Gliafärbung angefertigt wurden. Sie entstammen alle dem Grosshirn des Hundes. Die Konturen sind mit Hilfe des Abbeschen Apparates gezeichnet, die feineren Details nachher ausgeführt. Der Abstand zwischen dem Okular und der Projektionsfläche ist unter Kontrolle des Objektmikrometers so gewählt, dass sämtliche Strukturen in derjenigen Vergrösserung dargestellt werden, die durch das mikroskopische System bedingt wird. Für alle Abbildungen kam Zeiss Apochromat $2 \mathrm{~mm}$, Apert. 1,30 (Immersion), Komp.-Ok. 8 zur Verwendung.

Die Vergrösserung ist also überall $1: 1000$. 


\section{Tafel VI.}

Fig. 1. Das Neurogliagewebe der Marksubstanz an einer Stelle, wo in verschiedenen Richtungen verlaufende Nervenbündel einander kreuzen. Dicke des Schnittes $4 \mu$. Für die Darstellung der protoplasmatischen Verbindung zwischen den Gliazellen ist von der Mikrometerschraube fleissiger Gebrauch gemacht worden.

Fig. 2. Neurogliazelle mit umgebendem Gliareticulurn von der Schicht der grossen Pyramidenzellen, gezeichnet ohne Verwendung der Mikrometerschraube.

Fig. 3. Zwei Neurogliazellen mit umgebendem Gliagewebe aus der Grenzschicht zwischen Mark und Rinde. Von der Mikrometerschraube ist Gebrauch gemacht worden. Schnitt $5 \mu$.

Fig. 4. Neurogliazelle von dem grosskernigen Typus nebst umgebendem Glianetzwerk aus der weissen Substanz. Für die Darstellung der Gliafasern ist die Mikrometerschraube zur Verwendung gekommen.

Fig. 5. Das marginale, subpiale Gliagewebe der Rinde an der Seitenfläche einer Furche, etwa in der Mitte zwischen dem Boden der Furche und der freien Flïche des Gyrus. Der Schnitt ist etwas schief geführt, sodass die Grenzmembran als ein dicht an der Pia gelegener hellblauer Saum deutlicher hervortritt. Schnitt $5 \mu$. Die Mikrometerschraube ist nur in unbedeutendem Grade verwendet worden.

Figg. 6. Die marginale, subpiale Neuroglia am Boden einer Furche. Schnitt $5 \mu$. Die Einstellung ist nur in geringem Grade gewechselt worden.

\section{Tafel VII.}

Fig. 1. Gliagewebe der weissen Substanz. Gegen den starken gelbgrau gefärbten Achsenzylinder links im Bilde ziehen lamellenartige, teilweise netzartig durchbrochene Balken von dem umgebenden Netzwerke und vereinigen sich rings um denselben zu einem Schnürringe. Oberhalb und unterhalb von ihm wird der Markraum von dünnen Protoplasmamembranen begrenzt, die teilweise mit Gliafasern versehen sind. Für die Darstellung des Schnürrings ist die Mikrometerschraube zur Verwendung gekommen. Schnitt $5 \mu$.

Fig. 2. Perivasculäres Gliagewebe in der Umgebung eines tangential getroffenen Gefässes der Marksubstanz. Limitans perivascularis nebst in derselben verlaufenden Fasern; Gliafüsse. Rechts ein Teil eines durchgeschnittenen Kernes. Das Gefäss ist nicht abgebildet. Einstellung während des Abzeichnens nicht verändert.

Fig. :3. Membrana limitans perivascularis nebst angrenzendem perivasculärem Gliagewebe eines Gefässes der Marksubstanz. Das Gefäss selbst, das schräg getroffen ist uud in derselben Richtung verläuft wie die am meisten hervortretenden Fasern der Membrana limitans, ist nicht dargestellt worden. Schnitt $5 \mu$. Die Mikrometerschraube ist zur Verwendung gekommen. 
Fig. 4. Aus der Molekularschicht der Rinde. Feines gliosomführendes Gliareticulum. Verbindung zwischen den Balken des Yetzwerkes und dem Protoplasma der Gliazelle bezw. deren Ausläufer. Peridendritische gliöse Netzwerke. Kapillargefässe mit roten Blutkörperchen. Das Bild ist unter Einhaltung derselben Einstellung gezeichnet.

Fig. 5. Pyramidenzelle der Rinde nebst zwei Hauptdendriten und das umgebende Gliagewebe. Pericelluläres und peridendritisches Netzwerk nebst Gliosomen. Olne Änderung der Einstellung gezeichnet.

Fig. 6. Kalottenschnitt einer Pyramidenzelle der Rinde, eine „Begleitzelle“ und deren Zusammenhang mit dem pericellulären Netzwerk. Keine Veränderung der Einstellung.

Fig. 7. Ein grösseres Kapillargefäss nebst umgebendem, gliosomenfülırendem Gliareticulum aus der Schicht der polymorphen Rindenganglienzellen. Der Schnitt ist grösstenteils tangential gefallen. Membrana limitans perivascularis und ihr Zusammenhang mit dem gliösen Netzwerke; in jener einzelne Gliafasern und reihenartig angeordnete Gliosomen. R oth sche Räume. In orler an der Membran zwei Fragmente durchschnittener Kerne. Ohne Änderung der Einstellung gezeichnet.

\section{Tafel VIII.}

Die in diesen Tafeln wiedergegebenen Mikrophotogramme sind mit einem Apparat von $\mathrm{Z}$ e is s, Apochromat $2 \mathrm{~mm}$, Apertur 1,30 (Immersion). Projeltionsokular 4, aufgenommen. Länge des Auszuges der Camera $50 \mathrm{~cm}$, Vergrösserung also in sämtlichen Figuren 1:1000. Als Farbenfiltrum kam ein Filtrum von $\mathrm{Zet}$ tnow zur Anwendung.

Fig. 1. Die marginale, subpiale Neuroglia in der Mitte zwischen dem Boden einer Furche und der freien Oberfläche des Gehirns. An der unteren Begrenzung der Furche tritt ziemlich deutlich das gliöse Netzwerk hervor, eine der Grenzschicht der Glia gehörige Gliazelle mit ihren beiden nach der Oberfläche hinziehenden Auslïufern. Auch werden andere Fortsätze, wahrscheinlich anderen Zellen entstammend, sichtbar. Ebenso treten die sekundären, der Pia mehr oder weniger parallelen Balken und eine Anzahl von Gliafasern hervor. An der oberen Fläche der Furche tritt der kammartige Bau der Glia hervor, der durch die mehr membranähnliche Beschaffenheit der Balken des Gliasyncytiums bedingt wird.

Fig. 2. Das Gliagewebe der Marksubstanz. Einige Gliazellen mit grossen, chromatinarmen und nucleolführenden Kernen. Stellenweise sieht man Protoplasmaausläufer und Gliafasern. Letztere verlaufen sowohl in den Fortsätzen oder längs derselben, als auch durch den Zellkörper selbst. Eine Menge Gliazellen mit kleinem, chromatinreichem Kerne zeigen keine räumlichen Beziehungen zn den Gliafasern. Der Zusammenhang zwischen den Ausläufern dieser Zellen und dem Gliasyncytium tritt nur stellenweise hervor. An gewissen Stellen kann der Verlauf der Fasern in den Balken des Glianetzwerkes deutlich gesehen werden. 


\section{Tafel IX.}

Fig. 1. Gliagewebe der weissen Substanz. Ein der Länge nach getroffenes Kapillargefäss mit umgebender Glia; einige gröbere Gliafüsse treten deutlich hervor und können teilweise in die $\Delta$ usläufer nahegelegener Gliazellen verfolgt werden.

Fig. 2. Aus der Pyramidenzellenschicht. Das System war auf das feine pericelluläre Netzwerk eingestellt, das den Dendrit der etwas nach unten und links vom Zentrum des Bildes liegenden Pyramidenzelle bedeckt. In den Balken dieses Netzwerks stellenweise reihenartig angeordnete Körnchen (Gliosomen); die von drei zusammenstossenden Balken gebildeten Knotenpunkte treten stellenweise hervor; auch kann hie und da die Form der Maschen exkannt werden. Im übrigen sind im Bilde infolge der Dichtheit des Gewebes und der relativen Dicke des Schnittes $(4 \mu)$ kanm andere Details mit hinreichender Deutlichlieit zu sehen. 


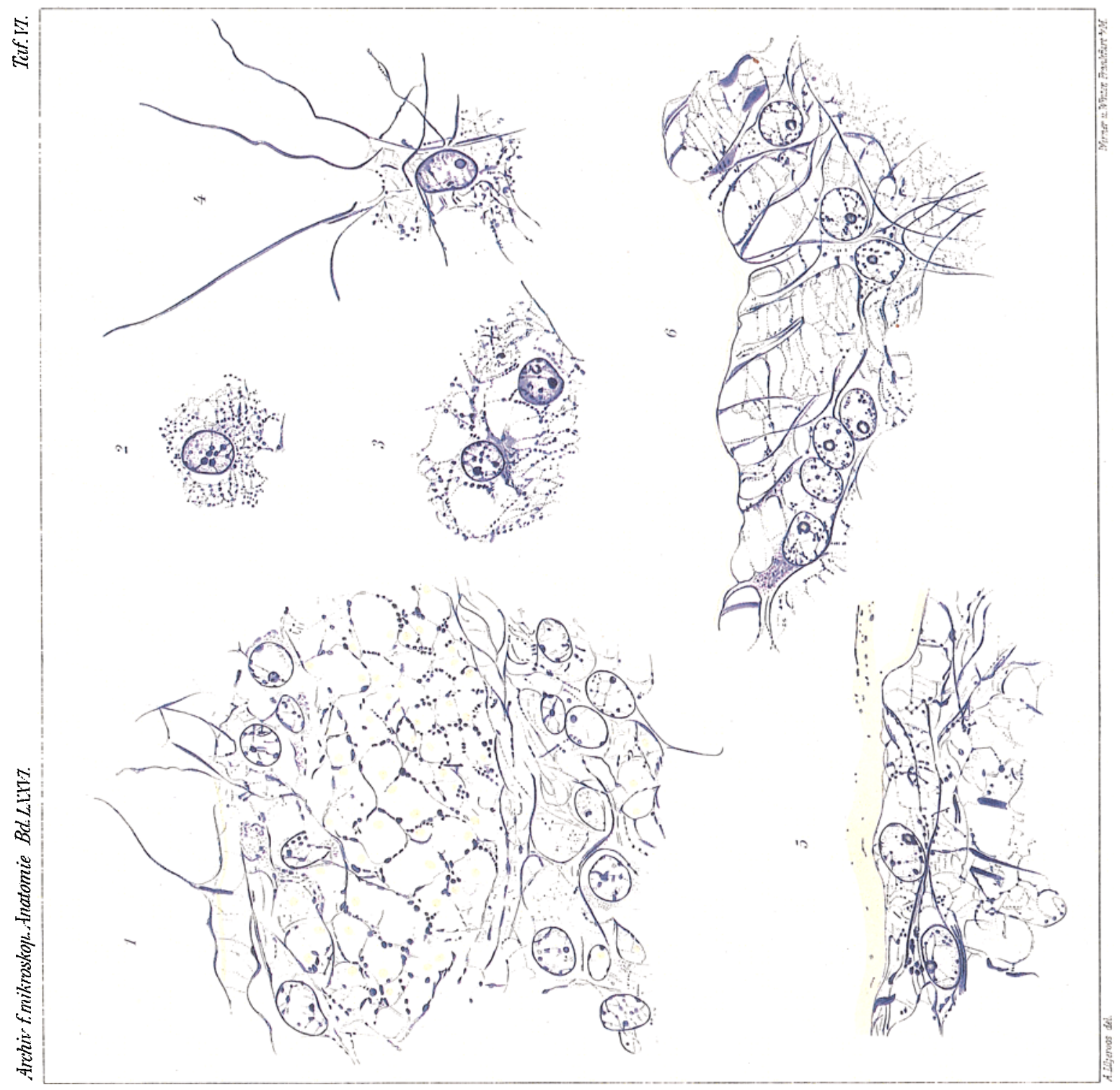



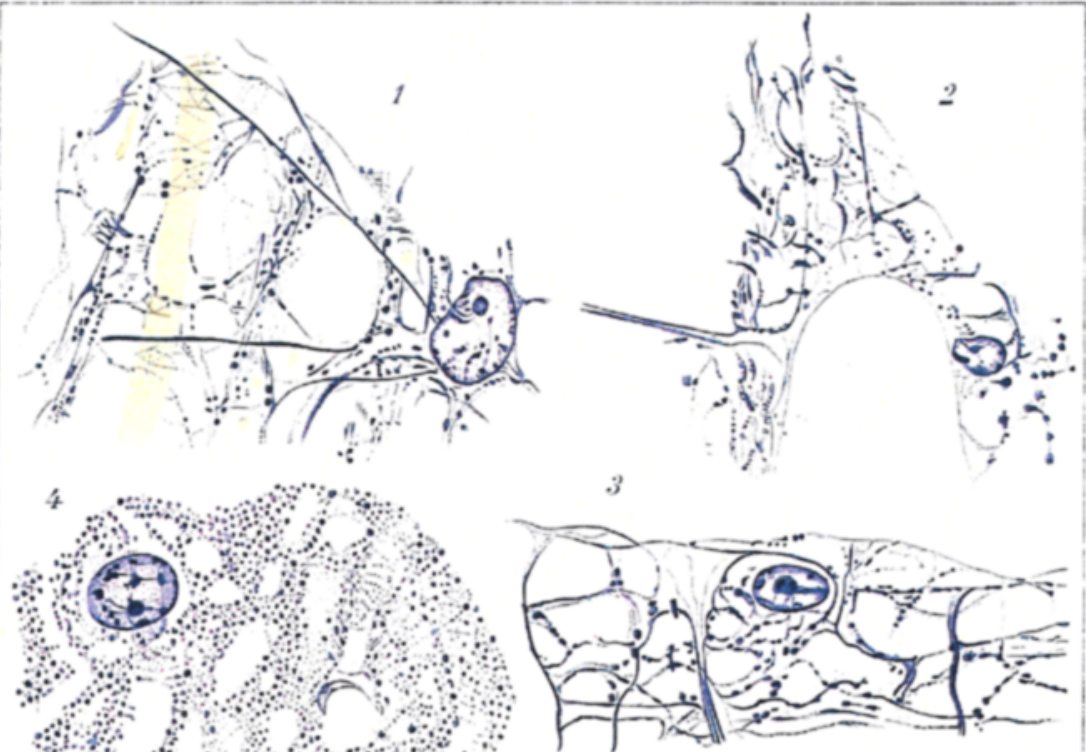

3
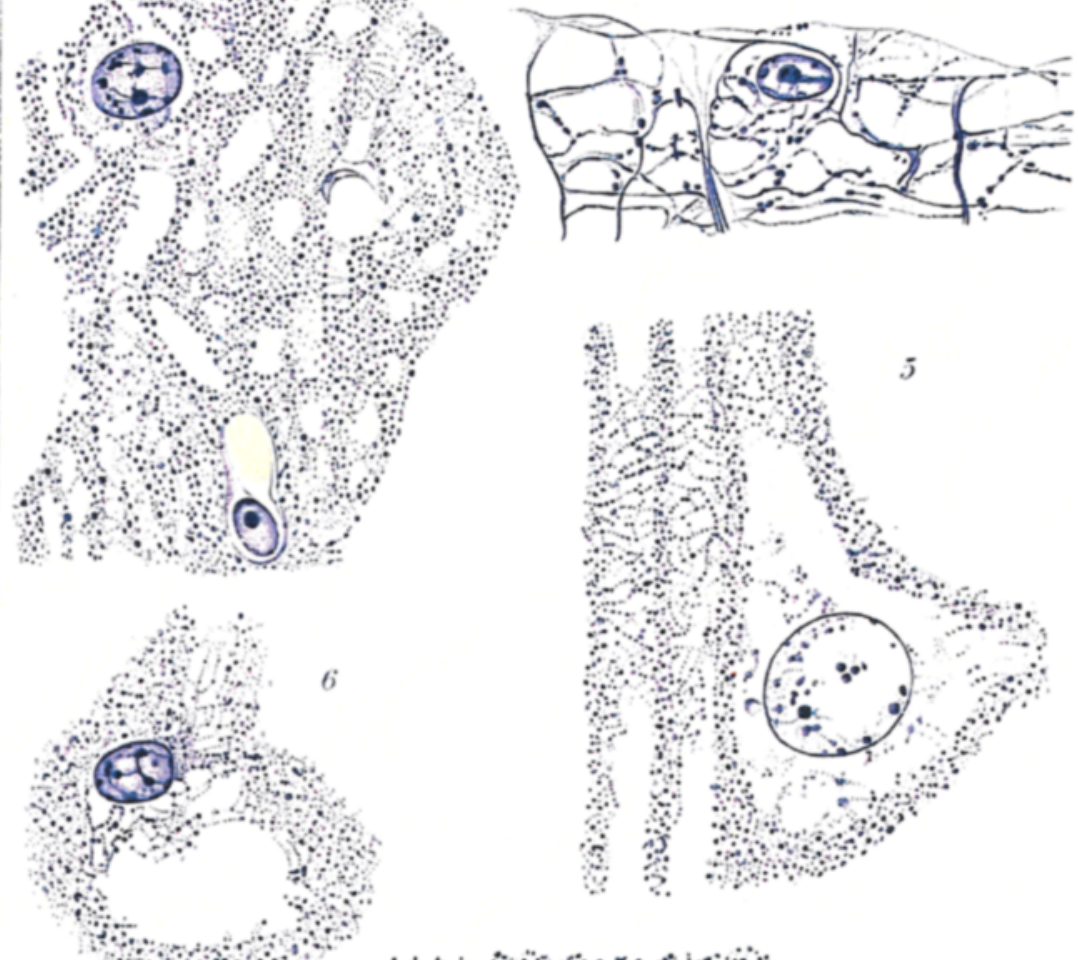

$\theta$

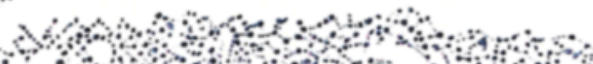

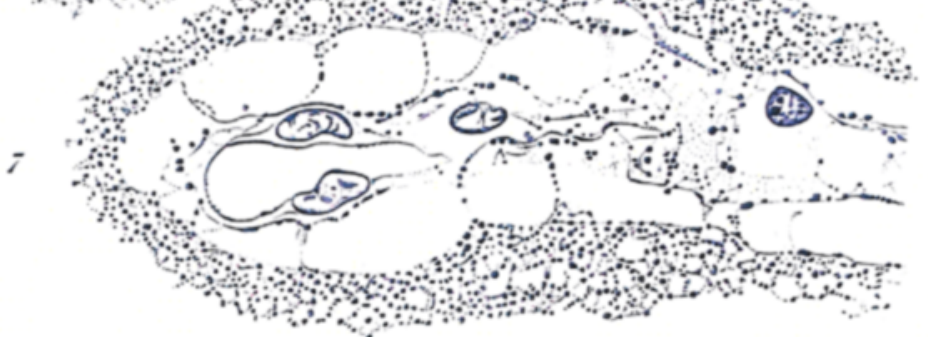




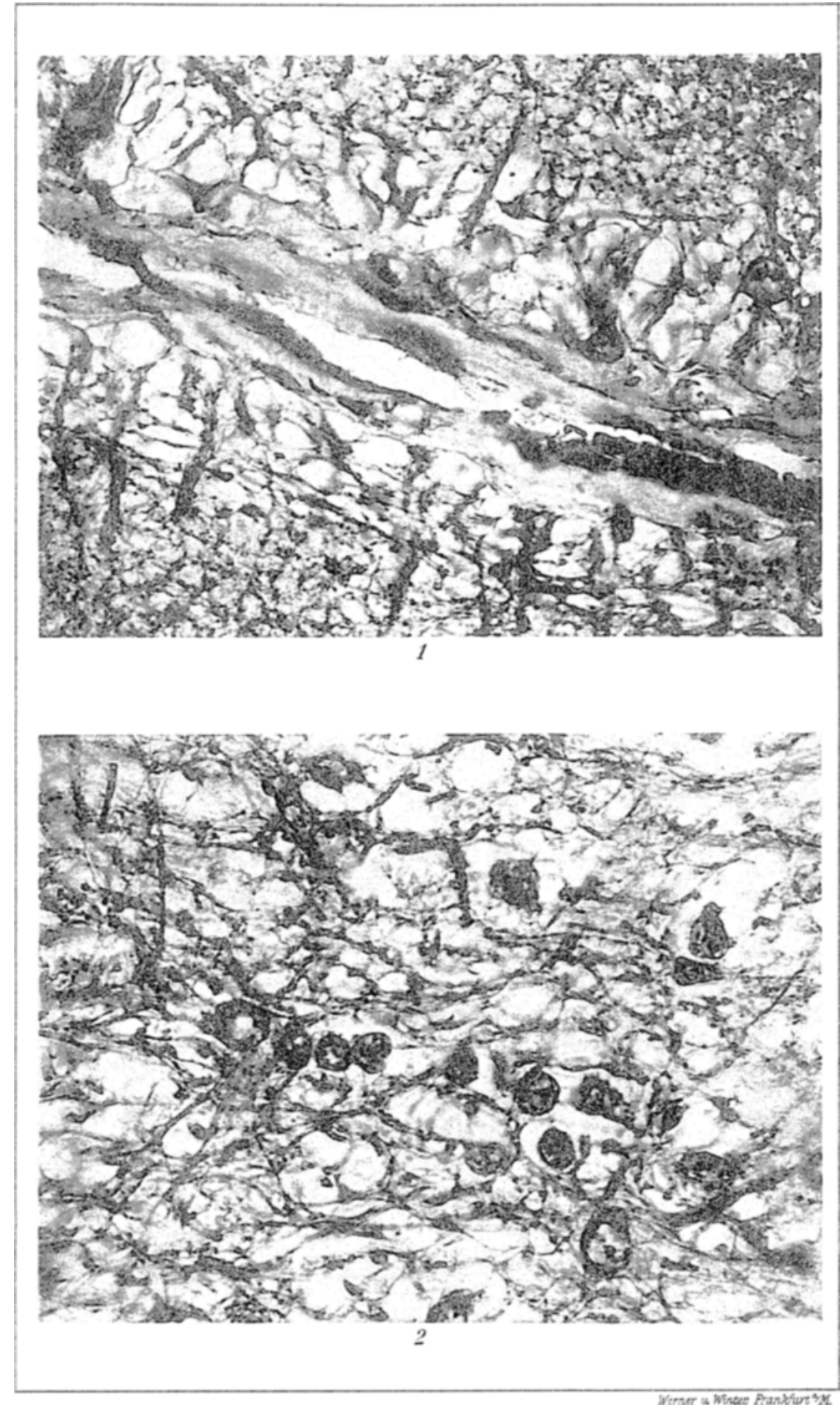




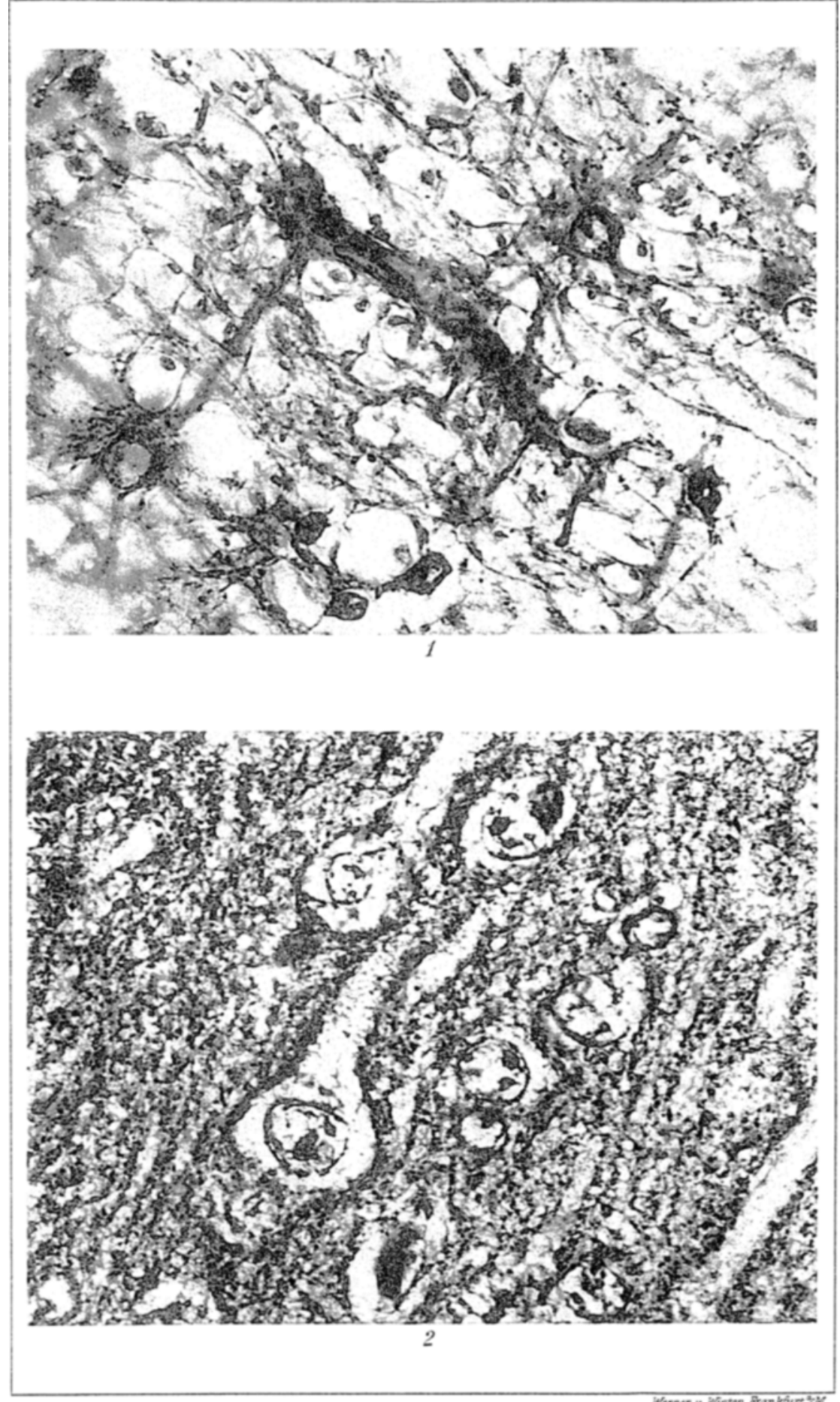

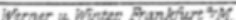

